Portland State University

PDXScholar

7-17-1996

\title{
Distribution Coefficients of Ionized and Un-ionized Halogenated Phenols in an Octanol-water System and their Relationship to Molecular Structure
}

Sven Hensler

Portland State University

Follow this and additional works at: https://pdxscholar.library.pdx.edu/open_access_etds

Part of the Physics Commons

Let us know how access to this document benefits you.

\section{Recommended Citation}

Hensler, Sven, "Distribution Coefficients of lonized and Un-ionized Halogenated Phenols in an Octanolwater System and their Relationship to Molecular Structure" (1996). Dissertations and Theses. Paper 5169.

https://doi.org/10.15760/etd.7045

This Thesis is brought to you for free and open access. It has been accepted for inclusion in Dissertations and Theses by an authorized administrator of PDXScholar. Please contact us if we can make this document more accessible: pdxscholar@pdx.edu. 


\section{THESIS APPROVAL}

The abstract and thesis of Sven Hensler for the Master of Science in Physics were presented July 17, 1996, and accepted by the thesis committee and the department.

COMMITTEE APPROVALS:
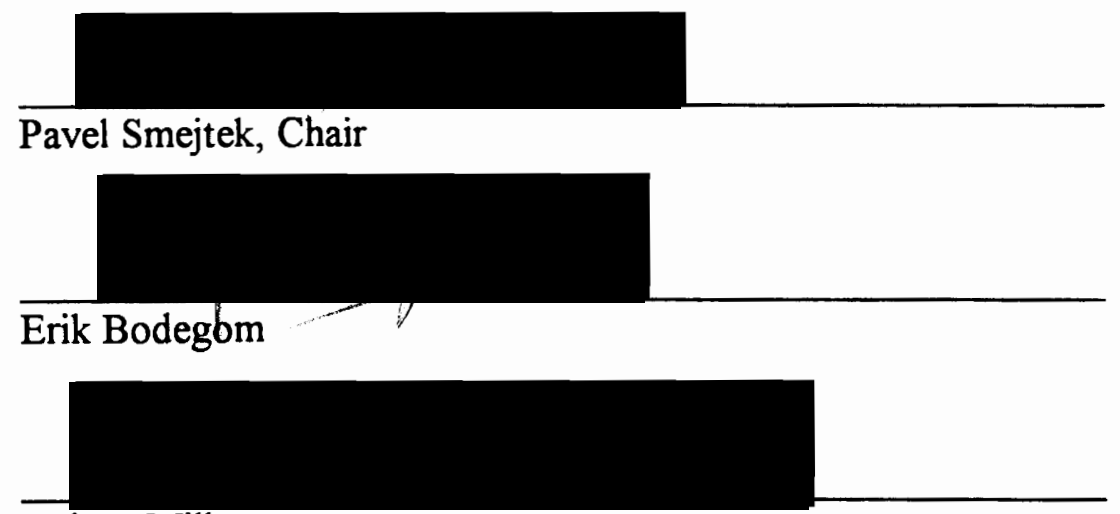

Robert Millette

Representative of the Office of Graduate Studies

DEPARTMENT APPROVAL:

Erik Bodegom, Chair

Department of Physics

ACCEPTED FOR PORTLAND STATE UNIVERSITY BY THE LIBRARY

by
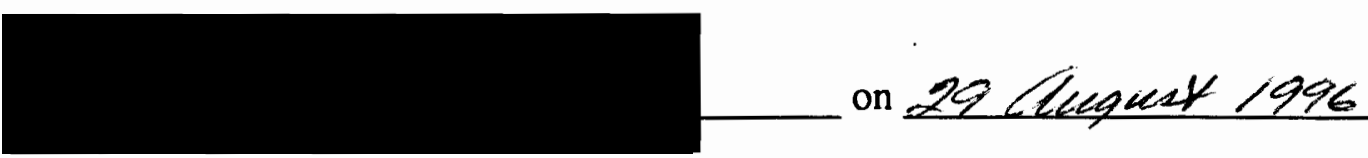


\begin{abstract}
An abstract of the thesis of Sven Hensler for the Master of Science in Physics presented July 17, 1996.
\end{abstract}

Title: Distribution Coefficients of Ionized and Un-ionized Halogenated Phenols in an Octanol-Water System and their Relationship to Molecular Structure.

Life supporting biological membranes are barriers to toxic chemicals. One of the factors determining the toxicity of chemical compounds is their distribution between membranes and their an environment. An octanol-water system is frequently used as a model for biological membranes to estimate the toxic potency of environmental pollutants. The distribution of a chemical between the octanol and the water phase is described by the octanol-water partition coefficient $\mathrm{K}_{\text {ow. }}$. This study is concerned with the relationship between $\mathrm{K}_{\mathrm{ow}}$ and the molecular structure of the toxic chemical.

In the study the following trihalophenols were included: $2,4,6$-trifluorophenol (TriFP), 2,4,6-trichlorophenol (TriCP); 2,4,6-tribromophenol (TriBP) and 2,4,6-triiodophenol (TriIP). The distribution of halophenols between octanol and water was measured as a function of the $\mathrm{pH}$. Experimental results were analyzed in terms of a two compartment distribution model which accounts for the $\mathrm{pH}$ dependent dissociation of the 
trihalophenol. We showed that, with the exception of TriIP, the $\mathrm{pH}$ dependence of the distribution coefficient of 2,4,6 trihalophenols can be understood with this model.

From the fit of the distribution model to the experimental results, the following $\log \left(\mathrm{K}_{\mathrm{ow}}\right)$ of the neutral molecules were determined: 1.96 (TriFP), 3.65 (TriCP), 4.11 (TriBP) and approximately 4.42 (TriIP). For the ionized species the $\log \left(\mathrm{K}_{\mathrm{ow}}\right)$ are 1.38 (TriFP), 0.15 (TriCP), 0.08 (TriBP) and 1.16 (TriIP).

In relation with these distribution studies, the following values for the dissociation constants $\mathrm{pK}_{\mathrm{a}}$ were obtained: 7.12 (TriFP), 6.15 (TriCP), 5.9 (TriBP) and 6.6 (TriIP). We also found that octanol dissolved in the water phase does not significantly affect the dissociation of TriIP.

The relationship between $\mathrm{K}_{\text {ow }}$ and trihalophenol molecular structure was studied in two models. Linear relationships were found between $\log \left(\mathrm{K}_{\mathrm{ow}}\right)$ and the surface area as well as between $\log \left(\mathrm{K}_{\mathrm{ow}}\right)$ and molar volume for both the neutral and the ionized halophenols. It was not possible to discriminate between the two models.

Distribution coefficients of the ionized and unionized 2,4,6-trihalophenols are proportional to the each other. The proportionality factor, $(3.54 \pm 1.49) \times 10^{-4}$, is a measure of the effect of electric charge on the transfer across the water-octanol interface. 


\title{
DISTRIBUTION COEFFICIENTS OF IONIZED AND UN-IONIZED HALOGENATED PHENOLS IN AN OCTANOL-WATER SYSTEM AND THEIR RELATIONSHIP TO MOLECULAR STRUCTURE
}

\author{
By \\ Sven Hensler
}

A thesis submitted in partial fulfillment of the requirements for the degree of

MASTER OF SCIENCE

in

PHYSICS

Portland State University

1996 


\section{Acknowledgments}

It is a pleasure to acknowledge many people who contributed to this work.

First and foremost, I would like to thank my adviser, Professor Pavel Smejtek.

Without his guidance, help and humor this thesis would not have been possible. He always found the time to discuss issues as they arose. I very much appreciate his comments on my thesis.

I am grateful for the support which I obtained from Shanru Wang. She was helping with chemical aspects of this work and thanks to her rapid replacement of nonfunctioning $\mathrm{pH}$-electrodes I was able to finish the project on time.

I enjoyed working with Rob Word and Margie Fyfield. I have my special thanks to Rob for the many hours he spent with me on introducing me to the required experimental techniques and on improving the style of my written English in this thesis.

Thanks to the members of my committee, to Professor Erik Bodegom, who found ways to assist me financially during my studies at Portland State University, and to Professor Robert Millette, whose centrifuge was essential for the preparation of octanol saturated buffer for the measurements of the distribution coefficient. I appreciate his and his lab group's tolerance of the smell of octanol, with which I polluted their lab.

Thanks to the members of the Science Support Office who helped me during my stay in the physics department and most recently with the preparation of the overheads for my thesis defense. 
I would like to thank my family and my friends, here in the US and in Germany, who cheered me up during the period of writing this thesis. Special thanks to Karin, Andi Thomas and Armin for helping me to survive during this time.

I have enjoyed the opportunity to do my own research, it was a great time and I had a great experience here in Portland. I will miss it a lot back in Germany.

\section{Thanks a lot !!!}




\section{TABLE OF CONTENTS}

INTRODUCTION 1

Octanol-Water as a Membrane Model System $\quad 1$

Halogenated phenols $\quad 6$

Purpose of the study. $\quad 9$

$\begin{array}{lr}\text { THEORY } & 10\end{array}$

$\begin{array}{ll}\text { Partitioning Theory } & 10\end{array}$

$\begin{array}{ll}\text { Phenols in an octanol-water system } & 13\end{array}$

$\begin{array}{ll}\text { Partition and Distribution Coefficient } & 15\end{array}$

Relationship between the partition coefficient and the molecular structure 17

Molecular Surface Model (Smejtek 1996, Word 1996) 17

Molar Volume Model (Gobas 1988) 19

MATERIALS AND METHODS

$\begin{array}{ll}\text { Chemicals } & 24\end{array}$

Spectrophotometric Measurements 25

UV-Visible absorption of molecules $\quad 25$

Lambert-Beer's Law $\quad 26$

$\begin{array}{ll}\text { Solvent effects } & 27\end{array}$

DU-7 UV-VIS Spectrophotometer $\quad 27$

pK $_{\mathrm{a}}$ - Measurement 29

Studies with TriFP and TriCP 31

Studies with TriBP and TriIP 31 
Phase Preparation

Extinction Coefficients

Partitioning

RESULTS AND DISCUSSION

Dissociation Constants

Extinction Coefficients and Absorption Spectra 46

Error Analysis of the Extinction Coefficient.

pH dependent Octanol-Water Distribution Coefficient

Error Analysis of the Partitioning Experiment 56

Unexpected results observed in TriFP and TrilP experiments

$\begin{array}{ll}\text { TriFP } & 65\end{array}$

$\begin{array}{ll}\text { TriIP } & 66\end{array}$

Molecular Surface Area and Molar Volume Models 73

Surface Area Model $\quad 74$

$\begin{array}{ll}\text { Molar Volume model } & 76\end{array}$

$\begin{array}{ll}\text { CONCLUSIONS } & 79\end{array}$ 


\section{LIST OF TABLES}

\section{SECTION RESULTS AND DISCUSSION}

1. Results of the $\mathrm{pK}_{\mathrm{a}}$ measurement 40

2. Extinction coefficient results 47

3. Extinction coefficient result calculated by averaging 48

4. Extinction coefficient data for 2,4,6 TriFP 49

5. Extinction coefficient data for $2,4,6 \mathrm{TriBP} \quad 51$

6. Extinction coefficient data for $2,4,6$ TrilP 53

7. Results of the partitioning experiments 56

8. Distribution data for $2,4,6$ TriFP 58

9. Distribution data for 2,4,6 TriBP 60

10. Distribution data for $2,4,, 6$ TriIP 62

11. Predictions of molecular modeling software 69

12. Molecular properties of halophenol 73

13. Results of the molecular surface model 75

14. Results of the molar volume model 77 


\section{LIST OF FIGURES}

\section{SECTION INTRODUCTION}

1. Fluid mosaic model 2

2a. Molecular structure and model of phoshatidylcholine 4

2b. Structure of a lipid bilayer 4

3. Comparison for a lipid and 1-octanol 5

4. Molecular structure of 2,4,6 TriFP, 2,4,6 TriCP, 2,4,6 TriBP
and 2,4,6 TrilP

\section{SECTION THEORY}

5. Partitioning model 13

6. Dissolution model 21

\section{SECTION MATERIALS AND METHODS}

7. Energy level system 26

8. Optical path in the spectrometer 28

9. Dissociation of $2,4,6$ Trihalophenols 29

10. Absorption spectrum of octanol saturated water 34

\section{SECTION RESULTS AND DISCUSSION}

11a,b. Titration curve of $2,4,6$ TriCP 41

12 Titration curve of $2,4,6$ TriFP 42

13a. Titration curve of $2,4,6$ TriBP 43

13b. $\mathrm{pK}_{\mathrm{a}}$ of $2,4,6 \mathrm{TriBP}$ as a function of the ethanol concentration

14a. Titration curve of $2,4,6$ TriIP 44

14b. $\mathrm{pK}_{\mathrm{a}}$ of $2,4,6$ TriIP as a function of ethanol concentration

15. $\mathrm{pK}_{\mathrm{a}}$ of $2,4,6$ TriIP as a function of ethanol concentration
in the octanol saturated solution

16. Absorption spectrum of 2,4,6 TriFP 50

17. Absorbance versus concentration of 2,4,6 TriFP 50

18. Absorption spectrum of 2,4,6 TriBP 52

19. Absorbance versus concentration of 2,4,6 TriBP 52

20. Absorption spectrum of 2,4,6 TrilP 54

21. Absorbance versus concentration of 2,4,6 TrilP 54

22. Distribution of $2,4,6$ TriFP 59 
23. Distribution of $2,4,6$ TriBP 61

24. Distribution of $2,4,6$ TriIP 63

25. Distribution of $2,4,6$ trihalophenols 64

26. Failure of the mass balance 65

27. Attempts to fit the distribution curve to the data of 2,4,6 TriIP 70

28. Shifts in the absorption spectra of 2,4,6 TriIP 71

29. Change in the absorption spectra of 2,4,6 TriIP 71

30. Contribution to $\log \mathrm{D}$ according to $\mathrm{ACD}$ - molecular modeling 72

31. Molecular surface area model $\quad 78$

32. Molar volume model $\quad 78$ 


\section{Introduction}

\section{Octanol-Water as a Membrane Model System}

Lipid membranes are the foundation of cellular structures including the cell membrane and the subcellular membranes ${ }^{1}$ of organelles. Membranes play important roles in the survival of the cell. Membrane proteins regulate the composition of molecules and ions in the cytoplasm via ion channels and carriers. Membranes are responsible for the information exchange and energy conversion progresses, such as photosynthesis in the inner membranes of chloroplasts and oxidative phosphorylation in mitochondria. Stryer (1975) describes biological membranes as "highly selective permeability barriers'. Biological membranes are liquid-crystalline, sheetlike structures (60-100 $\AA$ thick), containing lipids and proteins (Figure 1).

Lipids are organic molecules with hydrophobic (hydrocarbon tails) and hydrophilic (polar head group) moieties (Figure 2a). They are insoluble in water and have high solubility in organic solvents. In aqueous solutions they spontaneously cluster to form micelles or bilayers to minimize the contact between the hydrophobic moiety and water (Figure 2b). This structure is stabilized by van der Waals forces between the hydrocarbon tails and electrostatic and hydrogen-bond interactions between the polar head groups.

While lipid bilayers represent a permeability barrier, proteins imbedded in this fluid lipid structure give the membrane specific properties. They are mainly responsible for the interaction between the two compartments separated by the membrane. According to their position in the membrane, they are classified as peripheral or integral proteins.

\footnotetext{
${ }^{1}$ Cell membranes are sometimes in contact with subcellular membranes.
} 
Figure 1 shows the fluid mosaic model which was proposed by Singer and Nicholson. The membrane of the fluid mosaic model is a two-dimensional solution of oriented lipids, in which proteins were floating.

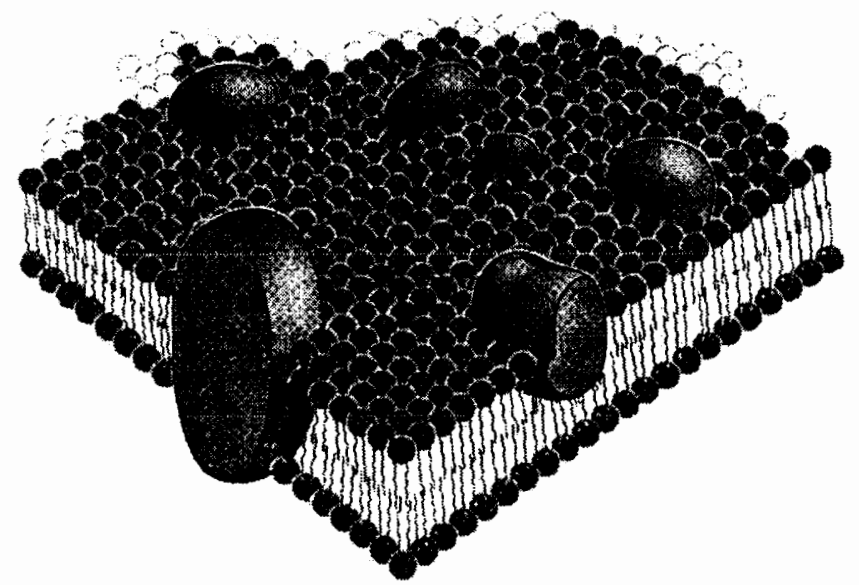

Figure 1: Fluid mosaic model

In this study we focus on the distribution of chemical compounds between the membrane and its environment, and thus, between the permeability barrier and the aqueous environment. It is therefore possible to reduce this model to a lipid membrane-water model. Since the distribution of chemical compounds is defined as the ratio of the concentrations of molecules in each of the two phases (lipid-water), a further reduction to a two bulk phase system composed of octanol and water was made. This octanol-water system is considered as a model for a membrane-water system.

The use of octanol as model for the membrane phase has several advantages (Zaslavsky 1995): 
- Octanol has a similar molecular structure as membrane lipids (Figure 3). A polar group is fixed on a hydrocarbon tail. This is a simple and regular structure, which exhibits similar properties as lipids, e.g. the formation of micelles.

- Most organic compounds are very soluble in octanol. Water saturated octanol is sufficient polar, so that dissolved molecules tend to associate with octanol rather than with each other.

- Additionally, octanol is chemically stable, commercially available and does not absorb light in the UV-visible wavelength range. This is important for the spectrophotometric determination of concentration of molecules distributing themselves between octanol and water.

It is obvious that the simplification to a two bulk-media system results in some loss of information. To apply the experimental results obtained from this simple model to the complex biological membrane structure, the limits of the model have to be known. In contrast to the membrane, the bulk media have a smaller equilibrium surface-tovolume ratio and have to maintain electrical neutrality, where as membranes can acquire and maintain a net electric charge. (Gobas 1988) demonstrated for a number of organic compounds, that there is a good agreement between partition coefficients for a lipid-water and a octanol-water system. However, in more recent studies (Smejtek 1993, Escher 1996, Word 1996), significant deviations are reported for ionized species of organic compounds between lipid membrane-water and octanol water systems. The similarity of partition reported in the literature has to be reexamined.

Understanding of the partitioning processes of chemicals between membranes and water and octanol and water is especially important for drug design and toxicology. The octanol-water partition coefficient $\mathrm{K}_{\mathrm{ow}}$ (or $\mathrm{P}_{\mathrm{ow}}$ ) is often used in these studies. It is 
given by the ratio of the sample concentration in the octanol phase to of the sample concentration in the water phase.

$$
K_{o w}=\frac{[\text { sample }]_{o c}}{[\text { sample }]_{a q}}
$$

The brackets indicate the sample concentration in the octanol (oc) phase and water phase (aq), respectively. $\mathrm{K}_{\mathrm{ow}}$ is commonly given as a decadic logarithm. The octanolwater partition coefficient is based on a simple two phase system and is easier and more convenient to measure than the lipid-water or the membrane-water partition coefficients. Several methods of determination have been developed including different experimental methods, estimation of partition coefficients from molecular properties, such as water solubility, surface area and volume, as well as empirical numerical methods relating partition coefficients to molecular structure.

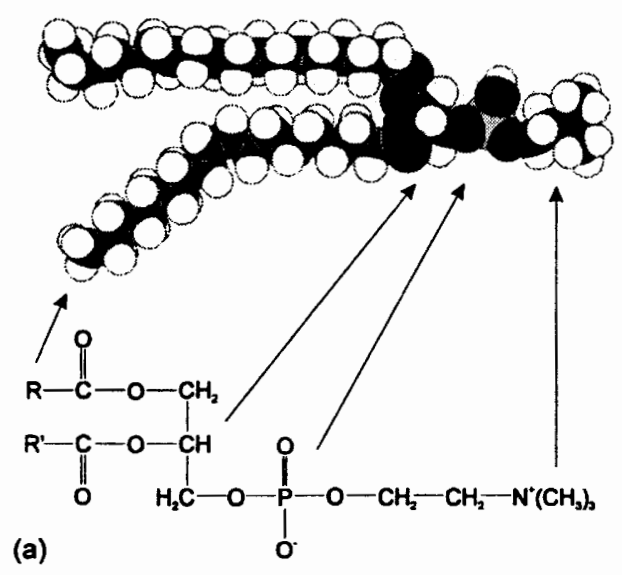

(b)

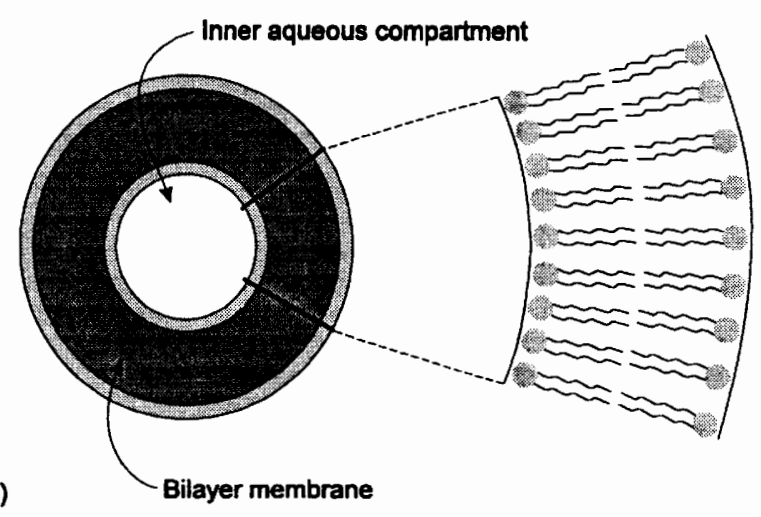

Figure 2a, 2b: (a) Molecular structure of and model of phoshatidylcholine as an example of a lipid. (b) Structure of a lipid bilayer. 


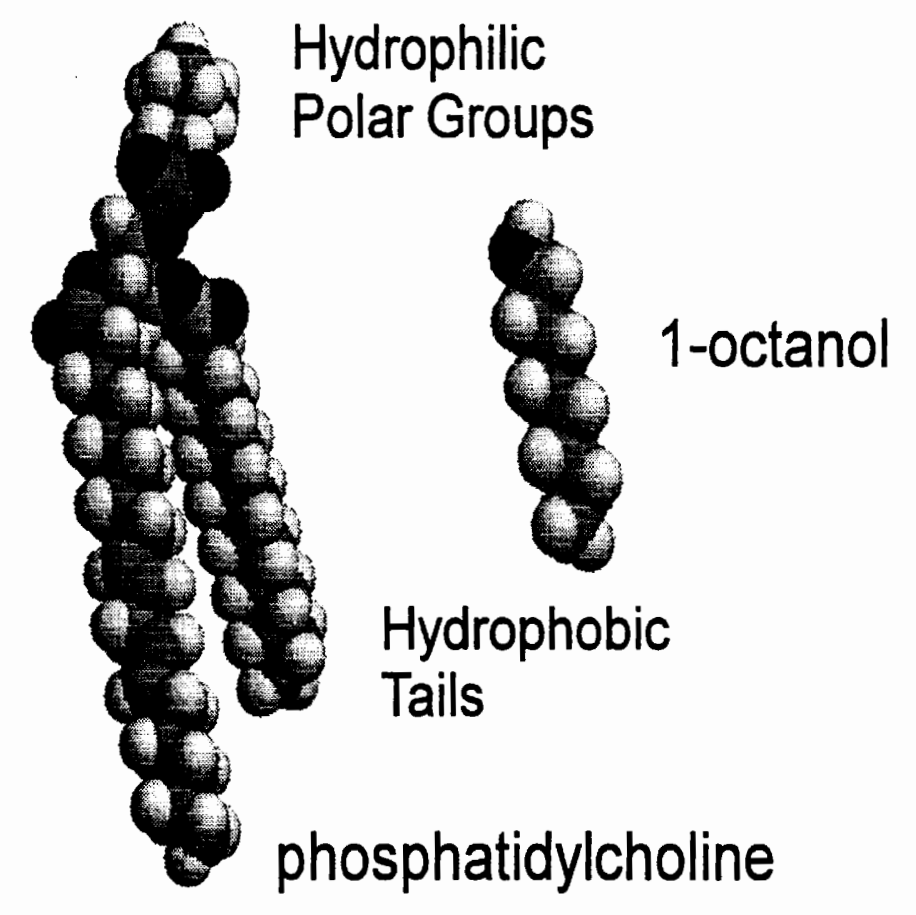

Figure 3: Comparison of 1-octanol with a lipid. 


\section{Halogenated phenols}

Chlorophenols were widely used in variety of agricultural, industrial and domestic applications, such as pesticides, biocides, as disinfectants for cleaning floors and as intermediates in industrial synthesis. The main representative is pentachlorophenol (PCP). From 1930 until 1980, when most countries restricted the use of PCP, PCP was produced and spread into the environment in a large amount. In the U.S, e.g., out of the annual PCP production of 23 thousand tons (1978), 80\% was used as a wood preservative. As a most versatile biocide, it controlled bacteria, fungi, mollusks, insects, etc. PCP is toxic to microorganisms, plants, animals and also humans.

Other eco-enviromentally important chlorinated phenols, such as tetrachlorophenols (TeCP) or trichlorophenols (TriCP), are often degradation products of PCP, produced by chemical, mircobiological and/or photochemical processes. Mussalo-Rauhamaa (1989) and Jansson (1993) described the chlorine bleaching of pulp in the paper and sawmill industries, the emissions from incineration of municipal wastes and chlorine disinfection of water as major sources of chlorophenols.

The 'thoughtless' and widespread use of PCP in the past resulted in a permanent human exposure to PCP at present. Humans are exposured to chlorophenols through their skin, lungs and by ingestion of contaminated food. Hattemer-Frey (1989) and Geyer (1987) estimated an long-term average daily intake of PCP of $16 \mu \mathrm{g} /$ day and 19 $\mu \mathrm{g} / \mathrm{day}$, respectively. According to Hattemer-Frey (1989), 99.9\% the human exposure is due to the food chain, especially to fruits, vegetables and grain. PCP was found in low concentrations in drinking water, fish, sugar, pork, chicken meat, etc.. Chicken and pigs were contaminated by PCP because they were raised on wooden floors (Greyer 1987). Chlorinated phenols were detected in the human liver, kidney and brain. Since similar concentrations of chlorophenols were found in infants and the elderly people, it is believed that chlororphenols are not permanently accumulated in 
body tissues. Symptoms of intoxication due to PCP appeared at concentrations around $3 \mu \mathrm{g} / \mathrm{ml}$ in the urine (Grimm 1981). Symptoms of intoxication in humans are loss of appetite, respiratory difficulties, anesthesia, hyperpyrexia, sweating, dyspnea and coma. Further information on chronical symptoms and cancer risk can be found in the paper by Mussalo-Rauhamaa (1988).

The toxicity of chlorophenols is due several disrupting mechanisms in cell membranes. The main source of perturbation of physical properties of cell membranes is associated with the induced electrical conduction in the presence of PCP, which is related to transmembrane proton translocation and the uncoupling of ATP synthesis from the electron transport.

The halogenated phenols in this study are structurally related to chlorophenols, but not significantly present in the environment. Even though they are not environmentally important, they have been included in the study for the development of a model for the prediction of partition coefficients.

Molecules of halogenated phenols consists of a phenol ring with 1 to 5 halogen substituents. The structure of 2,4,6 trifluorophenol (TriFP), 2,4,6 trichlorophenol (TriCP), 2,4,6 tribromophenol(TriBP) and 2,4,6 triiodophenol (TriIP) are shown in Figure 4. The difference between the molecule is in the substituent atoms. With the substitution from fluorine to iodine, the substituents become larger and less electronegative.

Each of these halophenols is in a crystalline form at room temperature. Crystals of TriFP form small needles, TriBP crystals have appearance of beige plate, and those of TrilP form a coarse gray-reddish powder. All three substances are very soluble in 
octanol. While the solubility of TriIP and TriBP in water is low, TriFP dissolves very quickly.

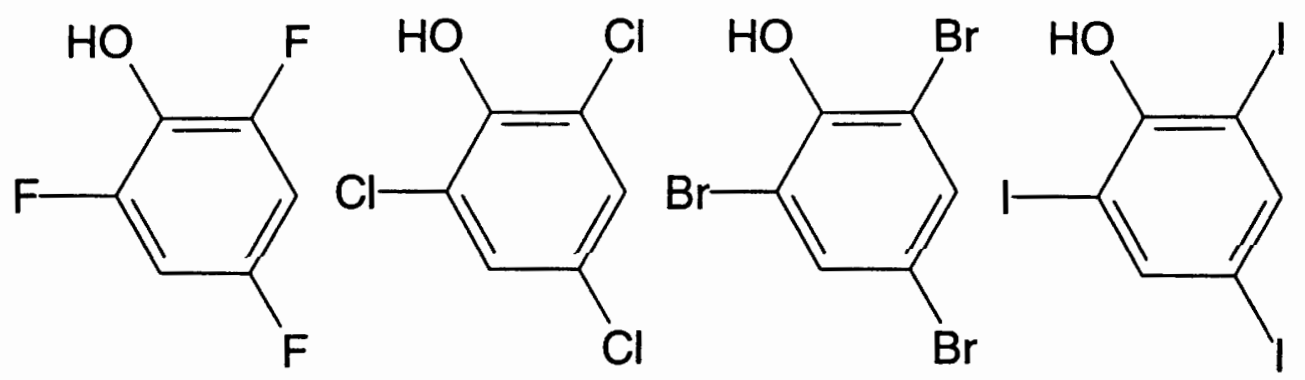

Figure 4: Molecular structure of 2,4,6 trifluorophenol, 2,4,6 trichlorophenol, 2,4,6 tribromophenol and 2,4,6 triiodophenol. 


\section{Purpose of the study.}

The present study is in line with Smejtek's and Wang's study of the absorption of pentachlorophenol and halophenols to membranes. For a better understanding of the sorption of halophenols in lipid membranes and distribution in octanol-water system, it became necessary to study the relationship between the octanol-water partition coefficient and the structure of the halogenated phenol. In this context, we choose the congeners 2,4,6 TriFP, 2,4,6 TriCP, 2,4,6 TriBP and 2,4,6 TriIP. Our goal was to study the effect of substituents on the octanol-water partition coefficient. In our series of molecules we used halosubstituents with differences in size, electronegativity and atomic number, all located in the same position on the phenol ring.

In this study the distribution coefficient of 2,4,6 TriFP, 2,4,6 TriBP and 2,4,6 TriIP has been measured as a function of $\mathrm{pH}$ using the shake-flask method. 2,4,6 TriCP, which had been already studied in the laboratory by Sieder (1995), was included for completeness and as a reference compound. The data were analyzed in terms of a partition model from which the partition coefficient of electrically neutral and ionized halophenols were obtained. These partition coefficients are discussed in terms of molecular structure of halophenols. 


\section{Theory}

\section{Partitioning Theory}

The theory of ideal partitioning is based on thermodynamics. A thermodynamic process, such as the distribution of molecules between two phases, has its equilibrium and final state, when the entropy of the system $S$ is at maximum. This is in the case of constant temperature $T$ and constant pressure $p$ equivalent to the minimization of the free energy $G$. The definition of free energy is

$$
G(T, p, n)=U(S, V, n)+p V-T S=H-T S
$$

Where $U$ is the internal energy, $n$ the number of particles and $H$ the enthalpy. The total differential of the free energy is

$$
\begin{aligned}
d G(T, p, n) & =\left(\frac{\partial G}{\partial T}\right)_{p, n} d T+\left(\frac{\partial G}{\partial p}\right)_{T, n} d p+\left(\frac{\partial G}{\partial n}\right)_{T, p} d n \\
& =d U(S, V, n)+p d V+V d p-T d S-S d T
\end{aligned}
$$

At constant pressure and temperature it reduces to

$$
d G=\left(\frac{\partial G}{\partial n}\right)_{T, p} d n
$$

The ratio $\left(\frac{\partial G}{\partial n}\right)_{T, p}$ is also known as chemical potential $\mu$. On the other hand, the following equation can be obtained by comparing the coefficients of dp in Equation 3.

$$
\left(\frac{\partial G}{\partial p}\right)_{T, p}=V
$$


Both, Equations 4,5, lead directly to one of Maxwell's relations

$$
\frac{\partial^{2} G}{\partial p \partial n}=\frac{\partial V}{\partial n}=\frac{\partial \mu}{\partial p}
$$

Applying the ideal gas law, the last terms transform into

$$
d \mu=\frac{R T}{p} d p
$$

Using the same law, the pressure dependence can be turned into a more useful concentration dependence:

$$
\begin{aligned}
& p=\frac{n}{V} R T=c R T \\
& d \mu=\frac{R T}{c} d c
\end{aligned}
$$

Integrating this equation results in

$$
\mu-\mu_{0}^{*}=R T\left(\ln c-\ln c_{0}\right)
$$

Where $\mu_{0}^{*}$ and $c_{0}$ are the initial chemical potential and concentration of the molecules in solution, respectively. From regrouping the terms we obtain

$$
\mu=\mu_{0}+R T \ln c
$$

For a two phase system with phases a and b, the total differential free energy is the sum of the differential free energies of each phase

$$
d G=d G^{a}+d G^{b}=\mu^{a} d n^{a}+\mu^{b} d n^{b} .
$$


Using the conservation of particle, $\mathrm{dn}^{\mathrm{a}}=\mathrm{dn}^{\mathrm{b}}$, and $\mathrm{dG}=0, \mu_{0}^{*}$ equals $\mu_{0}$ and it is possible to write:

$$
\begin{aligned}
& \mu_{0}{ }^{a}-\mu_{0}{ }^{b}=R T\left(\ln c^{b}-\ln c^{a}\right)=R T \ln \frac{c^{b}}{c^{a}} . \\
& \text { or } \quad \ln \frac{c^{b}}{c^{a}}=\frac{\mu_{0}{ }^{a}-\mu_{0}{ }^{b}}{R T}
\end{aligned}
$$

The ratio of the solute concentrations in the two phases $a$ and $b$ is called the partition coefficient $K_{a b}$.

$$
K_{a b}=\frac{c^{b}}{c^{a}}=e^{\left(\mu_{0}^{a}-\mu_{0}^{b}\right) / R T}=e^{-\Delta G_{0} / R T}
$$

The difference between chemical potentials is the free energy of transfer $\Delta \mathrm{G}_{0} . \Delta \mathrm{G}_{0}$ is the energy needed to transfer one mole of a substance from one phase to the other. 


\section{Phenols in an octanol-water system}

Halogenated phenols are weak acids. Their dissociation behavior in water is well known and can be controlled easily by the $\mathrm{pH}$ of the solution. The ionization behavior of halogenated phenols in the octanol phase is less understood. Jafvert et al (1990) proposed a simplified model (Figure 5) for the distribution of ionized and neutral species.

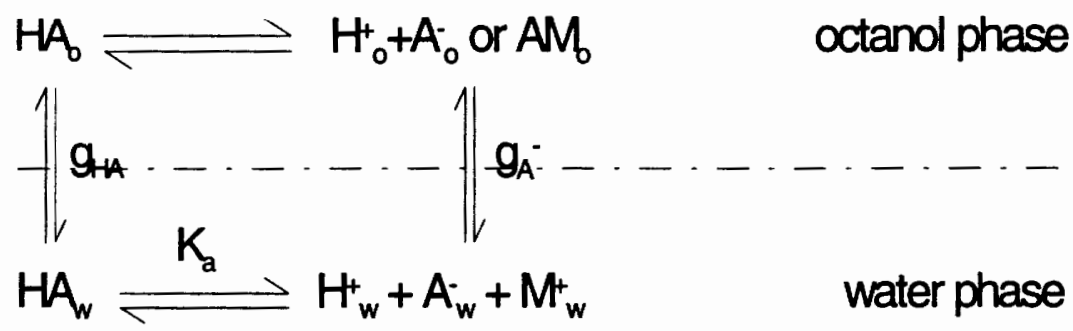

Figure 5: Partitioning model proposed by Jafvert et al.

Both the water and octanol phase contain the halophenol in its unionized (HA) and ionized $\left(\mathrm{A}^{-}\right)$form. Since all the partitioning experiments were conducted in an electrolyte solution, monovalent cations $\left(\mathrm{M}^{+}\right)$are also taking part in the partitioning process. The above model was also used in the present study. Heterodimers (AHA') and electrolyte species $\left(\mathrm{M}^{+}, \mathrm{Cl}, \mathrm{MCl}\right)$ were not considered, since the objective was to compare partitioning of different halophenols under identical conditions.

There are two major distribution processes:

1.) Interfacial transfer of the neutral species, which is described by the distribution parameter $\mathrm{g}_{\mathrm{HA}}$. 
2.) Distribution of the ionized species $A^{-}$between the two phases, either as free ion $\left(A^{-}\right)$or as ion pair $\left(\mathrm{AM}_{0}\right)$. As the two phases have to maintain electrical neutrality, each transfer of an anion $A^{-}$has to be accompanied by a transfer of a cation. This distribution of $A^{-}$is characterized by $g_{A}$. Former studies (Smejtek 1993, Escher 1996) have shown, that partitioning of $\mathrm{A}^{-}$species from water into octanol phases cannot be ignored.

Since the presence of the ionized species in the cell membrane is responsible for energy dissipation pathways and thus for the toxicity, the transfer of this species from

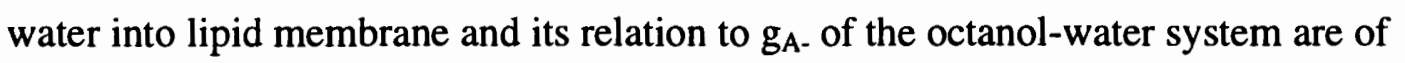
special interest. 


\section{Partition and Distribution Coefficient}

The ideal partitioning theory, which was presented in the first section of this chapter, requires that only one non-interacting species takes part in the partitioning process. This is not the case, for the partition experiment of weak acids such as halophenols in an octanol-water or membrane-water system. The simultaneous presence of the ionized and the neutral species of the solute contradicts this assumption. The ionized and neutral species partition coefficients are generally different and therefore the distribution of the halophenol between octanol and water is $\mathrm{pH}$ dependent. For this reason a distribution coefficient is introduced that describes the ratio of the total concentrations of the species between water and octanol,

$$
D(p H)=\frac{[H A]_{o c}+\left[A^{-}\right]_{o c}}{[H A]_{a q}+\left[A^{-}\right]_{a q}}
$$

$[\mathrm{HA}]$ and $\left[\mathrm{A}^{-}\right]$are the concentrations of the neutral and ionized halophenol in octanol $(\mathrm{oc})$ and water (aq). [ $\left.\mathrm{A}^{-}\right]$includes both species as shown in the previous section ([ $\left.\mathrm{A}^{-}\right]$ and $[\mathrm{AM}])$.

With the following definitions for $\mathrm{pH}, \mathrm{pK}_{\mathrm{a}}$ and the distribution parameters $\mathrm{g}_{\mathrm{HA}}$ and $\mathrm{g}_{\mathrm{A}}$,

$$
\begin{aligned}
& p H=-\log \left[H^{+}\right]_{a q} \\
& p K_{a}=-\log \frac{\left[H^{+}\right]_{a q}\left[A^{-}\right]_{a q}}{[H A]_{a q}} \\
& g_{H A}=\frac{[H A]_{o c}}{[H A]_{a q}} \\
& g_{A}=\frac{\left[A^{-}\right]_{o c}}{\left[A^{-}\right]_{a q}}
\end{aligned}
$$


the $\mathrm{pH}$-dependent equation for the distribution coefficient can be rewritten as follows.

$$
D(p H)=\frac{g_{H A}+g_{A} 10^{p H-p K_{a}}}{1+10^{p H-p K_{a}}}=\alpha g_{H A}+(1-\alpha) g_{A}
$$

where $\alpha=\frac{1}{1+10^{p H-p K_{a}}}$

This equation shows an explicit, non-linear relation between the $\mathrm{pH}$ of the water phase and the distribution of the sample between water and octanol. For low $\mathrm{pH}, \mathrm{pH}<<\mathrm{pK}_{\mathrm{a}}$, $10^{\mathrm{pH}-\mathrm{pKa}}$ becomes almost zero and $\alpha$ is about one. For high $\mathrm{pH}, \mathrm{pH}>>\mathrm{pK}_{\mathrm{a}}$ the denominator of $\alpha$ is large and $\alpha$ approaches zero. Therefore the distribution equation transforms in the limits of low and high $\mathrm{pH}$,

$$
\begin{aligned}
& D(p H) \stackrel{p H<<p K_{a}}{\longrightarrow} g_{H A} \\
& D(p H) \stackrel{p H>>p K_{a}}{\longrightarrow} g_{A}
\end{aligned}
$$

Since in these limits the balance of the neutral and ionized form is on either the neutral side $\left(\mathrm{pH}<<\mathrm{pK}_{\mathrm{a}}\right)$ or on the ionized side $\left(\mathrm{pH} \gg>\mathrm{pK}_{\mathrm{a}}\right)$, the assumption that only one species is taking part in the process is again valid and the distribution coefficient then equals the partition coefficient. It is sufficient to use the limits of $\mathrm{pH}$ equal to $\mathrm{pK}_{\mathrm{a}} \pm 4$, since the ratio of the concentrations of ionized to neutral species is 10000:1 or 1:10000. The partition coefficients of the neutral and ionized halophenols, $g_{H A}$ and $g_{A}$, were obtained by the fit of the above model to the measured $\mathrm{pH}$ dependence of halophenol distribution. 


\section{Relationship between the partition coefficient and the molecular}

\section{structure}

In recent years there were attempts to predict the partition coefficient using molecular parameters. Two methods (Word 1996) will be tested using the experimentally obtained data for trihalophenols.

\section{Molecular Surface Model (Smejtek 1996, Word 1996)}

The molar octanol-water partition coefficient $\mathrm{K}_{\mathrm{p}, \mathrm{ow}}$ is defined by

$$
K_{p, o w}=\frac{n_{o c}}{n_{a q}}
$$

Where $\mathrm{n}_{\mathrm{oc}}$ and $\mathrm{n}_{\mathrm{aq}}$ are the molar fractions of the species in the octanol and the water phase, respectively. Their definition is

$$
\begin{aligned}
& n_{o c}=\frac{[H A]_{o c}}{[H A]_{o c}+[O c t]_{o c}} \\
& n_{a q}=\frac{[H A]_{a q}}{[H A]_{a q}+\left[\mathrm{H}_{2} \mathrm{O}\right]_{a q}}
\end{aligned}
$$

$\mathrm{K}_{\mathrm{p}, \mathrm{ow}}$ can be related to the change of free energy of transfer and to the conventional octanol water partition coefficient:

$$
K_{p, o w}=e^{-\Delta G_{o w} / R T}=K_{o w} \frac{\left[H_{2} \mathrm{O}\right]_{a q}}{[O c t]_{o c}}
$$

Therefore the conventional octanol-water partition coefficient can be written as 


$$
K_{o w}=\frac{[O c t]_{o c}}{\left[H_{2} O\right]_{a q}} e^{-\Delta G_{o w} / R T}
$$

Due to the low solubility of octanol in water $\left(4.5 \times 10^{-3} \mathrm{M}\right)$ it was proposed to assume that $\left[\mathrm{H}_{2} \mathrm{O}\right]_{\mathrm{aq}}$ is equal to molar concentration of water. The solubility of water in octanol is between 1.75M and 2.3M (Bowman 1983, Chiou 1982). For the following calculations the concentration of octanol in the octanol phase is set to $6.15 \mathrm{M}$ as determined in (Bowman 1983) and of the water in the water phase to $55.41 \mathrm{M}^{2}$. Hence the free energy of transfer is

$$
\Delta G_{o w}=-R T\left(\ln 9.01+\ln K_{o w}\right)
$$

or using the decadic logarithm and assuming room temperature, the $\Delta \mathrm{G}_{\mathrm{ow}}$ in $\mathrm{kcal} / \mathrm{mol}$ is

$$
\Delta G_{o w}=-\left(1.28+1.34 \log K_{o w}\right)
$$

The free energy of transfer can be divided into an electrostatic and a non-electrostatic part. The non-electrostatic part is based on the collapse of the cavity surrounding the molecule in water and the formation of a cavity in the octanol. Work is done in producing this cavity, since any increase in surface of a liquid is associated with a definite energy change. In its simplest terms, it is given by the increase in the area of the cavity multiplied by the surface tension of the solvent Uhlig (Uhlig 1937). Hence, the free energy is given by

$$
\Delta G_{o w, n o n-e l .}=4 \pi R^{2}\left(\tau_{o c}-\tau_{a q}\right)
$$

\footnotetext{
${ }^{2}$ calculated from the density at $20^{\circ} \mathrm{C}$ and molar weight of $\mathrm{H}_{2} \mathrm{O}$.
} 
where $\tau_{\mathrm{aq}}$ and $\tau_{\mathrm{oc}}$ denote the surface tensions at the curved phenolate-water and the phenolate-octanol cavity interface. $4 \pi R^{2}$ is the molecular surface area (MSA) which can be obtained for a molecule by combining virtual spheres representing each atom. Each of these spheres represent an atom centered at the equilibrium position of the nucleus. The radius of the single sphere correspond to the van der Waals radius. Since $\tau_{\mathrm{oc}}$ and $\tau_{\mathrm{aq}}$ are not known and the difference of the two surface tensions is expected to be equal for similar molecules, the last equation becomes

$$
\Delta G_{o w, n o n-e l .}=\alpha M S A
$$

with $\alpha$ as the proportionality constant, containing the two surface tensions.

Equations 22 and 24 lead to

$$
\begin{aligned}
\log K_{o w} & =-0.746\left(\alpha M S A+\Delta G_{o w, e l .}\right)-0.96 \\
& =-0.746 \alpha M S A-\left(0.746 \Delta G_{\text {ow,el. }}+0.96\right)
\end{aligned} .
$$

$\alpha$ and $\Delta \mathrm{G}_{\mathrm{ow}, \mathrm{el} .}$ are expected to be similar for structurally similar molecules and is therefore regarded constant. Therefore parameters can be obtained by linear least square fit of the experimental $\mathrm{K}_{\mathrm{ow}}$ and the molecular surface area.

\section{Molar Volume Model (Gobas 1988)}

Since the solubility of halogenated phenols in octanol remains relatively constant, the distribution of halogenated phenol in an octanol-water system is believed to be mainly governed by the solubility of the molecule in the water phase.

The hydrophobicity of halogenated phenols is associated with the increase of entropy of the water phase on transfer of the halogenated phenol molecules into octanol. The presence of halophenols in water increases the order of water surrounding the 
halophenol molecules. The magnitude of this effect is proportional to the contact surface area of the cavity containing the halogenated molecule and water. These considerations led to the dependence of the octanol-water partition coefficient on the molecular size.

However, the free energy of solvation, which contributes to the free energy of transfer, is not only dependent on the relationship between the entropy and the molecular size. To a certain degree, it is also dependent on the relationship between the enthalpy of solvation and the volume size.

The free energy change, $\Delta G_{\text {sol,aq }}$, associated with dissolution, can also be seen as the sum of free energy of vaporization (solid-gas phase, $\Delta \mathrm{G}_{\mathrm{v}, \mathrm{aq}}$ ) and that of solvation (transfer of gaseous solute into solution, $\Delta \mathrm{G}_{\mathrm{s}, \mathrm{aq}}$ ).

$$
\Delta G_{s o l, a q}=\Delta G_{s, a q}+\Delta G_{v, a q}
$$

Zhang et al. (Zhang 1995) showed, that within a congeneric series of hydrophobic molecules, an increase in molecular size is associated with an unfavorable change in the entropy of solvation and a favorable change in enthalpy of solvation that are of similar magnitude, causing the free energy to be virtually independent on molecular size. Therefore

$$
\Delta G_{s, a q}=\Delta H_{s, a q}-T \Delta S_{s, a q} \cong \text { const }
$$

Consequently, the aqueous solubility is therefore dependent upon the vaporization and is more a solute-solute interactions rather than a solute-water interaction. 
The constant solubility of the congeneric samples in octanol is caused by the counterbalance of decreasing free energy of octanol solvation and increasing free energy of vaporization with increasing molar volume.

$$
\Delta G_{s o l, o c}=\Delta G_{s, o c}+\Delta G_{v} \cong \text { const }
$$

The free energy of transfer between octanol and water is the difference between free energy of solvation into water and the free energy of solvation into octanol.

$$
\Delta G=\Delta G_{s o l, a q}-\Delta G_{s o l, o c}=\Delta G_{s, a q}-\Delta G_{s, o c} \equiv \text { const. }-\Delta G_{s, o c}
$$

Hence, the increase of $\mathrm{K}_{\mathrm{ow}}$ with increasing molar volume of the solute is due to the decrease in the free energy of solvation and is thus a reflection of greater lipophilicity in octanol of the larger size congeners.

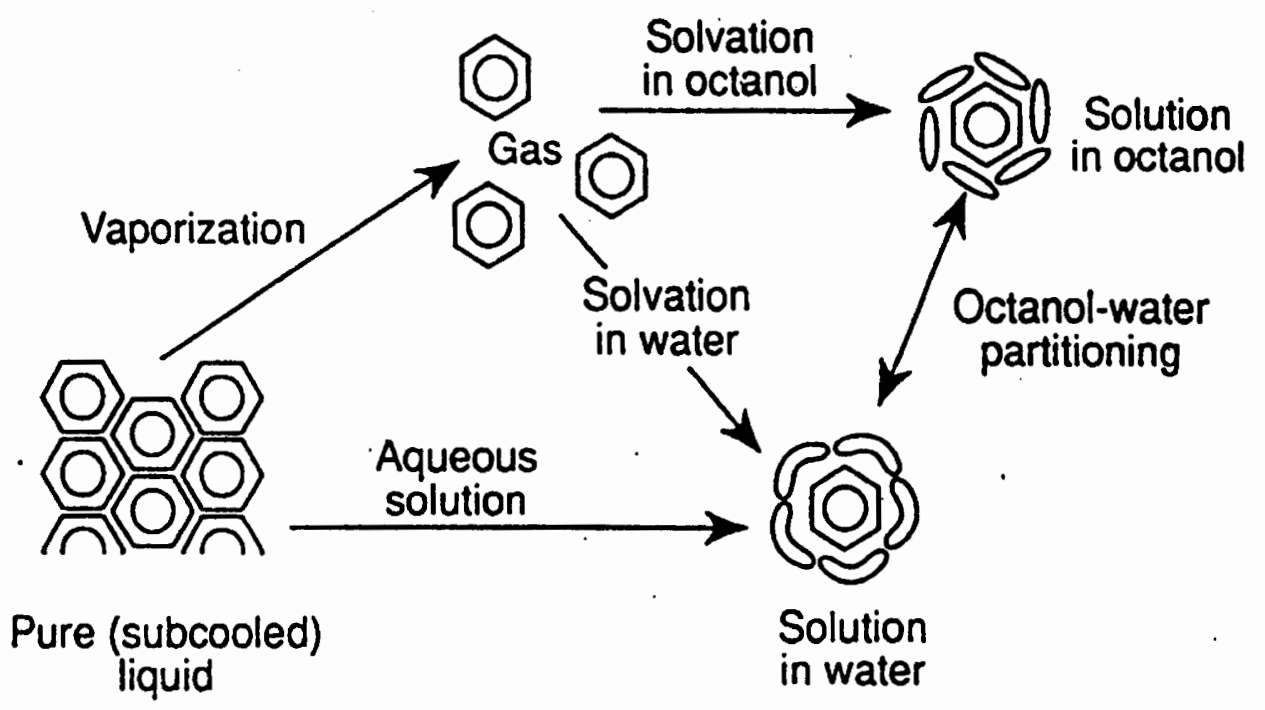

Figure 6: Dissolution model (Zhang 95) 
The starting point of this model is the Gibb's free energy of solution $\Delta \mathrm{G}_{\mathrm{s}} . \Delta \mathrm{G}_{\mathrm{s}}$ is the sum of the free energy of solvation and the free energy of vaporization. It is also related to the activity constant $\gamma$.

$$
\Delta G_{\text {sol }}=R T \ln \gamma
$$

$\Delta \mathrm{G}_{\text {sol }}$ can be divided into two parts:

$$
\Delta G_{s o l}=\Delta G_{c}+\Delta G_{i}
$$

Where $\Delta \mathrm{G}_{\mathrm{c}}$ is the free energy to create or collapse a cavity in a medium and $\Delta \mathrm{G}_{\mathrm{i}}$ is the free energy to place a molecule in or remove a molecule from the cavity.

Using the definition of the partition coefficient and the fact that the product of concentration and the activity constant is equal to the reciprocal molar volume (Chiou 1988).

$$
K_{o w}=\frac{[H A]_{o c}}{[H A]_{a q}}=\frac{V_{a q} \gamma_{a q}}{V_{o c} \gamma_{o c}}
$$

and Equation 30, it is possible to rewrite the expression for the octanol-water partition coefficient

$$
K_{o c}=\frac{V_{a q}}{V_{o c}} e^{\left(\left(\Delta G_{c, a q}-\Delta G_{c, c c}\right)+\left(\Delta G_{i, a q}-\Delta G_{i, o c}\right)\right) / R T}
$$

Where $\mathrm{V}_{\mathrm{aq}}$ and $\mathrm{V}_{\mathrm{oc}}$ are the molar volumes of the water and the octanol phase, respectively. According to Gobas, it is reasonable to assume, for a class of 
geometrically similar molecules, a linear proportionality between the difference of the free energies $\left(\Delta G_{c, a q}-\Delta G_{c, o c}\right)$ and the molar volume of the solute.

$$
\left(\Delta G_{c, a q}-\Delta G_{c, o c}\right)=(W-O) V_{s}
$$

Where $\mathrm{W}$ and $\mathrm{O}$ are constants, representing the free energy of cavity formation per unit of cavity volume in water and octanol, respectively.

The substitution results in the relationship between $\mathrm{K}_{\mathrm{ow}}$ and the molecular volume of the solute,

$$
K_{o w}=\frac{V_{u q}}{V_{o c}} e^{(W-o) V_{s} / R T} e^{\left(\Delta G_{i, u}-\Delta G_{i, o c}\right) / R T}
$$

By assuming that, for similar molecules, the second exponential factor and the volume ratio is constant, and combining the constant terms and taking the decadic logarithm the final form of the above equation is

$$
\log K_{o w}=\frac{W-O}{R T} V_{s}+I
$$

Thus we have obtained another linear relationship between $\log \mathrm{K}_{\mathrm{ow}}$ and a molecular property. From the knowledge of the slope and the intercept, the partition coefficient of similar molecules can be calculated. 


\section{Materials and Methods}

\section{Chemicals}

2,4,6 trifluorophenol (TriFP), 2,4,6 tribromophenol (TriBP), 2,4,6 triiodophenol (TriIP) and 99+\% spectroscopic grade 1-octanol were obtained from Aldrich Chemical Company, Inc. (Milwaukee, WI). Potassium-phosphate-dibasic-trihydrate $\left(\mathrm{K}_{2} \mathrm{HPO}_{4} \cdot 3 \mathrm{H}_{2} \mathrm{O}\right)$ and boric acid $\left(\mathrm{HBO}_{3}\right)$ were received from Mallinckrodt Chemicals (St. Louis, MO). Potassium citrate monohydrate $\left(\mathrm{K}_{3} \mathrm{C}_{6} \mathrm{H}_{5} \mathrm{O}_{7}\right)$ and potassium hydroxide $(\mathrm{KOH})$ for the partitioning experiments were ordered from Matheson Coleman \& Bell Manufacturing Chemists (Norwood, $\mathrm{OH}$ ). A standardized potassium hydroxide-solution $(\mathrm{KOH})$ for the $\mathrm{pK}_{\mathrm{a}}$-measurements was obtained from VWR Scientific (West Chester, PA), the concentration of $\mathrm{KOH}$ was $0.1 \pm 0.0005 \mathrm{~N}$. Potassium chloride $(\mathrm{KCl})$ was purchased from EM Science. Chemicals were used without further purification. The aqueous solutions were prepared with deionized water. Chemicals were weighed using a balance model from Mettler Instruments (Nightstown, NJ). 


\section{Spectrophotometric Measurements}

Concentrations were determined by UV-Visible (UV-VIS) spectrophotometry using Beer's law.

\section{UV-Visible absorption of molecules}

According to quantum mechanics, molecules can be found in different discrete energy states. These energy states have either electronic, vibrational or rotational origin. Absorption of energy (e.g. photons, kinetic energy, ...) results in a transition ${ }^{3}$ to a higher energy state of the molecule - the molecule gets excited. A transition is most likely, if the energy difference $\Delta E$ of the two involved quantum states equals the incident energy. The energy $E$ of a photon and its wavelength $\lambda$ are related by the following equation:

$$
E=h v=\frac{h c_{m}}{\lambda}
$$

Where $h$ is Planck's constant, $v$ is the frequency of the light, $c_{m}$ is the speed of light in the medium. The wavelength range for common UV-VIS spectrophotometers is usually between 200 and $700 \mathrm{~nm}$. Therefore the most important states for the absorption of UV- VIS light are the electronic states. The energy difference between rotational and vibrational states corresponds to wavelengths in the infrared (IR) or microwave radiation. It is not only possible to excite a molecule from the ground state to a higher state, it is also possible to excite it out of an already excited state. However at room temperature molecules are most likely ${ }^{4}$ in the electronic ground state. Once a

\footnotetext{
${ }^{3}$ Restricted by quantum mechanical selection rules

${ }^{4}$ According to the Boltzmann distribution
} 


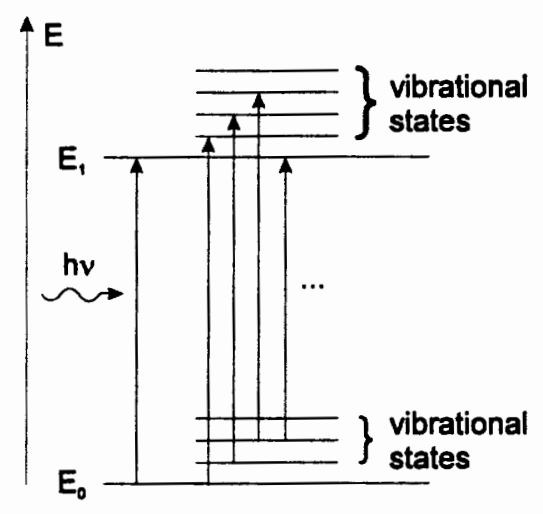

Figure 7: Energy level system molecule is excited it rapidly releases the excitation energy. This can happen either by emitting a photon in a random direction or by other mechanism of transition. Hence, the excitation reduce the photon flux towards the detector at that particular wavelength. The excitation of electrons and its reverse process can also be accompanied by the change of vibrational and rotational ${ }^{5}$ quantum states ${ }^{6}$, so an otherwise narrow absorption line becomes a broad peak containing vibrational and rotational fine structure.

\section{Lambert-Beer's Law}

A fundamental law relating the absorption of electromagnetic radiation to the concentration of light absorbing species is Lambert-Beer's law:

$$
I=I_{0} e^{-A}, A=\varepsilon c l
$$

Where $\mathrm{I}_{0}$ and $\mathrm{I}$ is the intensity of the incident and transmitted light, $\mathrm{A}$ is the absorbance, $\mathrm{c}$ the concentration of the sample and $l$ is the optical path length. It is based on observations of Lambert, namely, the fraction for the incident light to the absorbed light is independent of the intensity, and Beer's law: the absorbance is proportional to the number of absorbing molecules. This describes a very simple relationship between $\mathrm{A}$ and $\mathrm{c}$. However the origin of the absorbance in the absorption

\footnotetext{
${ }^{5}$ Which, in the case of solutions, are often suppressed by solvent molecules

${ }^{6}$ Which, because of their small energy gap, don't have to be in the ground state at room temperature
} 
measurements is not due only to the solute molecules. Scattering, reflections at the air-cuvette and cuvette-solution interfaces and absorption by the buffer produce a background absorbence which has to be subtracted. The use of Beer's law demands a relatively transparent solution and very small solute-solvent interaction.

\section{Solvent effects}

The absorption spectrum of a sample in a solution is influenced by different effects. Weak acids, like halophenols, are in a mixed state of ionized and un-ionized forms, depending on the $\mathrm{pH}$ of the solution. As ionized and un-ionized molecules have slightly different absorption bands, the resulting spectrum is a combination of both. To avoid these types of error, the solutions were titrated before each measurement to high a $\mathrm{pH}$, so that the absorption spectrum corresponds to the ionized form of halophenols.

Another effect is the interaction between dipoles in polar solvents. Frank-Condon principle states, that during electrical transitions atoms of a molecule do not move. Therefore electrons often reorganize in more polar, excited states $\left(\pi, \pi^{*}\right)$. This happens in molecules of the solute and the solvent and is connected with an dipole change in the molecule. The interaction between the dipole solute and the dipole of the solvent lowers than the energy gap (red-shift). $\left(n-\pi^{*}\right)$ transitions (e.g. transition of oxygen lone pair in ketones) show the opposite effect (blue shift).

Another effect, which will be discussed later on in detail, is the formation of micelles.

\section{DU-7 UV-VIS Spectrophotometer}

For the spectrophotometric measurements the DU-7 UV-Visible Spectrophotometer from Beckman Instrument, Irvine, CA, was used. The spectrophotometer has $\pm 0.5 \mathrm{~nm}$ 
wavelength accuracy, $\pm 0.5 \mathrm{~nm}$ photometric accuracy and a baseline drift below 0.003 A/hr. Cuvettes were purchased from Spectrocell Corp. Orland, $\mathrm{Pa}(5 \mathrm{~cm}$ and $1.11 \mathrm{~mm})$ and from Pyrocell Manufacturing Co. Inc. Westwood, NY $(1 \mathrm{~cm})$.

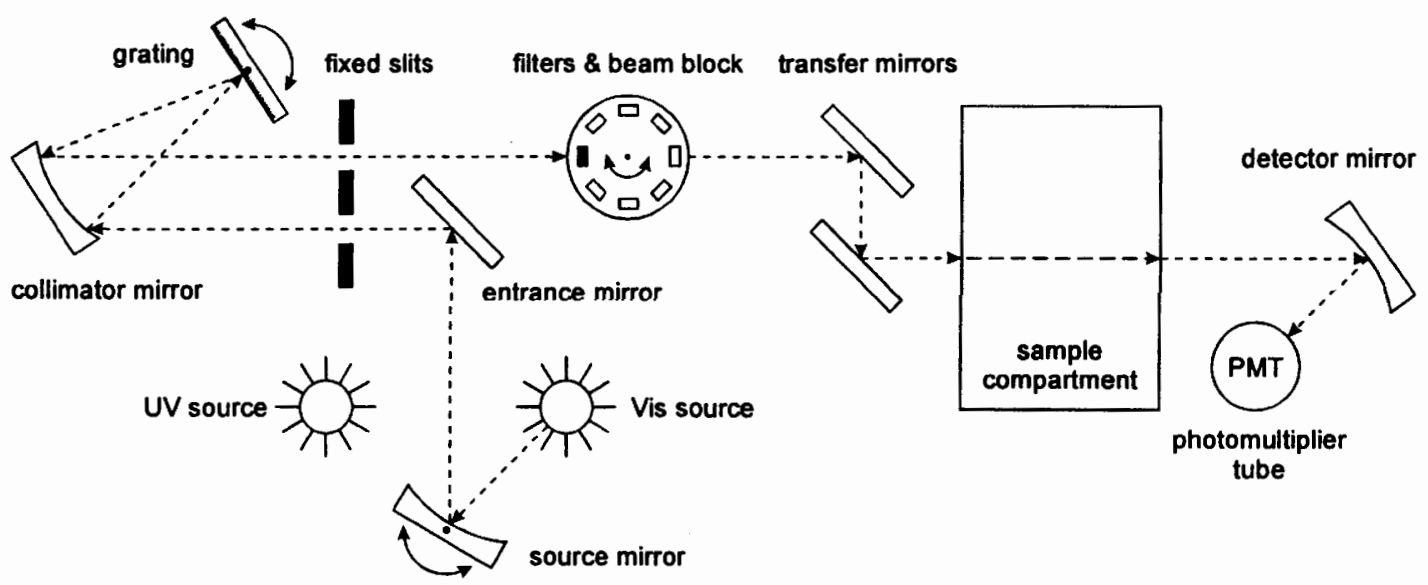

Figure 8: Optical path in the spectrophotometer.

Light from either the UV or the visible light source guided by mirrors and narrowed by a slit is focused by a concave mirror to a grating. Depending on the angle of the beam to the grating, the wavelength of the reflected beam is selected from the constructive interference pattern produced by the grating. Via a filter and further mirror system, the now monochromatic light propagates through sample compartment, where a fraction of light gets absorbed by the sample. The filters are necessary to achieve about equal intensity for all wavelengths of the light before it enters the sample. The light passed through the sample produces then an electrical signal in the photomultiplier tube. The spectrophotometer is microprocessor controlled. By varying the angle of the grating a wavelength scan over a wide range $(200-700 \mathrm{~nm})$ is obtained. The data, absorbance vs. wavelength, are displayed on a cathode ray display and can be either printed or acquired by a laboratory PC. 


\section{$p K_{a}-$ Measurement}

The distribution curve of a compound between octanol and water depends on three

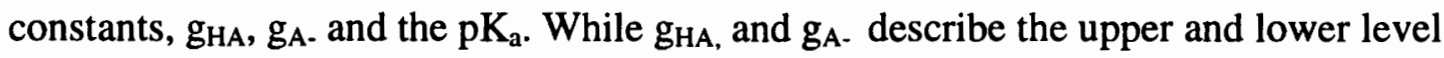
of the curve, the $\mathrm{pK}_{\mathrm{a}}$ is affects the part in the middle of the $\mathrm{pH}$ range. With the best fit of the distribution function to the data, all three constants can be obtained. The $\mathrm{pK}_{\mathrm{a}}$ value of a sample was used as a data quality control parameter of the obtained data. The $\mathrm{pK}_{\mathrm{a}}$-values of TriCP (6.15) (Schellenberg 1984), TriBP $(5.9,6.0)$ (Ogston 1936, Krahl 1938) and TrilP (6.6) (Krahl 1938) were found in literature. The $\mathrm{pK}_{\mathrm{a}}$ value for TriFP was not found and had to be determined. The $\mathrm{pK}_{\mathrm{a}}$ value of Krahl (1938) for TrilP was uncertain. Since the measured distribution of TriIP between water and octanol could not be reproduced from the model using the published $\mathrm{pK}_{\mathrm{a}}$ value, there was a special interest in redetermination of this value. The values of TriCP and TriBP are well established and were used as references.

Due to the presence of the $\mathrm{OH}$-group, which dissociates in aqueous solutions, halogenated phenols are weak acids. In aqueous solutions, an equilibrium exists between the ionized $\left(\mathrm{H}^{+}, \mathrm{A}^{-}\right)$and un-ionized (HA) species of the phenol, depending on the $\mathrm{pH}$ of the solution.

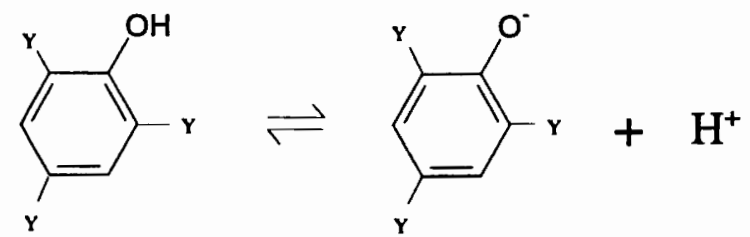

Figure 9: Dissociation of 2,4,6 trihalophenols in aqueous solutions, $Y$ symbolizes the location of the halogens. 
The ionization constant expresses the strength of an acid or a base. The definition of $\mathrm{K}_{\mathrm{a}}$ and $\mathrm{pK}_{\mathrm{a}}$ is

$$
K_{a}=\frac{\left[H^{+}\right]\left[A^{-}\right]}{[H A]}, p K_{a}=-\log K_{a}
$$

The $\mathrm{pH}$ dependence of this equilibrium is described by using (39) and the definition of $\mathrm{pH}$.

$$
p K_{a}=p H+\log \frac{[H A]}{\left[A^{-}\right]}
$$

The $\mathrm{pK}_{\mathrm{a}}$ equals the $\mathrm{pH}$, if $[\mathrm{HA}]=\left[\mathrm{A}^{-}\right]$. With the $\mathrm{pH}$ and $\mathrm{pK}_{\mathrm{a}}$ of a solution the distribution coefficient $\mathrm{D}$ can be calculated.

There are three ways of determining the $\mathrm{pK}_{\mathrm{a}}$ :

1.) Directly from the definition given in equation

The $\mathrm{pK}_{\mathrm{a}}$ is equal to the $\mathrm{pH}$, where $[\mathrm{HA}]$ and $\left[\mathrm{A}^{-}\right]$have the same value. This requirement is fulfilled in the middle of this significant plateau in the graph. So it is possible to read the value directly from the graph.

2.) From electroneutrality condition

Because of the electrical neutrality of the solution, the sum of the positive charges must equal the sum of the negative charges.

$$
\left[A^{-}\right]+\left[O H^{-}\right]=\left[K^{+}\right]+\left[H^{+}\right]
$$


Because all salts are completely ionized, the amount of $\mathrm{K}^{+}$equals the $\mathrm{KOH}$ added to the solution. By recognizing that the initial concentration $\left[\mathrm{HA}_{0}\right]$ is the sum of $\left[\mathrm{A}^{-}\right]$and [HA] in the solution, Equation 41 turns into

$$
[H A]=\left[H A_{0}\right]-[\mathrm{KOH}]+\left[\mathrm{OH}^{-}\right]-\left[\mathrm{H}^{+}\right]
$$

For $\mathrm{pH}$ - values in the range from 4 to 10 the difference of concentrations $\left[\mathrm{OH}^{-}\right]-\left[\mathrm{H}^{+}\right]$ becomes very small and can be neglected. Therefore equations for $[\mathrm{HA}]$ and $\left[\mathrm{A}^{-}\right]$can be written as

$$
\begin{aligned}
& {[H A]=\left[H A_{0}\right]-[K O H]} \\
& {\left[A^{-}\right]=\left[H A_{0}\right]-[H A]}
\end{aligned}
$$

It is now possible, by using Equation 40 , to calculate the $\mathrm{pK}_{\mathrm{a}}$ from each data point and average over the obtained values.

3.) The dissociation constant can also by obtained by fitting the $\mathrm{pH}$ equation (40) to experimental titration data curve.

\section{Studies with TriFP and TriCP}

The experiments were done in pure deionized water. To minimize errors, due to dissolved $\mathrm{CO}_{2}$ in the water, a very high concentration of the compound (about 10 $\mathrm{mM} / \mathrm{l}$ ) was chosen. After adding the chemical to the water and stirring it for a while, the $\mathrm{pH}$ was measured by a Model $6072 \mathrm{pH}$ Meter from Jenco Instruments, Inc. (San Diego, CA). The next step was to titrate the solution with $\mathrm{KOH}(0.1 \mathrm{M})$ while measuring the $\mathrm{pH}$. 


\section{Studies with TriBP and TriIP}

Because of the low solubility ${ }^{7}$, atmospheric influences and solvation of undissolved particles of these compounds during the experiment, the procedure for $\mathrm{pK}_{\mathrm{a}}$ determination had to be changed for TriBP and TriIP. TriBP and TriIP were first dissolved in ethanol. The advantage of this modified method is that the compounds are soluble in ethanol and therefore the required high concentrations could easily be obtained. However, the addition of ethanol to water is accompanied by a $\mathrm{pK}_{\mathrm{a}}$ shift. The pKa of an acid increases and that of a base decreases due to the presence of ethanol.

The $\mathrm{pK}_{\mathrm{a}}$ corresponding to pure water can be extrapolated from the data obtained at different ethanol-water concentrations, assuming a linear relationship between the ethanol concentration and the $\mathrm{pK}_{\mathrm{a}}$ shift.

Octanol is expected to influence the $\mathrm{pK}_{\mathrm{a}}$ in a similar way as ethanol. However, it was unclear if the low concentration of octanol can result in significant change of the $\mathrm{pK}_{\mathrm{a}}$. It, therefore, became necessary to determine the $\mathrm{pK}_{\mathrm{a}}$ of the sample in the octanol saturated water phase, since this is the aqueous solution used in the partitioning experiment.

\footnotetext{
${ }^{7}$ It was only possible to reach a concentration $<10 \mu \mathrm{M} / 1$ in pure water. The proposed concentration of the sample is $0.01 \mathrm{Mol}$.
} 


\section{Phase Preparation}

For the aqueous phase a citrate/borate/phosphate buffer $(2 \mathrm{mM} / 2 \mathrm{mM} / 0.5 \mathrm{mM})$ with a salt concentration of $0.03 \mathrm{M} \mathrm{KCl}$ was used. The citrate/borate/phosphate buffer maintains the $\mathrm{pH}$ over a wide $\mathrm{pH}$ range. The $\mathrm{pH}$ was adjusted in the experiment between 2.5 and 12.5. It was shown by (Westall 1990) that the partition coefficient is dependent on the concentration of salt in the solution. Therefor $\mathrm{KCl}$ had to be added to maintain ionic strength and to make the conditions comparable to previous experiments in this laboratory. The term water phase in this thesis refers to this buffer.

Since water and octanol were both soluble in each other, the two phases had to be presaturated, so that the volume change in the experiment is negligible and it is possible to make a mass balance calculation. Moreover, because of the variation of the dielectric constant in the presence of octanol in the water, a presaturated water was also needed for the determination of the extinction coefficient. However, the presence of octanol in water affected the absorbance peaks only to a very small degree.

The presaturation was done in $250 \mathrm{ml}$ polypropylene centrifuge bottle. Octanol and water were transferred to the bottles at volume ratio 5 to 1 . This ratio is also used in the following partition experiments. After shaking the bottles for one hour on a Model BB Wrist Action Shaker (Burrel Corp., Pitsburth, PA), the octanol-water mixtures were centrifuged at $1500 \mathrm{~g}$ for one hour in an IEC DPR-600 Temperature controlled centrifuge (International Equipment Comp., Needhan Hights, M). Then the octanol phase, which floats on top of the water phase, was carefully extracted by a glass syringe and stored in a glass bottle. The saturated buffer was extracted by a pipette and also transferred into a separate glass bottle. The last few $\mathrm{ml}$ were discarded to avoid mixing the buffer and octanol near the interface. Figure 10 shows the difference in the absorption spectrum between water and the octanol saturated water. The 
absorbance in the UV range in saturated water is due to light scattering from octanol micelles. The negative absorbance is probably due to constructive interference effects.

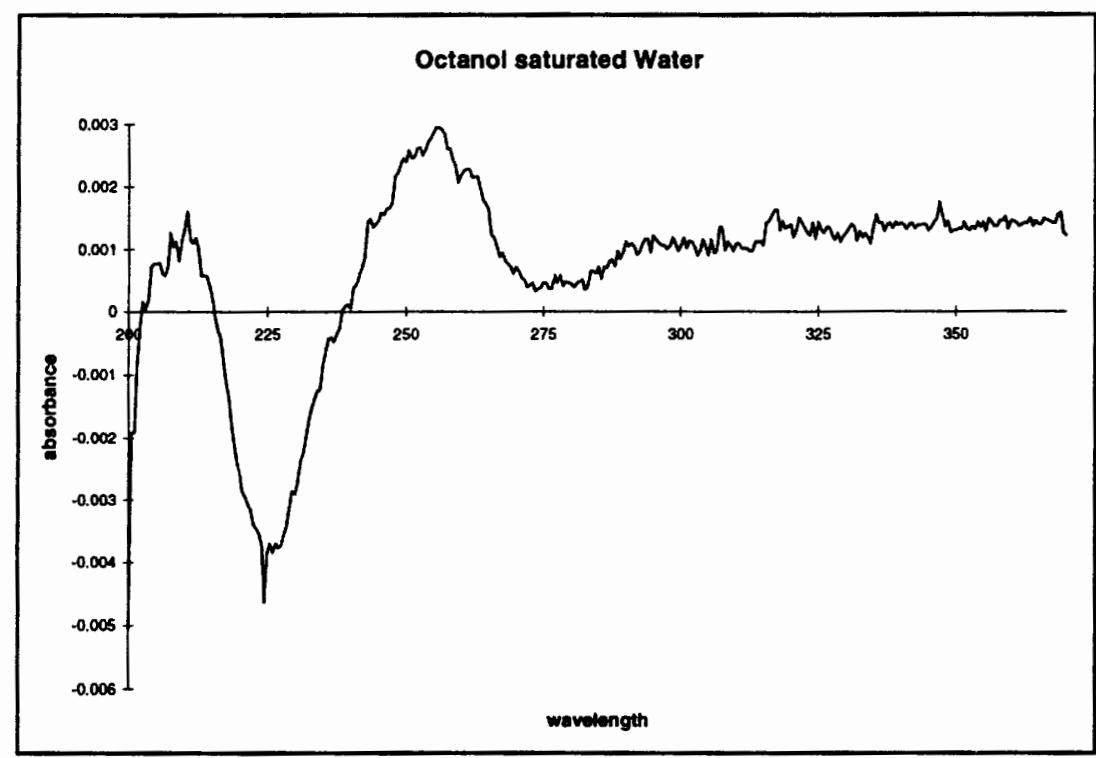

Figure 10: Absorption spectrum of octanol saturated water. 


\section{Extinction Coefficients}

According to Beer's law, the absorbance A is given by the product of concentration c, path length 1 and extinction coefficient $\varepsilon$ of the sample. The extinction coefficient combines properties of the chemical, the solvent and the spectrophotometer to relate the absorbance to the concentration of the sample. For the interpretation of the partitioning data it is therefore essential to measure this constant for each halophenol. Because the only interest was in the concentration of the sample in octanol-saturated buffer, the extinction coefficient for each sample was only determined in saturated buffer.

Assuming that the value of the extinction coefficient is around 5000 for each compound TriFP, TriBP and TriIP three stock solutions were prepared in saturated buffer. The concentration of the solutions allowed the absorbance limit to be about 2 with a path length of $1 \mathrm{~cm}$. Because of the low solubility of TriBP and TriIP, $\mathrm{KOH}$ had to be added to the buffer during the preparation of the stock solution. Each of theses stock solution were stirred for several hours to completely dissolve the halophenol. Out of each sock solution about 5 working solutions were prepared by diluting the stock solution with saturated buffer. The spectrophotometric measurements were done with $\mathrm{pH} \approx \mathrm{pK}_{\mathrm{a}}+4$. At this $\mathrm{pH}$ the sample is almost totally ionized and the absorption spectrum is only due to the concentration of the ionized species. Concentration changes due to the dilution of $\mathrm{KOH}$ were taken into account. The length of the cuvettes was chosen so that the absorbance was between 2 and 0.1 . The spectrophotometer was calibrated before each measurement. The absorbance was measured against the octanol-saturated buffer. A instrumental problem due to a switch from the UV to visible source affected, to a small degree, absorbance measurements of TriBP and TrilP solutions. The cuvettes were cleaned carefully at the end of the experiment or rinsed at least three times with the next solution to be measured. The 
obtained data were fitted to a line (A/l vs. c) and the slope or extinction coefficient of this line (according to $A=c \varepsilon l)$ was used for further measurements. 


\section{Partitioning}

The partition coefficients were determined using the traditional shake-flask method. For about 20 data points $100 \mathrm{ml}$ octanol stock solution was needed. Again the sample concentration was chosen so that the expected absorbance of the buffer was in the linear absorbance range (0.1-2) of the spectrophotometer. However, this was not always possible, because of the large difference between the buffer concentrations of the ionized and unionized form. Therefore two stock solutions of different concentration were needed. The solubility of each compound in octanol was very good, and the desired concentration could be reached without any further tricks.

The $\mathrm{pH}$-adjusted buffer (between 2.5 and 12.5) was brought into contact with the octanol stock solution in the following way. For each data point $25 \mathrm{ml}$ of buffer and 5 $\mathrm{ml}$ of the octanol stock solution were added to a $50 \mathrm{ml}$ glass centrifuge bottle. In the same way a background buffer was prepared with water-saturated octanol. The volume ratio of phases was dependent on the solubility of the solute in octanol and buffer (the lower the solubility of a sample in water the more buffer is needed). Solvent volumes influence the analytical errors and consequently the error in determining $\mathrm{K}_{\text {ow }}$ (Leo et al 1971). Because of the higher volume water to octanol ratio (Standard for test data development) the sample and the background octanol-water system were shaken for an hour on a wrist action shaker and centrifuged at $1500 \mathrm{~g}$ for another hour by a Safeguard Centrifuge (Clay-Adams, Inc., Parsippany, NJ). Afterwards the two phases in each bottle were carefully separated by removing the octanol phase by pipette. The $\mathrm{pH}$ of the buffer was measured and titrated to a value over $\mathrm{pK}_{\mathrm{a}}+4$ with $0.1 \mathrm{M} \mathrm{KOH}$. Again the change of the concentration caused by this volume change was accounted for. Finally, the concentration of the buffer phase was determined by spectrophotometric measurements. The concentration of the sample in 
the octanol phase was calculated by applying the conservation of mass in the octanolwater system.

$$
\begin{aligned}
& {[\text { sample }]_{o c}^{i} V_{o c}^{i}=[\text { sample }]_{a q}^{f} V_{a q}^{f}+[\text { sample }]_{o c}^{f} V_{o c}^{f}} \\
& D(p H)=\frac{[\text { sample }]_{o c}^{i}}{[\text { sample }]_{a q}^{f}(p H)}-\frac{V_{a q}}{V_{o c}}
\end{aligned}
$$

Where $i$ and $f$ stand for initial and final, oc for octanol phase and aq for aqueous phase. The initial and final volumes should be equal, because the phases were presaturated. A direct measurement of the sample concentration in the octanol phase was not possible because the unknown and uncontrollable ionization of the sample in octanol. For the high $\mathrm{pH}$ range of TriFP it was not possible to use the technique which is described above. Due to the very low final concentration of TriFP in octanol and the measurement errors of the concentration in the water phase, it was not possible to determine reliably a concentration of sample in octanol from the mass balance. In this case the halogenated phenol was introduced into the water phase, rather than into the octanol phase and the direction of partition was from water unto octanol. The concentration of the sample in the water phase was determined before and after the partitioning process by spectrophotometric measurements. The concentration of the octanol phase was then calculated using the difference of both measurements and applying the mass balance. This procedure yield more accurate results for TriFP.

Since $\mathrm{K}_{\mathrm{ow}}$ is influenced by temperature, the experiments were all done at room temperature. Variations due to changes in the room temperature are small compared to those inherent errors in the other measurements.

The data were analyzed with Microsoft EXCEL. AXUM (Trimetrix) was used to fit the data to the distribution curve. 


\section{Results and Discussion}

\section{Dissociation Constants}

Dissociation constants are an important parameter in the model describing the $\mathrm{pH}$ dependence of the distribution coefficient of halophenols between octanol and water. Due to the inavailability of $\mathrm{pK}_{\mathrm{a}}$ value for 2,4,6-trifluorophenol in the literature and uncertainty of other published data, the $\mathrm{pK}_{\mathrm{a}}$ values were measured for all compounds in the trihalophenol series. This assured that the dissociation constants used in the analysis of octanol-water partition were analyzed using $\mathrm{pK}_{\mathrm{a}}$ values obtained by the same method.

The $\mathrm{pK}_{\mathrm{a}}$ determination method was developed using TriCP. The titration data of TriCP are shown in Figures 11 a,b. Figure 11a shows the dependence of $\mathrm{pH}$ of TriCP solution in water as a function of volume of $0.1 \mathrm{~N} \mathrm{KOH}$, the $\mathrm{pK}_{\mathrm{a}}$ values determined for each titration point, and the titration curve computed from the measured $\mathrm{pK}_{\mathrm{a}}$. Figure $11 \mathrm{~b}$ illustrates same data analyzed without the correction on concentration change in the titration process and the anomalies at higher volume of added $\mathrm{KOH}$. Figure 12 shows the titration curve of TriFP whose $\mathrm{pK}_{\mathrm{a}}$ has not been available in the literature.

In contrast, $\mathrm{pK}_{\mathrm{a}}$ values of TriBP and TriIP could not be obtained by the same method as used above for TriFP and TriCP due to their very limited solubility in water. Instead, their dissociation constants were obtained in ethanol-water solutions and the $\mathrm{pK}_{\mathrm{a}}$ for water was obtained by extrapolation to zero ethanol concentration. The titration curve of TriBP is shown in Figure 13a. The $\mathrm{pK}_{\mathrm{a}}$ values of TriBP obtained as a function of ethanol concentration are shown in Figure 13b. Similar results for TrilP are shown in Figures 14a,b. 
In octanol-water partition experiments the water phase is saturated with octanol. Octanol has lower dielectric constant than water and due its presence in water the dissociation constant of TriIP may be different from that in pure water. This possible effect was explored by repeating in the TriIP titration experiment in octanol-saturated water. The results are shown in Figure 15. From the regression analysis of $\mathrm{pK}_{\mathrm{a}}$ versus ethanol concentration data the presence of octanol in water increased $\mathrm{pK}_{\mathrm{a}}$ by about 0.1 units, which is a rather insignificant change with regard to the error which was made by extrapolating the data to zero concentration of octanol.

The $\mathrm{pK}_{\mathrm{a}}$ values are calculated at each data point in the titration curve. The average of these calculations is the $\mathrm{pK}_{\mathrm{a}}$ of the measurement. The $\mathrm{pK}_{\mathrm{a}}$ results obtained in this study are summarized in Table 1.

Table 1: Results of the pKa measurement

\begin{tabular}{l|ll}
\hline & & \\
Compound & measured $p K_{a}$ & literature value \\
\hline $2,4,6$ TriFP & $7.12 \pm 0.04$ & n.a. \\
$2,4,6$ TriCP & $6.15 \pm 0.01$ & 6.15 (Schellenberg 1984) \\
& & 6.2 (Krahl 1937) \\
& & $5.9($ Oston 1936) \\
$2,4,6$ TriBP & 5.9 & 6.0 (Krahl 1937) \\
& & 6.6 (Krahl 1937) \\
$2,4,6$ TriIP & 6.44 (pure water) & \\
& 6.57 (oct. sat. water) \\
\hline
\end{tabular}




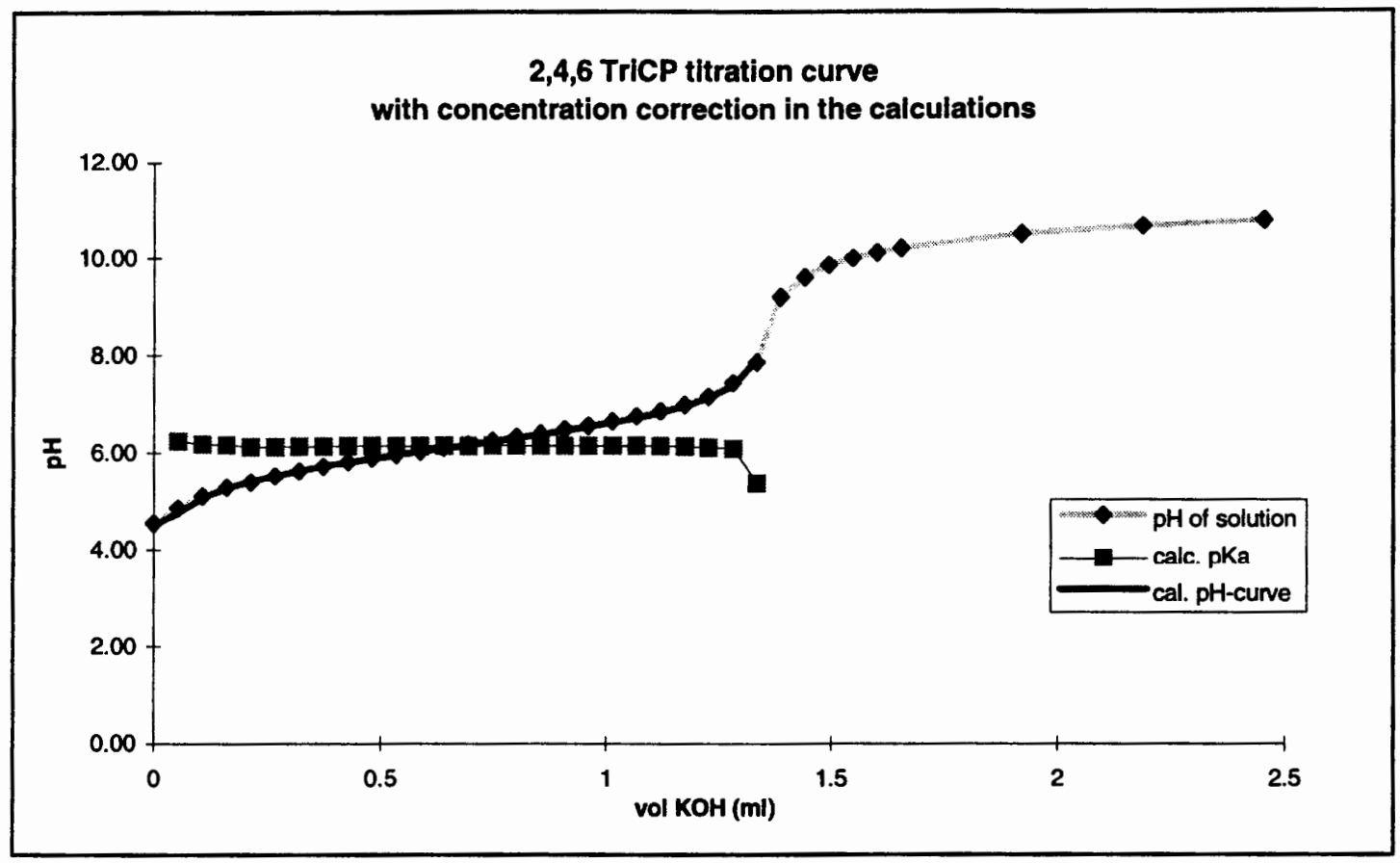

Figure 11a: Titration curve of 2,4,6 TriCP

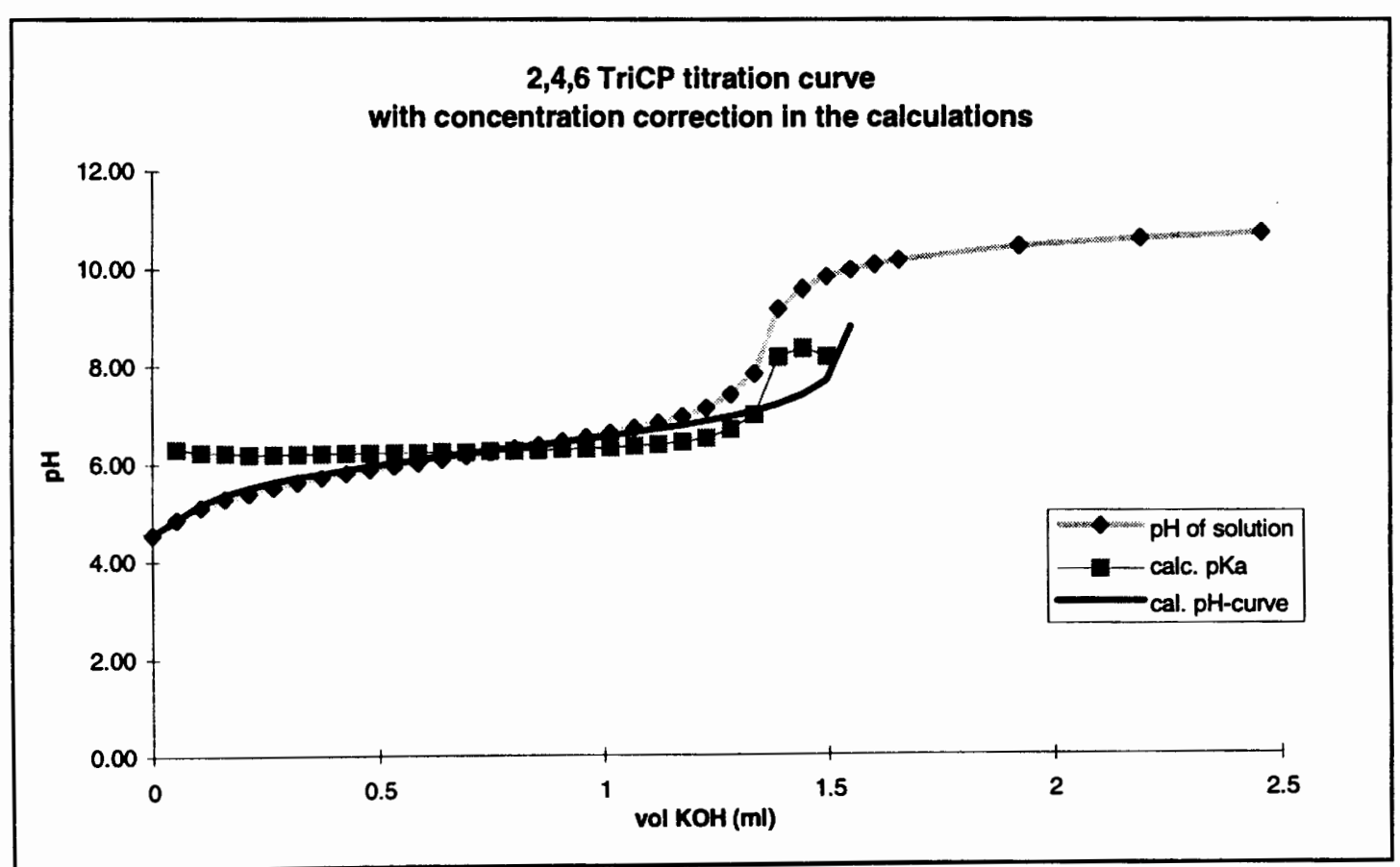

Figure 11b: Titration curve of 2,4,6 TriCP 


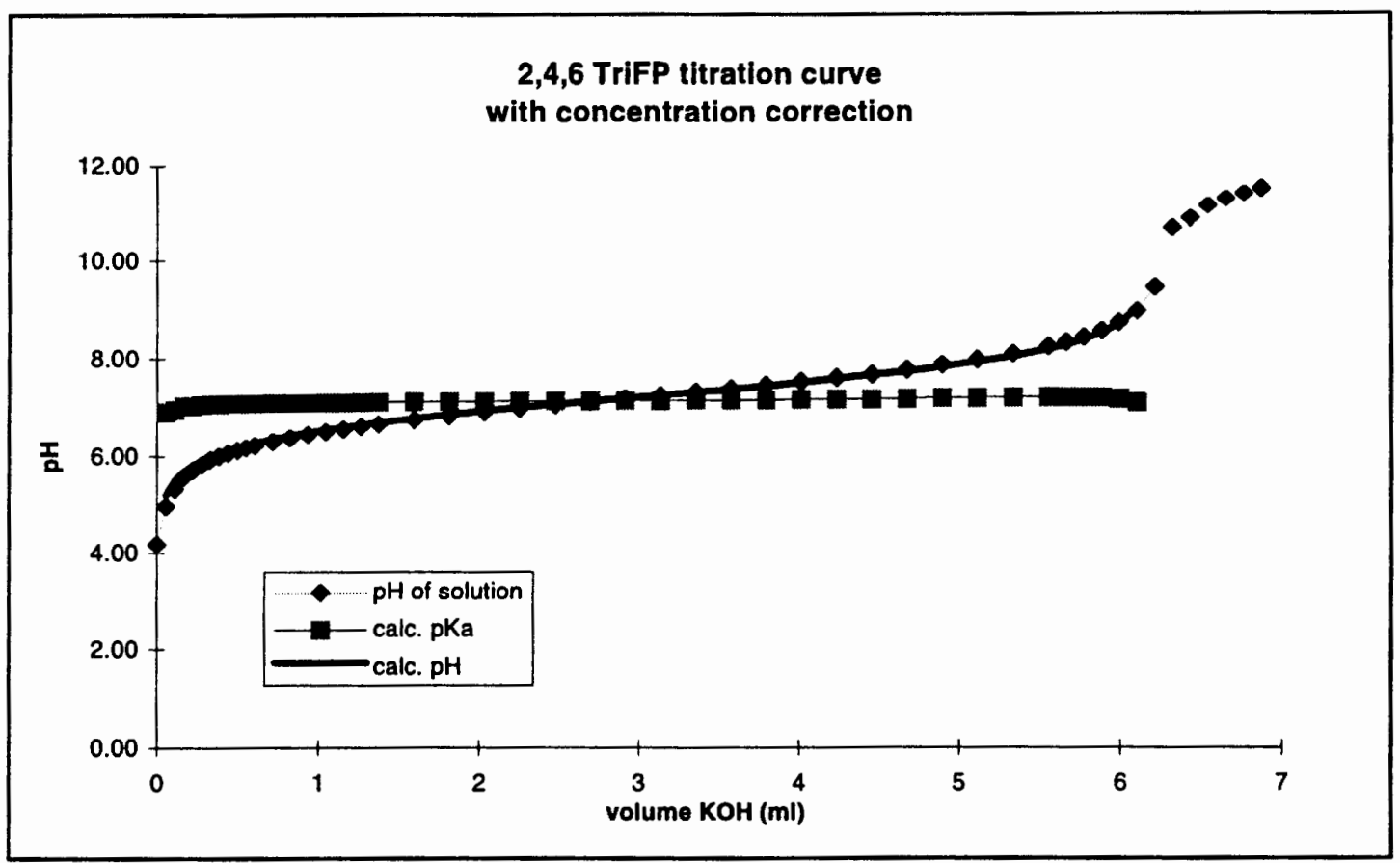

Figure 12: Titration curve of 2,4,6 Trifluorophenol 


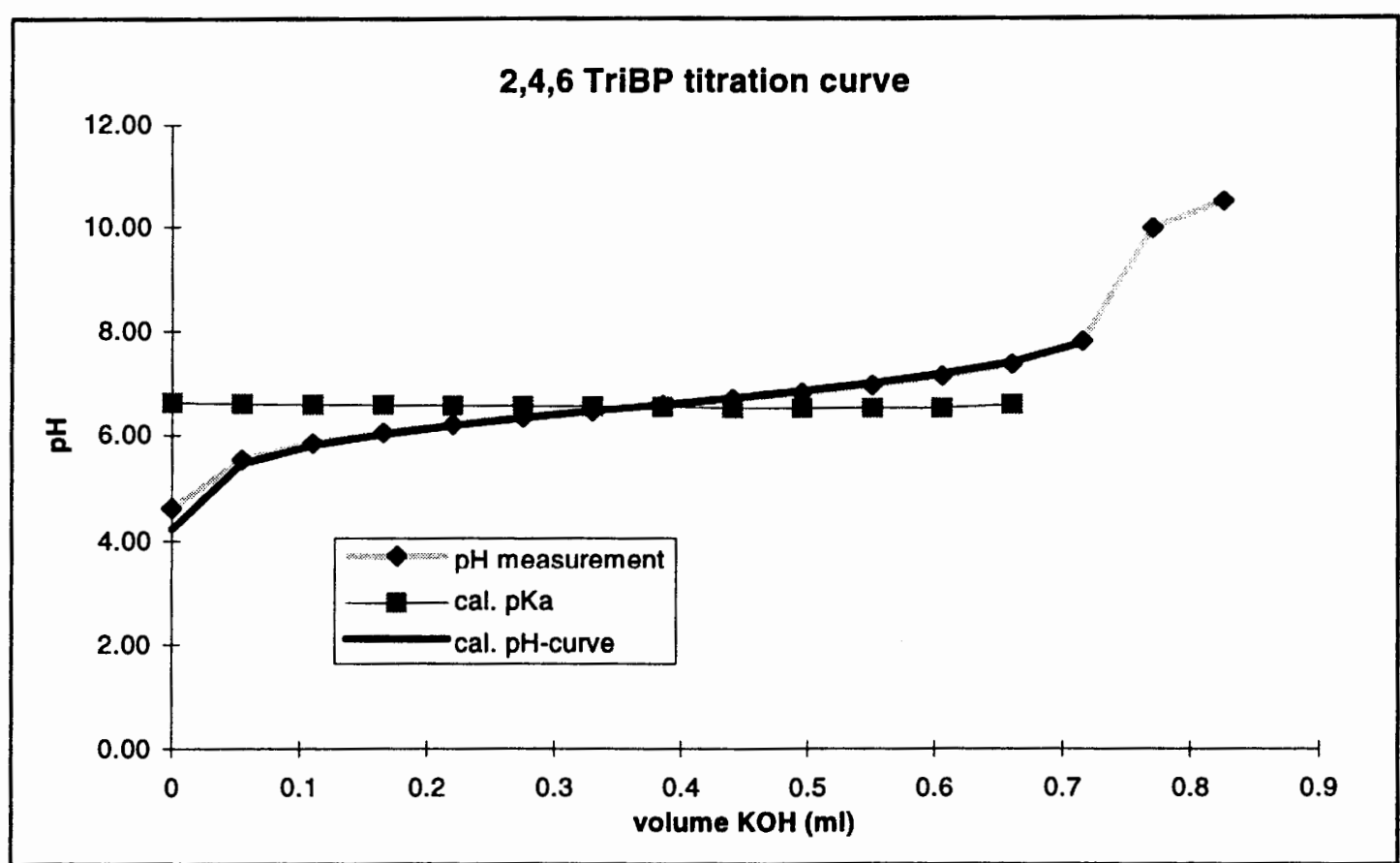

Figure 13a: Titration curve of 2,4,6 TriBP in an ethanol-water solution

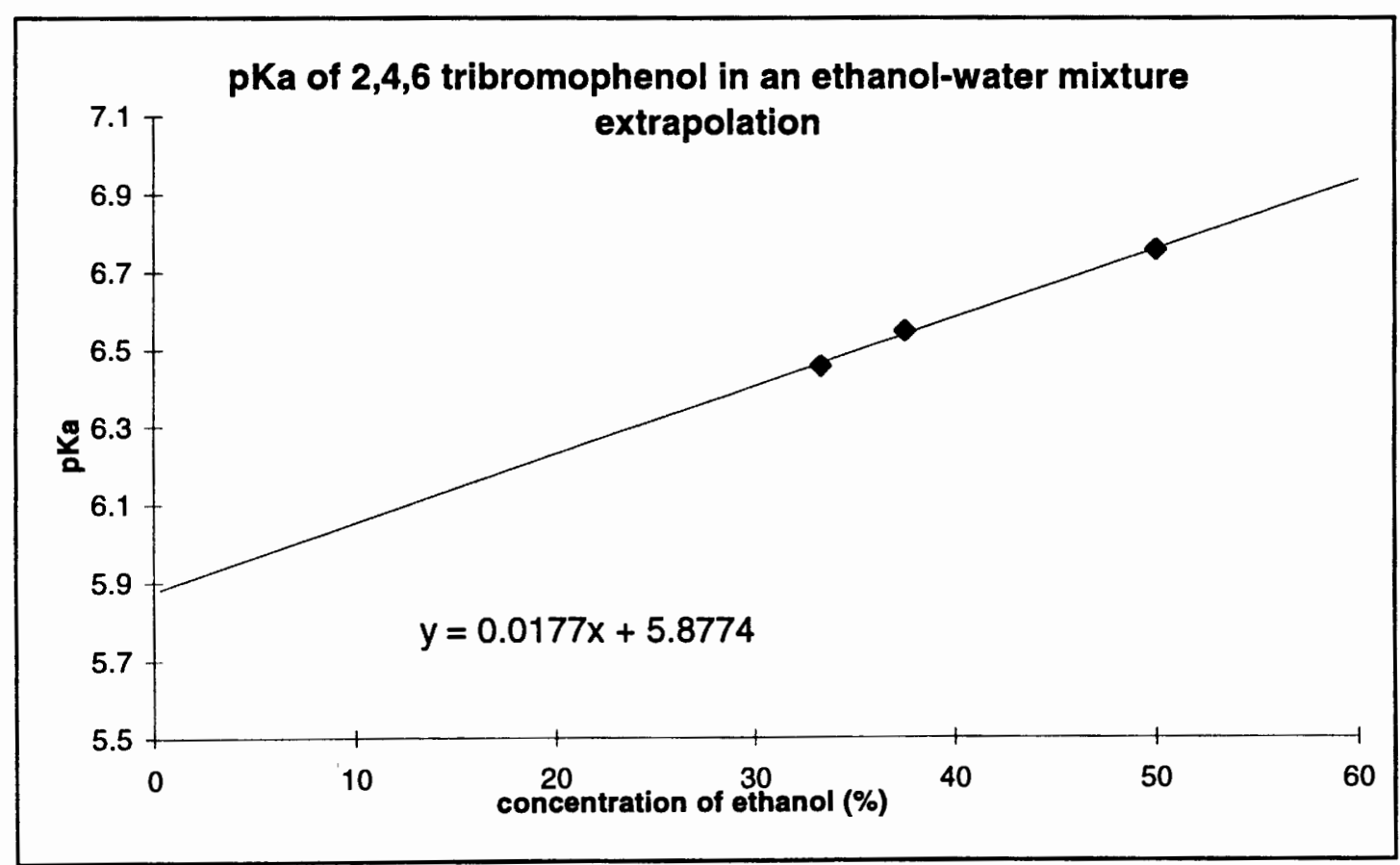

Figure 13b: Extrapolation of the data of 2,4,6 TriBP to 0\% ethanol 


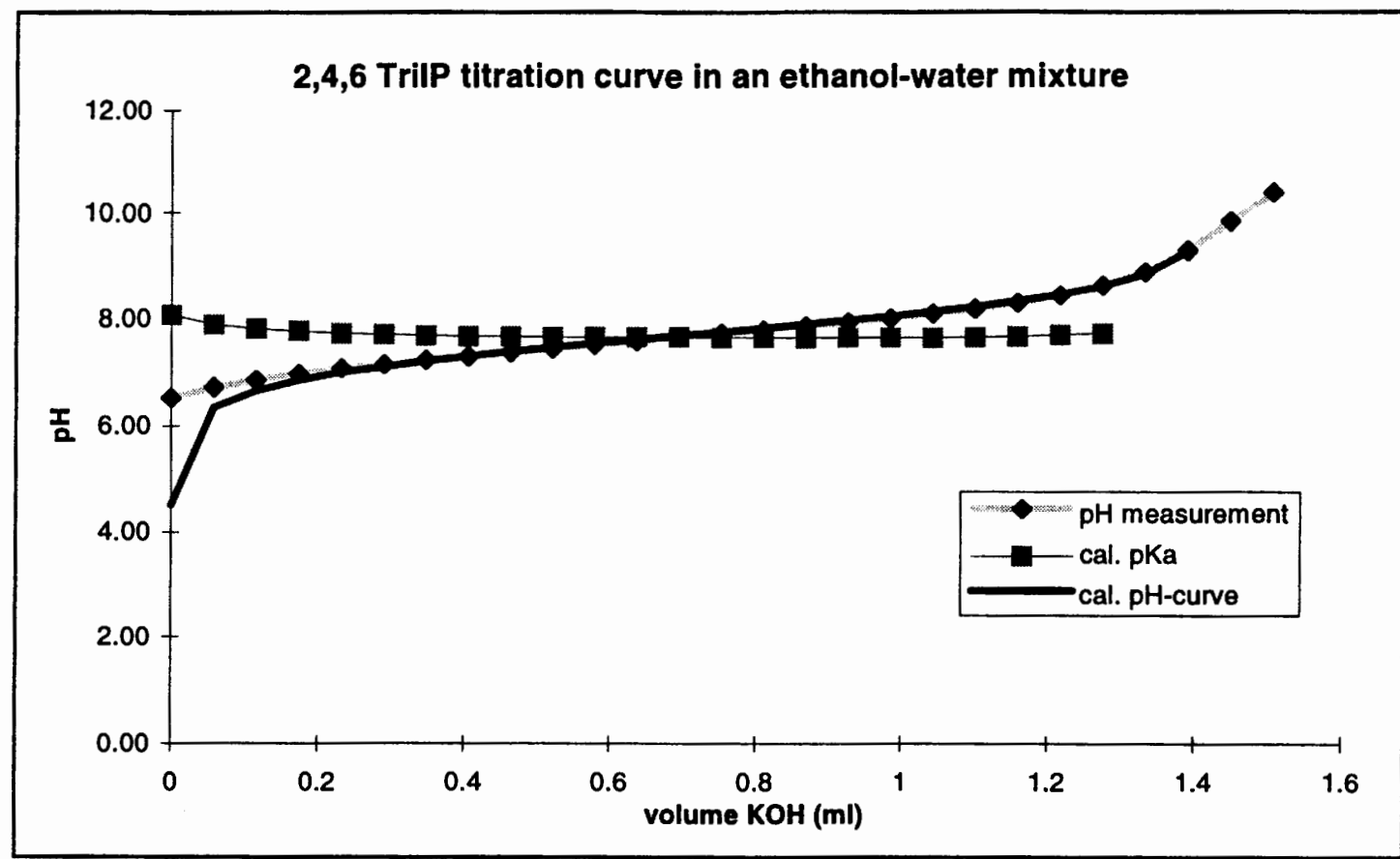

Figure 14a: Titration curve of 2,4,6 TrilP in an ethanol-water solution

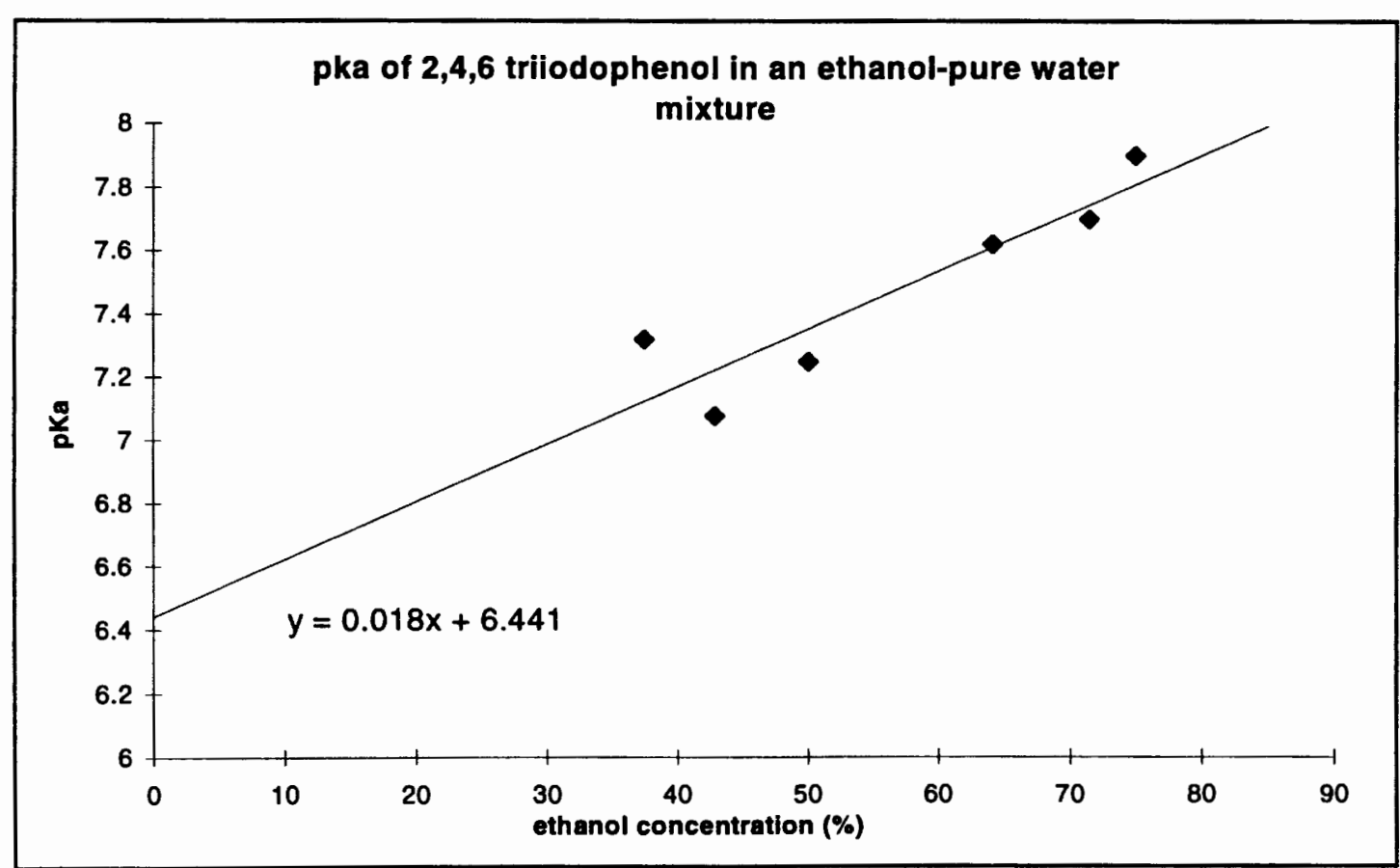

Figure 14b: Extrapolation of the data of 2,4,6 TriIP in an ethanol-pure water solution to 0\% ethanol 


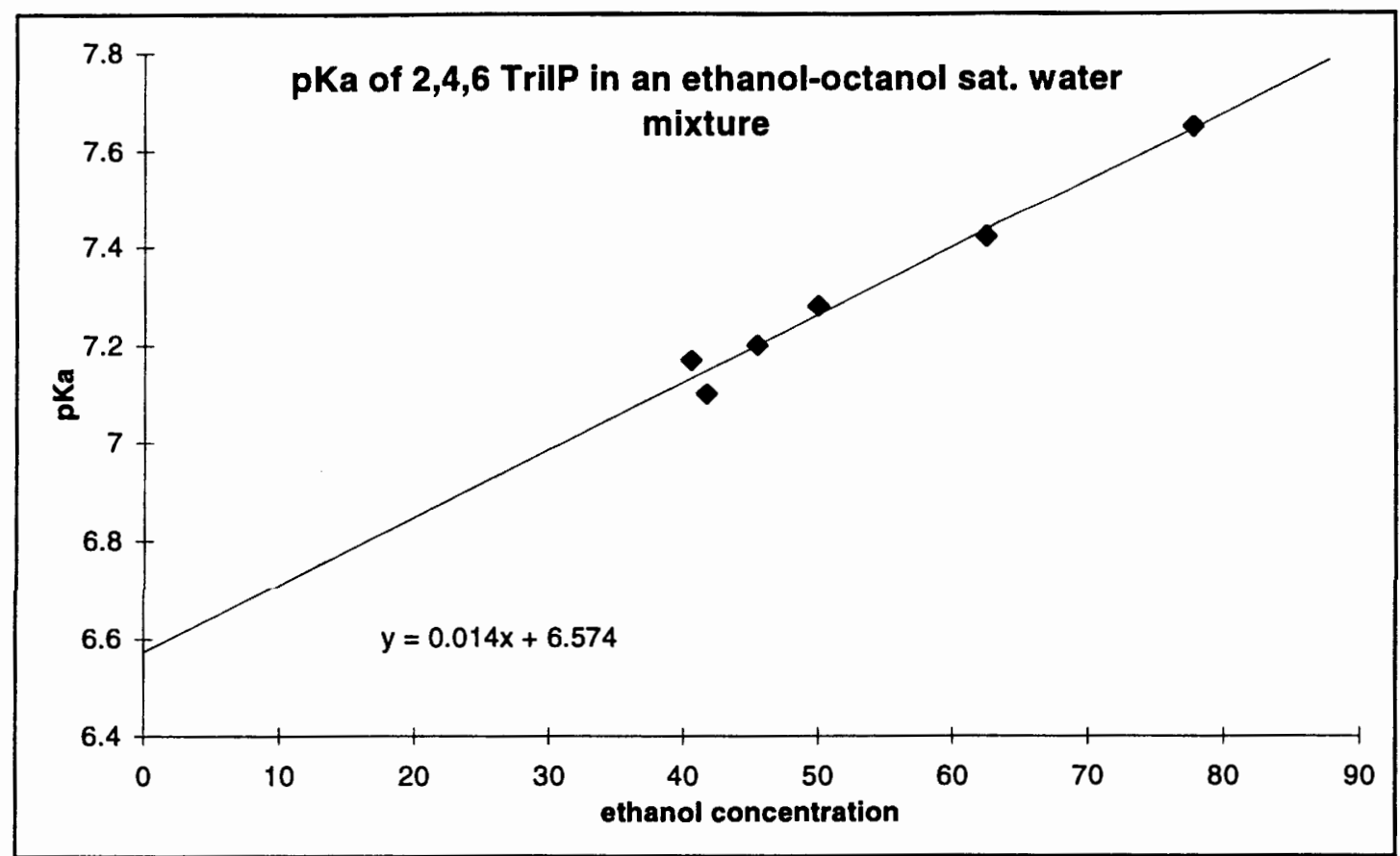

Figure 15: Extrapolation of the data of 2,4,6 TrilP in an ethanol-octanol sat. water solution to $0 \%$ ethanol 


\section{Extinction Coefficients and Absorption Spectra}

The determination of the extinction coefficient of each compound is essential for the concentration measurements.

The UV-VIS absorption spectra of the ionized species of TriFP, TriBP and TriIP are shown in Figure 16, 18 and 20. The two absorbance peaks are significant features of the spectra. The second, smaller peak on the right at higher wavelength was used in the partition experiment. This selection was made because the first peak is located in wavelength range, in which the light scattering of octanol micelles affects the absorbance, and because its position is near the lower wavelength limit of the UV spectrophotometer. The disadvantage of using the second peak is that higher concentrations are required which is a limiting factor especially for less soluble compounds.

The extinction coefficient for each compound was measured at least twelve times using different sample concentrations in saturated buffer. Experimental data are listed in Table 4, 5 and 6. Figure 17, 19 and 21 show the linear relationship, expected for the Lambert-Beer's law, between the absorbance per unit path length of the solution and the sample concentration.

Figure 17, 19 and 21 also contain the regression lines through the origins. The slopes of this lines yield the extinction coefficients. The results are summarized in Table 2. 
Table 2: Extinction coefficient results

\begin{tabular}{l|ll}
\hline Molecule & $\begin{array}{l}\text { Extinction } \\
\text { coefficient } \\
{\left[\text { cm }^{-1} \mathbf{M o I}^{\mathbf{I}}\right]}\end{array}$ & $\begin{array}{l}\text { Wavelength } \\
{[\text { [nm }]}\end{array}$ \\
\hline $2,4,6$ TriFP & $2103 \pm 145$ & 282.0 \\
$2,4,6 \mathrm{TriBP}$ & $4783 \pm 172$ & 315.0 \\
2,4,6 TriIP & $5866 \pm 146$ & 317.5 \\
\hline
\end{tabular}

\section{Error Analysis of the Extinction Coefficient.}

Since each term in Lambert-Beer's law is experimentally measurable, the experimental error is determined by contributions of all of these factors. The largest source of error is probably in the sample concentration prepared in saturated buffer. Each adjustment of the solution increases the error. The instrumental absorbance error increases especially below and above the absorbance limits $(0.1-2)$. The wavelength of the absorbance peak of TriBP (at $315 \mathrm{~nm}$ ) coincides with the wavelength at which the light source of the spectrophotometer is switched from visible to UV light and thus increases the uncertainty of the extinction coefficient of TriBP. The cuvette path length is expected to introduce the least uncertainty to the results.

The total experimental error for each data point can be expressed by

$$
(\Delta \varepsilon)^{2}=(\Delta c)^{2}\left(\frac{l}{A}\right)^{2}+(\Delta A)^{2}\left(-\frac{c l}{A^{2}}\right)^{2}+(\Delta l)^{2}\left(\frac{c}{A}\right)^{2}
$$

where $\Delta \mathrm{A}$ and $\Delta \mathrm{l}$ are the absolute values corresponding to the uncertainty in absorbance and path length, respectively. $\Delta c$ originates from the preparation of the solution and therefore consist of error in volume and mass. 


$$
(\Delta c)^{2}=(\Delta m)^{2}\left(\frac{1}{V M}\right)^{2}+(\Delta V)^{2}\left(-\frac{m}{V^{2} M}\right)^{2}
$$

The average value of the extinction coefficient calculated from each data point was different from the result that was obtained by the slope of the regression line through the origin. The average are given in Table 3. The difference is about 1-3\%. However, since the absorbance of a null solution must equal zero, the best results were obtained from the slope of a regression line passing through the origin.

Table 3: Extinction coefficient results calculated by averaging

\begin{tabular}{l|l}
\hline Molecule & $\begin{array}{l}\text { Extinction coefficient } \\
{\left[\mathrm{cm}^{-1} \mathrm{Mol}^{-1}\right]}\end{array}$ \\
\hline $2,4,6$ TriFP & $2188 \pm 120$ \\
$2,4,6 \mathrm{TriBP}$ & $4866 \pm 135$ \\
$2,4,6 \mathrm{TriIP}$ & $5797 \pm 133$ \\
\hline
\end{tabular}




\section{2,4,6 Trifluorophenol}

\begin{tabular}{|c|c|c|c|c|c|}
\hline solution & $\begin{array}{c}\text { sample } \\
\text { concentration }\end{array}$ & $\begin{array}{c}\text { path length } \\
{[\mathrm{cm}]}\end{array}$ & absorbance & $\begin{array}{l}\text { extinction } \\
\text { coefficient } \\
{\left[\mathrm{L} /\left(\mathrm{mol}{ }^{*} \mathrm{~cm}\right)\right]}\end{array}$ & $\Delta \varepsilon$ \\
\hline sol1 & 0.00029 & 1.00 & 0.61 & 2136.34 & 23.36 \\
\hline sol1 & 0.00037 & 1.00 & 0.75 & 2056.89 & 32.14 \\
\hline sol1 & 0.00036 & 1.00 & 0.73 & 2095.77 & 30.61 \\
\hline sol1 & 0.00019 & 1.00 & 0.42 & 2229.45 & 14.57 \\
\hline sol1 & 0.00023 & 1.00 & 0.48 & 2172.98 & 17.09 \\
\hline sol2 & 0.00036 & 1.00 & 0.74 & 2085.06 & 55.79 \\
\hline sol2 & 0.00032 & 1.00 & 0.64 & 2091.63 & 45.11 \\
\hline sol2 & 0.00012 & 1.00 & 0.28 & 2365.05 & 16.10 \\
\hline sol2 & 0.00007 & 1.00 & 0.15 & 2139.81 & 9.63 \\
\hline sol2 & 0.00005 & 1.00 & 0.10 & 2090.54 & 7.48 \\
\hline sol3 & 0.00016 & 1.00 & 0.37 & 2370.52 & 12.73 \\
\hline sol3 & 0.00019 & 1.00 & 0.44 & 2376.95 & 15.60 \\
\hline sol3 & 0.00026 & 1.00 & 0.59 & 2360.89 & 22.11 \\
\hline sol3 & 0.00032 & 1.00 & 0.73 & 2344.83 & 29.87 \\
\hline sol3 & 0.00048 & 1.00 & 1.08 & 2307.35 & 55.19 \\
\hline sol4 & 0.00082 & 1.00 & 1.66 & 2015.00 & 43.67 \\
\hline sol4 & 0.00027 & 1.00 & 0.59 & 2148.52 & 7.98 \\
\hline sol4 & 0.00044 & 1.00 & 0.93 & 2121.21 & 15.46 \\
\hline sol4 & 0.00033 & 1.00 & 0.71 & 2145.48 & 10.16 \\
\hline sol4 & 0.00055 & 1.00 & 1.16 & 2108.46 & 22.18 \\
\hline
\end{tabular}

Stocksolutions:

$\begin{array}{lrlll}\text { sol1 : } & 0.0036 \mathrm{~g} & \text { TriFP in } & 0.05 \text { I sat. buffer } \Rightarrow & 0.00049 \mathrm{Mol} / 1 \\ \text { sol2 : } & 0.0027 \mathrm{~g} & \text { TriFP in } & 0.05 \text { I sat. buffer } \Rightarrow & 0.00036 \mathrm{Mol} / 1 \\ \text { sol3 : } & 0.00355 \mathrm{~g} & \text { TriFP in } & 0.05 \text { I sat. buffer } \Rightarrow & 0.00048 \mathrm{Mol} / / \\ \text { sol4: } & 0.0061 \mathrm{~g} \text { TriFP in } & 0.05 \text { I sat. buffer } \Rightarrow & 0.00082 \mathrm{Mo} / /\end{array}$

Table 4: Experimental data for the extinction coefficient of $2,4,6$ trifluorophenol (at $\lambda=282 \mathrm{~nm}$ ). 


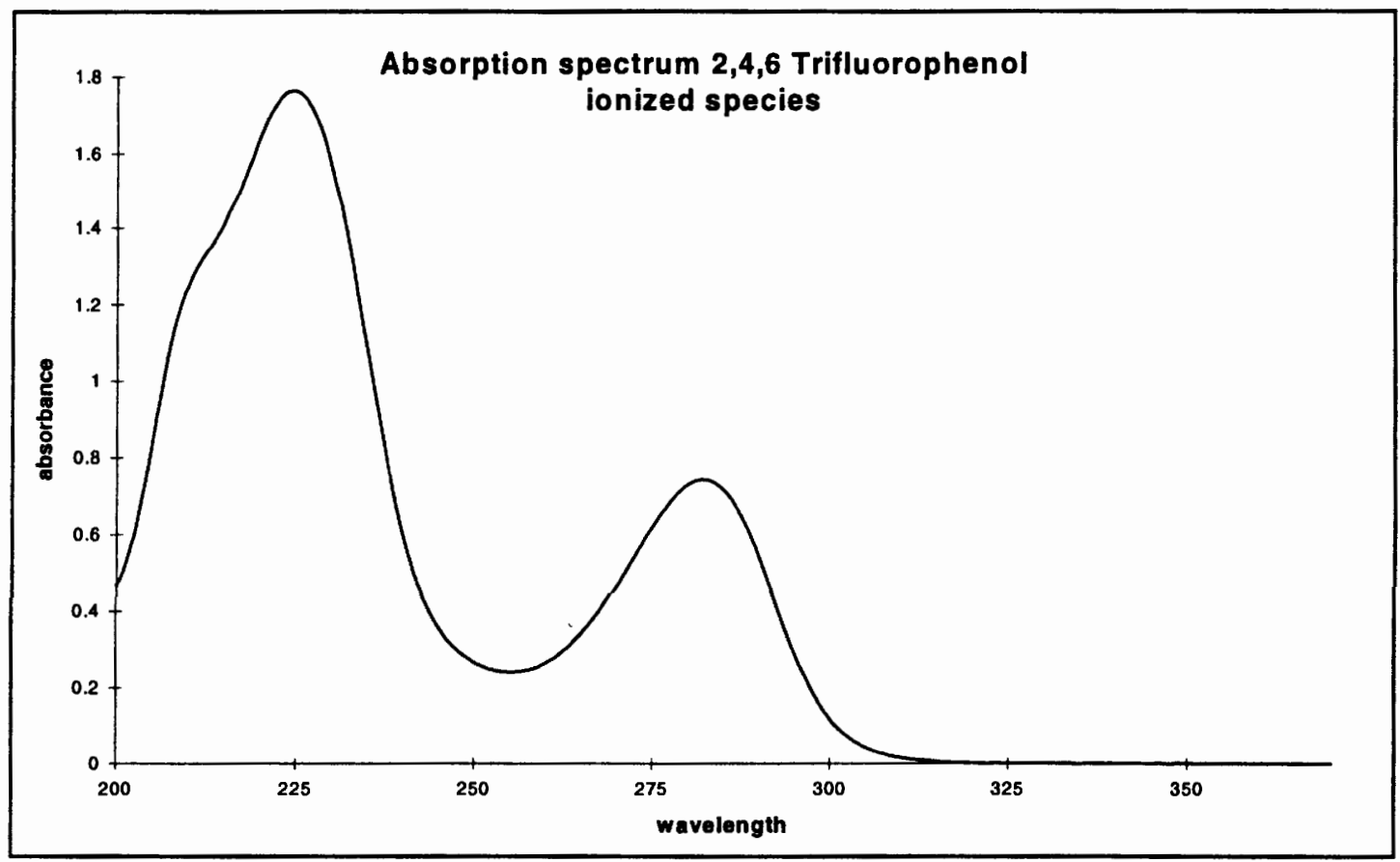

Figure 16: Absorption spectrum of ionized 2,4,6 trifluorophenol in octanol saturated buffer.

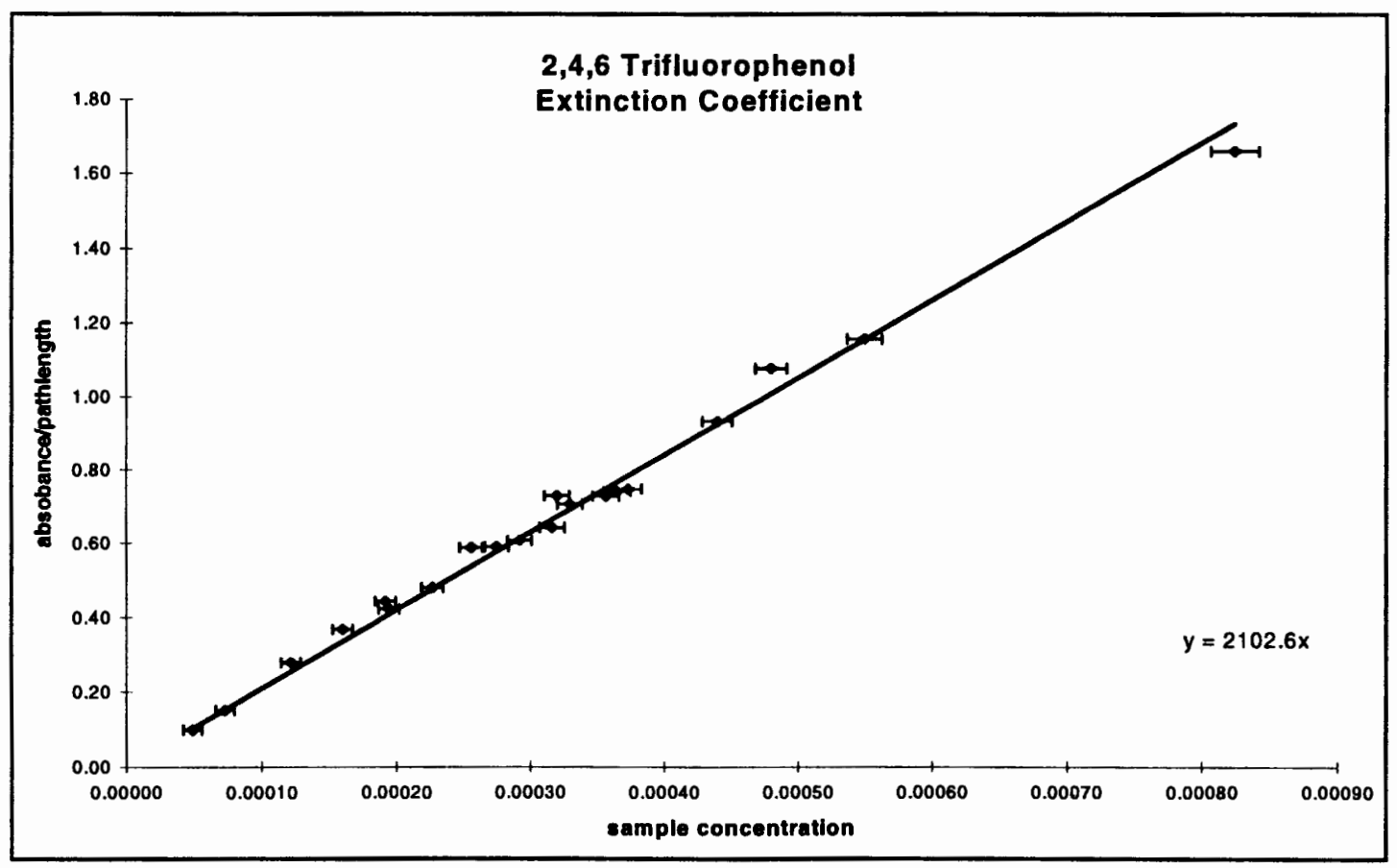

Figure 17: Absorbance versus concentration of ionized TriFP at $\lambda=282 \mathrm{~nm}$. 


\section{2,4,6 Tribromophenol}

\begin{tabular}{lllllll}
\hline & $\begin{array}{c}\text { sample } \\
\text { solution }\end{array}$ & \multicolumn{3}{c}{$\begin{array}{c}\text { extinction } \\
\text { concentration }\end{array}$} & path length absorbance & abs.Jpathl. \\
coefficient & $\Delta \varepsilon$ \\
\hline sol1 & 0.00009 & 1.00 & 0.46 & 0.46 & 5042.16 & 8.97 \\
sol1 & 0.00027 & 1.00 & 1.36 & 1.36 & 5036.73 & 41.15 \\
sol1 & 0.00030 & 1.00 & 1.51 & 1.51 & 5001.97 & 49.45 \\
sol1 & 0.00015 & 1.00 & 0.76 & 0.76 & 5025.20 & 16.27 \\
sol1 & 0.00018 & 1.00 & 0.92 & 0.92 & 5086.77 & 21.36 \\
sol2 & 0.00051 & 0.11 & 0.24 & 2.22 & 4843.20 & 104.35 \\
sol2 & 0.00034 & 1.00 & 1.59 & 1.59 & 4731.06 & 45.33 \\
sol2 & 0.00031 & 1.00 & 1.43 & 1.43 & 4717.49 & 37.39 \\
sol2 & 0.00017 & 1.00 & 0.79 & 0.79 & 4716.17 & 14.32 \\
sol2 & 0.00010 & 1.00 & 0.48 & 0.48 & 4760.21 & 7.78 \\
sol3 & 0.00017 & 1.00 & 0.80 & 0.80 & 4866.40 & 14.92 \\
sol3 & 0.00010 & 1.00 & 0.48 & 0.48 & 4909.09 & 8.08 \\
sol3 & 0.00027 & 1.00 & 1.30 & 1.30 & 4911.57 & 31.97 \\
& & & & & & \\
\hline
\end{tabular}

Stocksolutions:

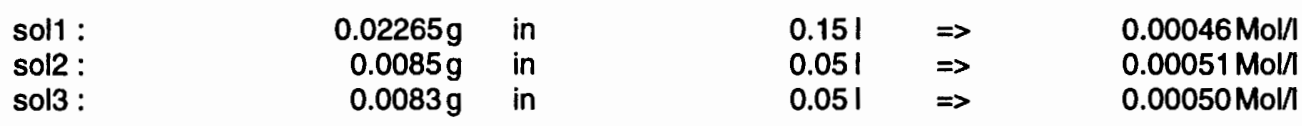

Table 5: Experimental data for the extinction coefficient of 2,4,6 tribromophenol (at $\lambda=315 \mathrm{~nm}$ ). 


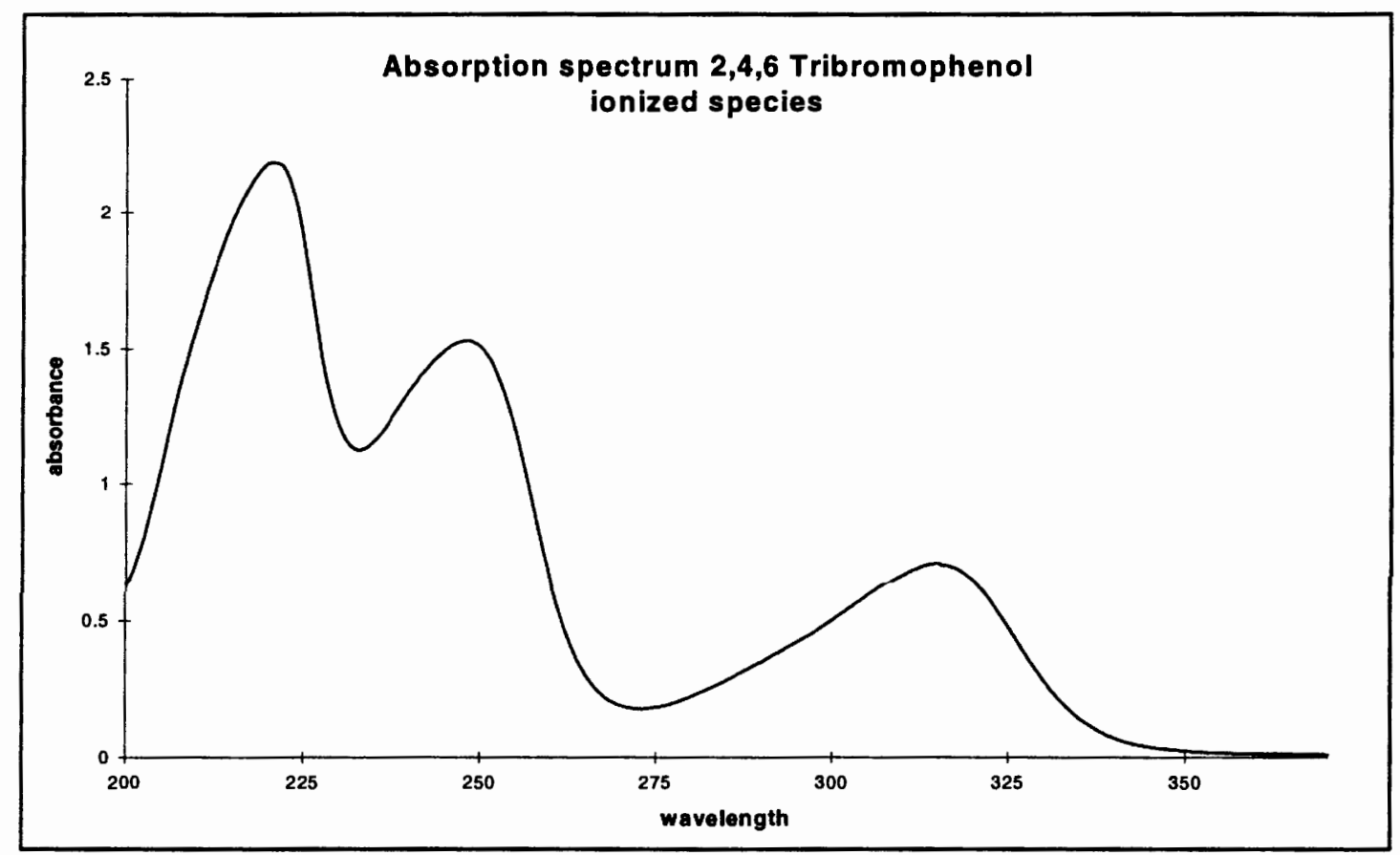

Figure 18: Absorption spectrum of ionized 2,4,6 tribromophenol in octanol saturated buffer.

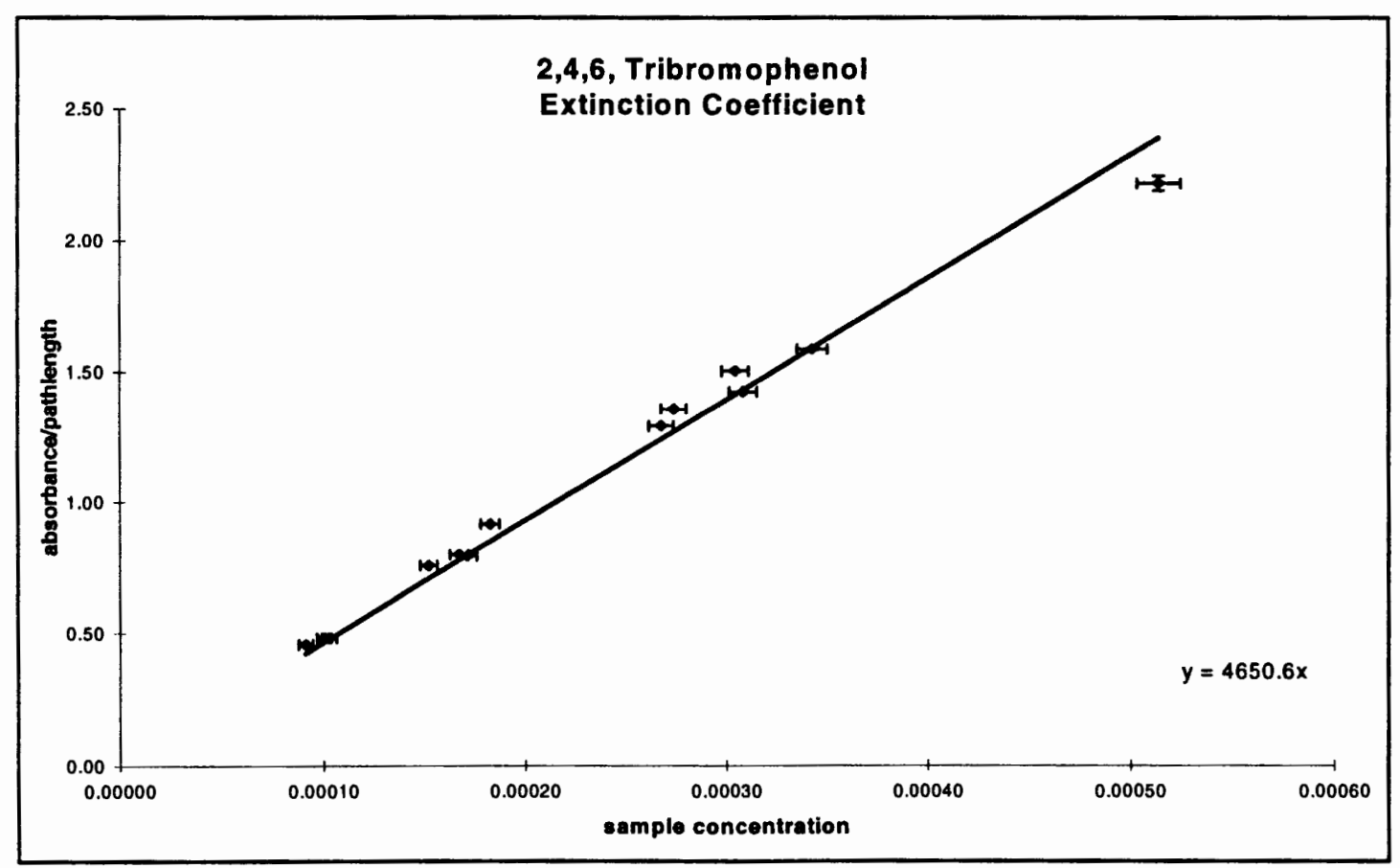

Figure 19: Absorbance versus concentration of ionized TriBP at $\lambda=315 \mathrm{~nm}$. 


\section{2,4,6 Triiodophenol}

\begin{tabular}{|c|c|c|c|c|c|c|}
\hline solution & $\begin{array}{c}\text { sample } \\
\text { concentration }\end{array}$ & path length & absorbance & abs.Jpathl. & $\begin{array}{l}\text { extinction } \\
\text { coefficient }\end{array}$ & $\Delta \varepsilon$ \\
\hline sol1 & 0.00010 & 1.00 & 0.57 & 0.57 & 5820.04 & 13.44 \\
\hline sol1 & 0.00015 & 1.00 & 0.85 & 0.85 & 5779.20 & 23.56 \\
\hline sol1 & 0.00020 & 1.00 & 1.12 & 1.12 & 5731.21 & 37.59 \\
\hline sol1 & 0.00024 & 1.00 & 1.37 & 1.37 & 5611.74 & 54.75 \\
\hline sol1 & 0.00037 & 0.11 & 0.22 & 2.01 & 6017.45 & 133.75 \\
\hline sol2 & 0.00010 & 1.00 & 0.56 & 0.56 & 5851.77 & 13.76 \\
\hline sol2 & 0.00014 & 1.00 & 0.83 & 0.83 & 5802.66 & 23.92 \\
\hline sol2 & 0.00019 & 1.00 & 1.09 & 1.09 & 5751.79 & 38.00 \\
\hline sol2 & 0.00024 & 1.00 & 1.35 & 1.35 & 5674.96 & 55.65 \\
\hline sol2 & 0.00036 & 0.11 & 0.22 & 1.95 & 6034.20 & 134.88 \\
\hline sol3 & 0.00009 & 1.00 & 0.52 & 0.52 & 5824.83 & 8.57 \\
\hline sol3 & 0.00015 & 1.00 & 0.86 & 0.86 & 5775.64 & 16.48 \\
\hline sol3 & 0.00021 & 1.00 & 1.18 & 1.18 & 5668.31 & 28.17 \\
\hline sol3 & 0.00027 & 1.00 & 1.51 & 1.51 & 5627.31 & 43.92 \\
\hline sol3 & 0.00045 & 0.11 & 0.27 & 2.44 & 5992.53 & 129.01 \\
\hline
\end{tabular}

Stocksolutions:

\begin{tabular}{|c|c|c|c|c|c|}
\hline $\begin{array}{l}\text { sol1 } \\
\text { sol2 } \\
\text { sol3 }\end{array}$ & $\begin{array}{l}0.01005 \mathrm{~g} \\
0.00975 \mathrm{~g} \\
0.01055 \mathrm{~g}\end{array}$ & $\begin{array}{l}\text { in } \\
\text { in } \\
\text { in }\end{array}$ & $\begin{array}{r}0.0581 \\
0.058 \text { । } \\
0.051\end{array}$ & $\begin{array}{l}\Rightarrow \\
\Rightarrow \\
\Rightarrow\end{array}$ & $\begin{array}{l}0.00037 \mathrm{Mol} \\
0.00036 \mathrm{Mol}\end{array}$ \\
\hline & $0.01055 \mathrm{~g}$ & in & 0.051 & $\Rightarrow$ & $0.00045 \mathrm{Moll}$ \\
\hline
\end{tabular}

Table 6: Experimental data for the extinction coefficient of 2,4,6 triiodophenol (at $\lambda=317.5 \mathrm{~nm}$ ). 


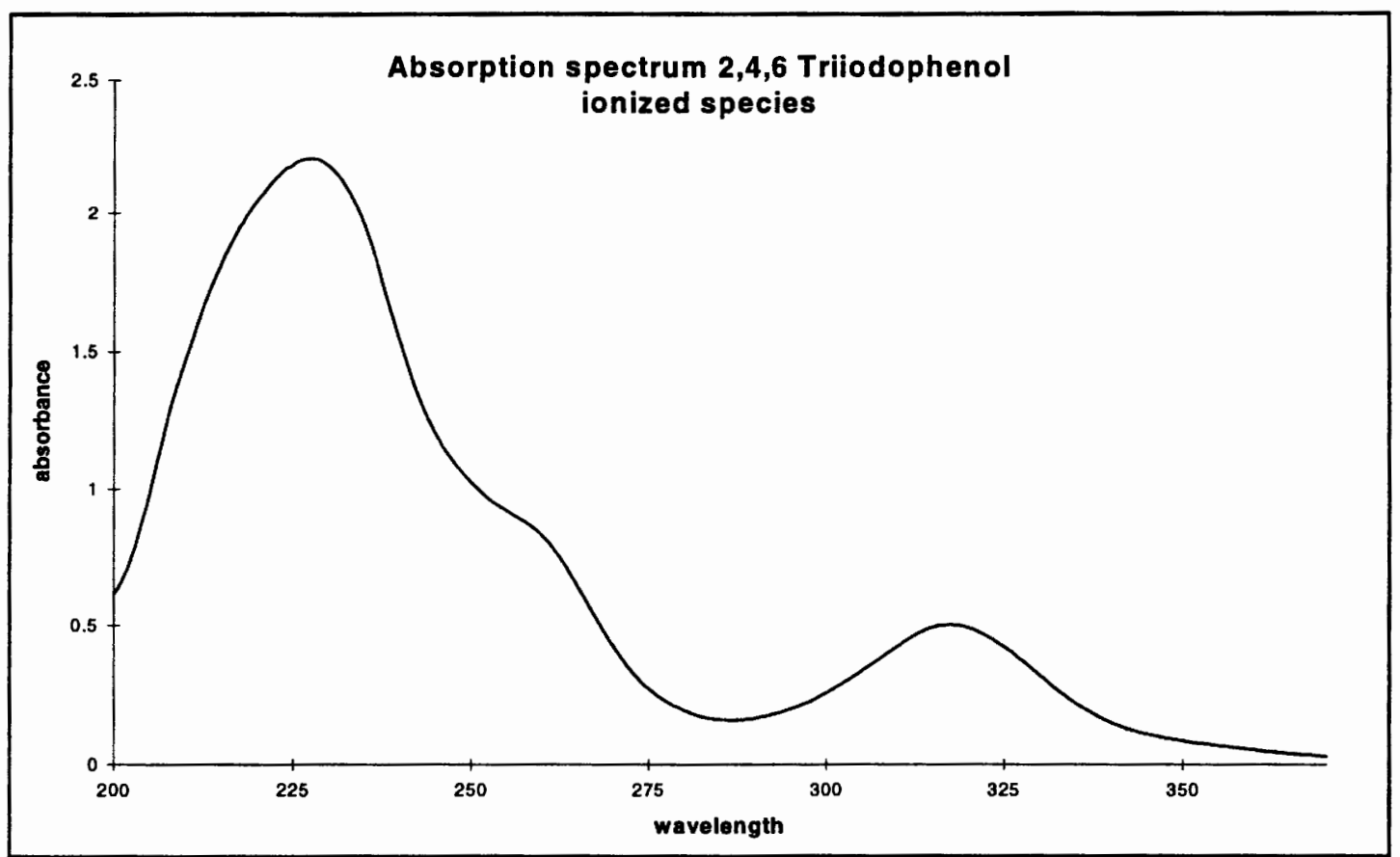

Figure 20: Absorption spectrum of ionized 2,4,6 triiodophenol in octanol saturated buffer.

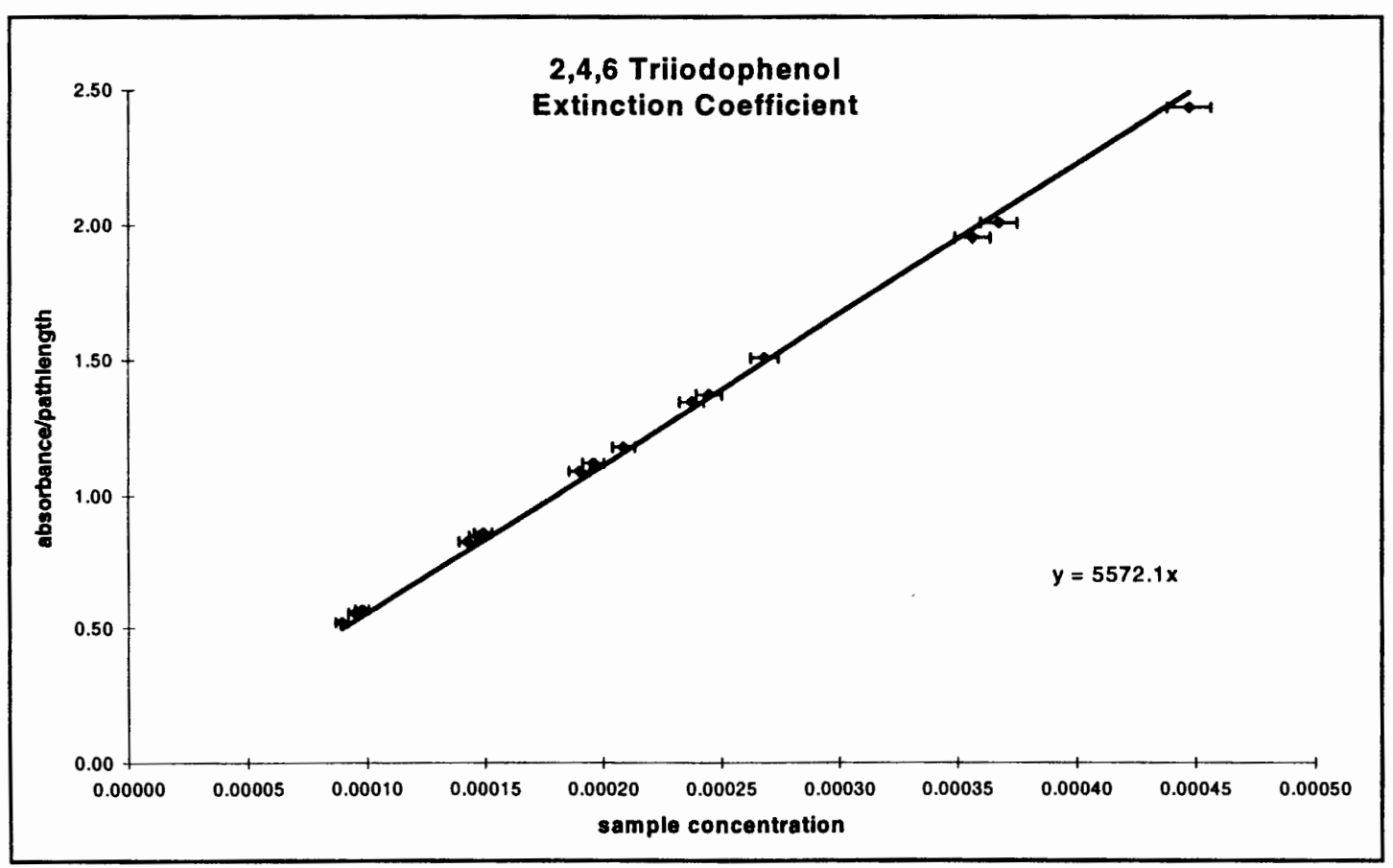

Figure 21: Absorbance versus concentration of ionized TriFP at $\lambda=317.5 \mathbf{n m}$. 


\section{pH dependent Octanol-Water Distribution Coefficient}

The halophenol distribution between octanol and water was measured at different $\mathrm{pH}$ values of the aqueous phase. The experimental distribution data for TriFP, TriBP and TriIP are given in table 8,9 and 10, respectively. Figure 22,23,24 and 25 show plots of the final $\mathrm{pH}$ of each data point of a compound versus the decadic logarithm of the sample distribution between octanol and water. The plots illustrate a notable change in the distribution of the sample depending on the $\mathrm{pH}$. The range between the higher distribution-values level in the low $\mathrm{pH}$ range to the lower level in the high $\mathrm{pH}$ range is of several orders of magnitude.

These figures also include the fit of the data to the distribution curve, which was derived in chapter 2.3.

$$
D(p H)=\frac{g_{H A}+g_{A} 10^{p H-p K_{a}}}{1+10^{p H-p K_{a}}}
$$

The distribution parameters $\mathrm{g}_{\mathrm{HA}}$ and $\mathrm{g}_{\mathrm{A}}$ from this fit are the partition coefficients for the neutral and the ionized species, respectively.

While the data of TriBP and TriFP (even with the change in the method) fit nicely to the theoretical distribution curve, Figure 24 shows, that it is not possible to fit the distribution curve to the data of TriIP. The $\mathrm{g}_{\mathrm{HA}}$ and $\mathrm{g}_{\mathrm{A}}$ - values of TrilP were obtained from the average of the value in the low and high $\mathrm{pH}$ - range, respectively.

Table 7: Results of the partitioning experiments. 


\begin{tabular}{l|llllll}
\hline molecule & \multicolumn{1}{|l}{$g_{H A}$} & $\log g_{H A}$ & $g_{A}$ & $\log _{A}$ & $p K_{a} \begin{array}{l}\text { literature } \\
\text { values of } \\
\log g_{H A}\end{array}$ \\
\hline $2,4,6$ TriFP & $92 \pm 5.570$ & $1.96 \pm$ & $0.042 \pm$ & $-1.38 \pm$ & 7.12 & n.a. \\
& & 0.06 & 0.006 & 0.14 & & \\
$2,4,6$ TriBP & $12893 \pm$ & $4.11 \pm$ & $1.19 \pm 0.1$ & $0.08 \pm 0.08$ & 5.9 & n.a. \\
& 569 & 0.04 & & & & \\
$2,4,6$ TriIP & $4427 \pm 225$ & $3.65 \pm$ & $14.3 \pm 2.3$ & $1.16 \pm$ & 6.6 & $3.96,4.13$, \\
& & 0.05 & & 0.16 & & 4.23 \\
& & & & & (Hansch 1995) \\
\hline
\end{tabular}

\section{Error Analysis of the Partitioning Experiment}

The uncertainty in $\mathrm{g}_{\mathrm{HA}}$ and $\mathrm{g}_{\mathrm{A}}$ for TriFP and TriBP were standard deviations obtained from the Axum non-linear fit program. Errors in $g_{H A}$ and $g_{A}$ of TriIP are the standard deviation of the average.

The greatest contribution to the experimental error is, again, the sample concentration in the water phase preparation. The error bars in the Figure 22, 23 and 24 were calculated using the error propagation formula.

$$
(\Delta D)^{2}=\left(\Delta c_{o c}^{i}\right)^{2}\left(\frac{1}{c_{a q}^{f}}\right)^{2}+\left(\Delta c_{a q}^{f}\right)^{2}\left(-\frac{c_{o c}^{i}}{\left(c_{a q}^{f}\right)^{2}}\right)^{2}+\left(\Delta V_{a q}\right)^{2}\left(-\frac{1}{V_{o c}}\right)^{2}+\left(\Delta V_{o c}\right)^{2}\left(\frac{V_{a q}}{\left(V_{o c}\right)^{2}}\right)^{2}
$$


The error of initial concentration in octanol becomes more significant, if there is a low concentration of the sample in the final aqueous phase. 
Table 8: Experimental distribution data of 2,4,6 trifluorophenol.

* indicates, that the sample is initially in the buffer phase.

\begin{tabular}{|c|c|c|c|c|c|c|c|c|c|c|c|c|}
\hline $\begin{array}{c}\text { stock } \\
\text { solution }\end{array}$ & $\begin{array}{c}\text { volume } \\
\text { of } \\
\text { buffer } \\
\text { (ml) }\end{array}$ & $\begin{array}{c}\text { volume } \\
\text { of } \mathrm{KOH} \\
(\mathrm{ml})\end{array}$ & $\begin{array}{c}\text { initial } \\
\mathbf{p H} \\
\text { of } \\
\text { sample }\end{array}$ & $\begin{array}{c}\text { final pH } \\
\text { of } \\
\text { sample }\end{array}$ & $\begin{array}{c}\mathrm{pH} \text { at } \\
\text { measure- } \\
\text { ment } \\
\mathrm{pH}>10\end{array}$ & $\begin{array}{c}\text { absorbance } \\
\text { at } 282 \mathrm{~nm}\end{array}$ & $\begin{array}{l}\text { path } \\
\text { length } \\
(\mathrm{cm}) \\
\end{array}$ & $\begin{array}{c}\text { [TCP] in } \\
\text { Buffer } \\
\text { (M) }\end{array}$ & $\begin{array}{c}{[\text { TCP] in }} \\
\text { octanol } \\
(M)\end{array}$ & $\begin{array}{c}\text { distribution } \\
\text { coefficient }\end{array}$ & $\log (D)$ & $\begin{array}{l}\text { graph } \\
\text { ref. }\end{array}$ \\
\hline sol1 & 20 & 2.5 & 2.99 & 2.99 & 10.87 & 0.324 & 5 & 0.000035 & 0.003149 & \begin{tabular}{|c|}
90.84 \\
\end{tabular} & 1.96 & ref. \\
\hline sol1 & 20 & 2.2 & 3.64 & 3.67 & 10.97 & 0.325 & 5 & 0.000034 & 0.003151 & 91.84 & 1.96 & tfp 3.2 \\
\hline sol1 & 15 & 1.2 & 4.02 & 4.03 & 10.6 & 0.331 & 5 & 0.000034 & 0.003152 & 92.72 & 1.97 & tfp 3.1 \\
\hline sol1 & 20 & 1.7 & 4.47 & 4.51 & 11.09 & 0.3289 & 5 & 0.000034 & 0.003153 & 92.89 & 1.97 & tfp 2.4 \\
\hline sol1 & 20 & 1.5 & 5.09 & 5.18 & 10.73 & 0.337 & 5 & 0.000034 & 0.003150 & 91.43 & 1.96 & tfp 3.4 \\
\hline sol1 & 20 & 1.5 & 5.46 & 5.52 & 10.51 & 0.3429 & 5 & 0.000035 & 0.003147 & 89.77 & 1.95 & tfp 2.3 \\
\hline sol1 & 20 & 1.1 & 6.48 & 6.54 & 10.65 & 0.0884 & 1 & 0.000044 & 0.003101 & 69.92 & 1.84 & tfp 2.2 \\
\hline sol1 & 20 & 0.7 & 7.4 & 7.36 & 10.76 & 0.1756 & 1 & 0.000086 & 0.002890 & 33.44 & 1.52 & ttp 2.1 \\
\hline sol1 & 20 & 0.3 & 8.25 & 7.89 & 10.08 & 0.381 & 1 & 0.000184 & 0.002403 & 13.07 & 1.12 & tfp 1.1 \\
\hline sol1 & 20 & 0.2 & 9.68 & 8.54 & 10 & 0.91 & 1 & 0.000437 & 0.001137 & 2.60 & 0.42 & $\operatorname{tfp} 1.2$ \\
\hline sol1 & 20 & 0.25 & 9.66 & 8.56 & 10.44 & 0.901 & 1 & 0.000434 & 0.001153 & 2.66 & 0.42 & tfp 4.1 \\
\hline sol5* & 20 & 3.71 & 9.89 & 8.6 & 10.88 & 1.218 & 1 & 0.000687 & 0.001424 & 2.07 & 0.32 & $w>02 s 1$ \\
\hline sol1 & 20 & 0.2 & 10.2 & 9 & 10.2 & 1.224 & 1 & 0.000588 & 0.000383 & 0.65 & -0.19 & tfp 4.2 \\
\hline sol6* & 20 & 3.18 & 10.31 & 9.3 & 10.67 & 1.7571 & 1 & 0.000968 & 0.000340 & 0.35 & -0.45 & $w>02 s 2$ \\
\hline sol7* & 20 & 2.65 & 10.92 & 9.99 & 10.75 & 0.2392 & 0.1 & 0.001288 & 0.000090 & 0.07 & -1.15 & $w>02 s 3$ \\
\hline sol3* & 20 & 0 & 11.3 & 10.74 & 10.74 & 1.805 & 1 & 0.000858 & 0.000036 & 0.04 & -1.38 & $w>0$ s3 \\
\hline sol8* & 20 & 0 & 11.56 & 11.28 & 11.28 & 1.299 & 1 & 0.000618 & 0.000026 & 0.04 & -1.37 & $w>02 s 4$ \\
\hline sol4* & 20 & 0 & 11.94 & 11.81 & 11.81 & 1.771 & 1 & 0.000842 & 0.000038 & 0.05 & -1.35 & $w>0 \leq 4$ \\
\hline
\end{tabular}




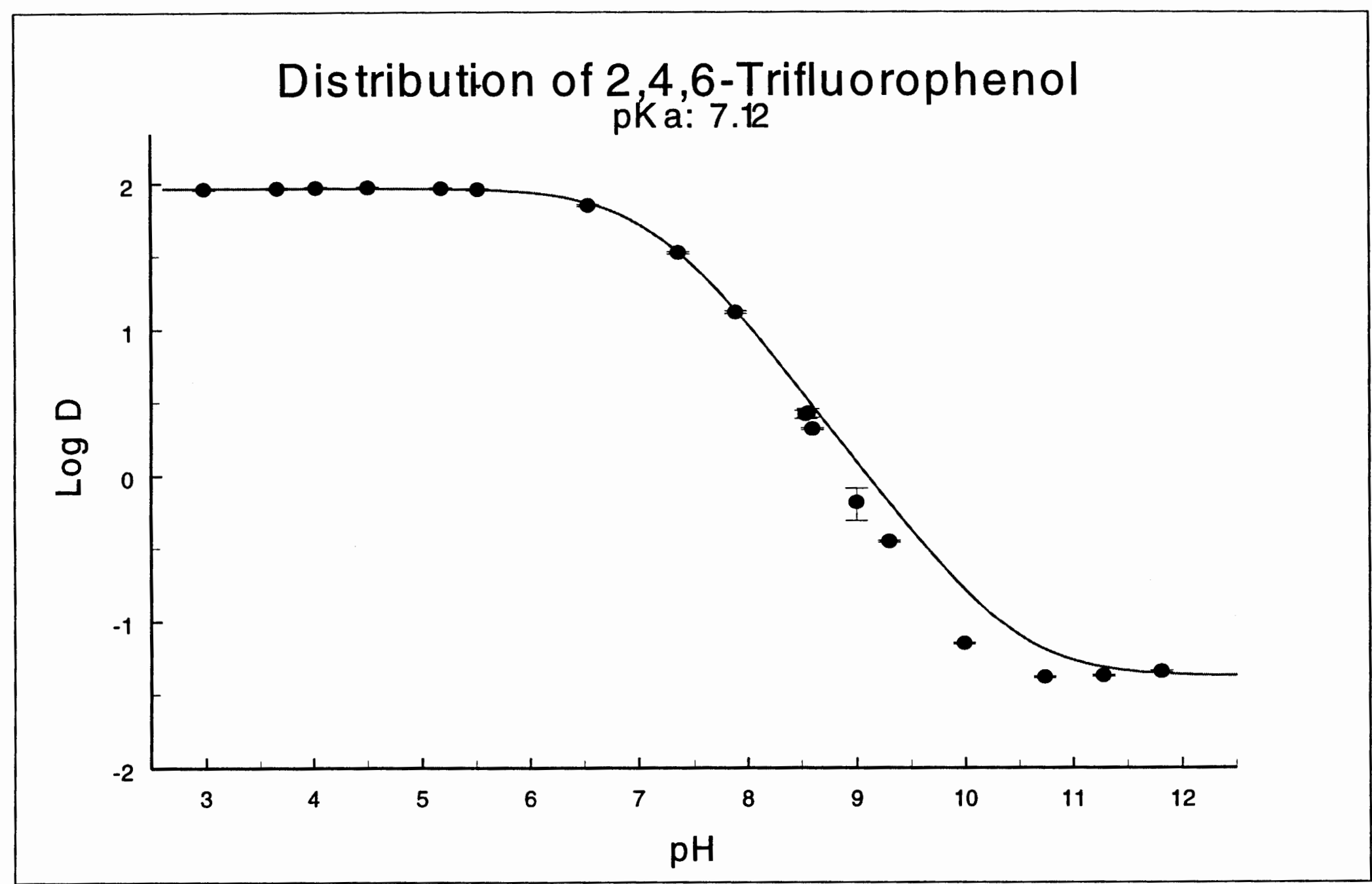

Figure 22: Distribution as a function of the pH for 2,4,6 trifluorophenol. 
Table 9: Experimental distribution data of 2,4,6 tribromophenol.

\begin{tabular}{|c|c|c|c|c|c|c|c|c|c|c|c|c|}
\hline $\begin{array}{c}\text { stock } \\
\text { solution }\end{array}$ & $\begin{array}{c}\text { volume } \\
\text { of } \\
\text { buffer } \\
\text { (ml) }\end{array}$ & $\begin{array}{c}\text { volume } \\
\text { of } \mathrm{KOH} \\
(\mathrm{ml})\end{array}$ & $\begin{array}{c}\text { initial } \\
\mathrm{pH} \\
\text { of } \\
\text { sample }\end{array}$ & $\begin{array}{c}\text { final pH } \\
\text { of } \\
\text { sample }\end{array}$ & $\begin{array}{c}\mathrm{pH} \text { at } \\
\text { measure- } \\
\text { ment } \\
\mathrm{pH}>10\end{array}$ & $\begin{array}{c}\text { absorbance } \\
\text { at } 315 \mathrm{~nm}\end{array}$ & $\begin{array}{l}\text { path } \\
\text { length } \\
(\mathrm{cm})\end{array}$ & $\begin{array}{c}\text { [TCP] in } \\
\text { Buffer } \\
\text { (M) }\end{array}$ & $\begin{array}{c}{[\mathrm{TCP}] \text { in }} \\
\text { octanol } \\
(\mathrm{M})\end{array}$ & $\begin{array}{c}\text { distribution } \\
\text { coefficient }\end{array}$ & $\log (D)$ & $\begin{array}{c}\text { graph } \\
\text { ref. }\end{array}$ \\
\hline 1 & 20 & 2.2 & 3.08 & 3.07 & 10.57 & 0.175 & 5 & 0.000008 & 0.099997 & 12810.11 & 4.11 & $1 / 4$ \\
\hline 1 & 20 & 2 & 3.33 & 3.31 & 10.46 & 0.1564 & 5 & 0.000007 & 0.100002 & 14464.52 & 4.16 & $3 / 4$ \\
\hline 1 & 20 & 1.7 & 4.05 & 4.01 & 10.57 & 0.189 & 5 & 0.000008 & 0.099995 & 12134.25 & 4.08 & $1 / 3$ \\
\hline 1 & 20 & 1.5 & 4.37 & 4.37 & 10.33 & 0.1916 & 5 & 0.000008 & 0.099995 & 12080.91 & 4.08 & $3 / 3$ \\
\hline 1 & 20 & 1.3 & 4.95 & 4.94 & 10.39 & 0.164 & 5 & 0.000007 & 0.100001 & 14247.46 & 4.15 & $1 / 2$ \\
\hline 1 & 20 & 1.05 & 5.47 & 5.48 & 10.05 & 0.0518 & 1 & 0.000011 & 0.099982 & 9126.91 & 3.96 & $3 / 2$ \\
\hline 1 & 20 & 0.7 & 6.02 & 6.02 & 10.09 & 0.118 & 1 & 0.000025 & 0.099914 & 4071.53 & 3.61 & $1 / 1$ \\
\hline 1 & 20 & 0.5 & 6.87 & 6.89 & 10.32 & 0.2955 & 1 & 0.000061 & \begin{tabular}{|l|}
0.099732 \\
\end{tabular} & 1638.74 & 3.21 & $3 / 1$ \\
\hline 1 & 20 & 0.5 & 8.04 & 7.54 & 10.17 & 1.3195 & 1 & 0.000272 & 0.098677 & 363.11 & 2.56 & $2 / 1$ \\
\hline 1 & 20 & 0.3 & 9.22 & 7.78 & 10.18 & 0.2312 & 0.1 & 0.000472 & \begin{tabular}{|l|}
0.097679 \\
\end{tabular} & 207.16 & 2.32 & $2 / 3$ \\
\hline 1 & 20 & 0.4 & 10.09 & 7.97 & 10.19 & 0.3822 & 0.1 & 0.000783 & 0.096120 & 122.71 & 2.09 & $2 / 2$ \\
\hline 2 & 20 & 0.3 & 8.66 & 8.17 & 10.02 & 0.493 & 1 & 0.000101 & 0.006607 & 65.71 & 1.82 & $4 / 1$ \\
\hline 1 & 20 & 0.25 & 11.05 & 8.36 & 10.08 & 0.8847 & 0.1 & 0.001800 & 0.091037 & 50.58 & 1.70 & $2 / 4$ \\
\hline 2 & 20 & 0.25 & 9.87 & 8.92 & 10.21 & 0.1909 & 0.1 & 0.000388 & 0.005168 & 13.31 & 1.12 & $4 / 2$ \\
\hline 2 & 20 & 0.2 & 10.51 & 9.39 & 10.13 & 0.36 & 0.1 & 0.000731 & 0.003457 & 4.73 & 0.67 & $4 / 3$ \\
\hline 2 & 20 & 0 & 11.01 & 10.2 & 10.2 & 0.5021 & 0.1 & 0.001009 & 0.002065 & 2.05 & 0.31 & $5 / 1$ \\
\hline 2 & 20 & 0 & 11.31 & 11.04 & 11.04 & 0.566 & 0.1 & 0.001137 & 0.001423 & 1.25 & 0.10 & $4 / 4$ \\
\hline 2 & 20 & 0 & 11.5 & 11.36 & 11.36 & 0.5456 & 0.1 & 0.001096 & 0.001628 & 1.49 & 0.17 & $5 / 2$ \\
\hline 2 & 20 & 0 & 11.94 & 11.83 & 11.83 & 0.5409 & 0.1 & 0.001087 & 0.001675 & 1.54 & 0.19 & $5 / 3$ \\
\hline 2 & 20 & 0 & 12.21 & 12.21 & 12.21 & 0.521 & 0.1 & 0.001047 & 0.001875 & 1.79 & 0.25 & $5 / 4$ \\
\hline
\end{tabular}




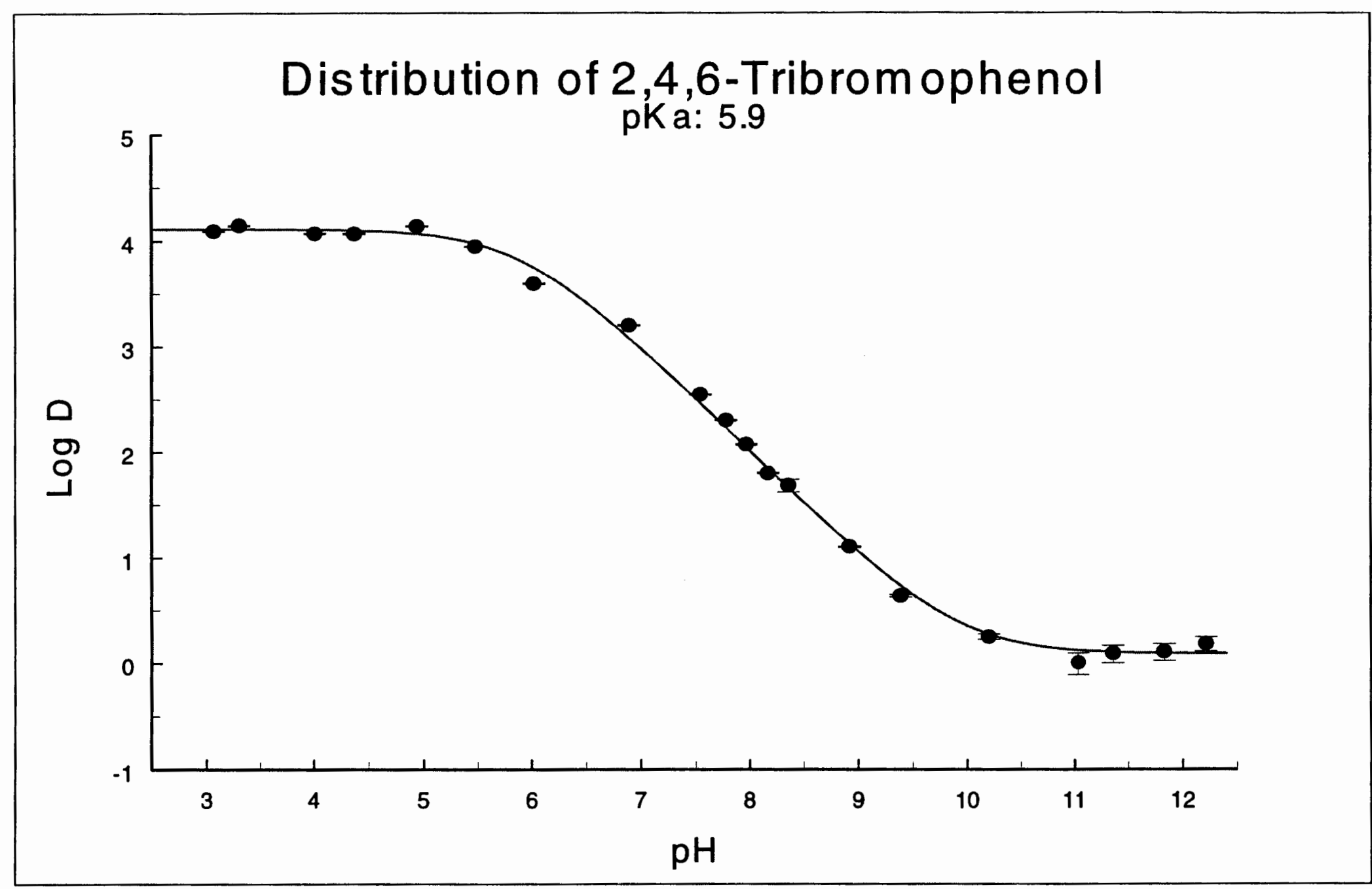

Figure 23: Distribution as a function of the $\mathrm{pH}$ for 2,4,6 tribromophenol. 
Table 10: Experimental distribution data of 2,4,6 trifluorophenol.

\begin{tabular}{|c|c|c|c|c|c|c|c|c|c|c|c|c|}
\hline $\begin{array}{c}\text { stock } \\
\text { solution }\end{array}$ & $\begin{array}{c}\text { volume } \\
\text { of } \\
\text { buffer } \\
\text { (ml) }\end{array}$ & $\begin{array}{c}\text { volume } \\
\text { of } \mathrm{KOH} \\
(\mathrm{ml})\end{array}$ & $\begin{array}{c}\text { initial } \\
\mathrm{pH} \\
\text { of } \\
\text { sample }\end{array}$ & $\begin{array}{c}\text { final pH } \\
\text { of } \\
\text { sample }\end{array}$ & $\begin{array}{c}\mathrm{pH} \text { at } \\
\text { measure- } \\
\text { ment } \\
\mathrm{pH}>10\end{array}$ & $\begin{array}{l}\text { absorbance } \\
\text { at } 317.5 \mathrm{~nm}\end{array}$ & $\begin{array}{l}\text { path } \\
\text { length } \\
\text { (cm) }\end{array}$ & $\begin{array}{c}\text { [TCP] in } \\
\text { Buffer } \\
\text { (M) }\end{array}$ & $\begin{array}{c}\text { [TCP] in } \\
\text { octanol } \\
\text { (M) }\end{array}$ & $\begin{array}{c}\text { distribution } \\
\text { coefficient }\end{array}$ & $\log (D)$ & $\begin{array}{l}\text { graph } \\
\text { ref. }\end{array}$ \\
\hline sol2 & 20 & 3 & 2.6 & 2.76 & 10.54 & 0.243 & 5 & 0.000010 & 0.030330 & 3183.28 & 3.50 & tip 5/2 \\
\hline sol1 & 20 & 2.6 & 3.06 & 3.26 & 10.76 & 0.177 & 5 & 0.000007 & 0.030451 & 4465.41 & 3.65 & tip $5 / 1$ \\
\hline sol3 & 20 & 2.2 & 3.2 & 3.36 & 10.59 & 0.4019 & 5 & 0.000015 & 0.030301 & 1992.19 & 3.30 & wligh2b \\
\hline sol3 & 18 & 2 & 3.2 & 3.37 & 10.62 & 0.243 & 5 & 0.000009 & 0.030331 & 3294.87 & 3.52 & $12 i b$ \\
\hline sol2 & 20 & 2.3 & 3.44 & 3.76 & 10.6 & 0.214 & 5 & 0.000008 & 0.030337 & 3728.98 & 3.57 & tip $5 / 3$ \\
\hline sol3 & 20 & 1.6 & 4.3 & 4.57 & 10.53 & 0.2011 & 5 & 0.000007 & 0.030340 & 4097.28 & 3.61 & $11 \mathrm{ib}$ \\
\hline sol3 & 20 & 1.6 & 4.3 & 4.59 & 10.57 & 0.2113 & 5 & 0.000008 & 0.030338 & 3899.25 & 3.59 & wligh1b \\
\hline sol1 & 20 & 1.9 & 4.49 & 4.74 & 10.81 & 0.146 & 5 & 0.000005 & 0.030458 & 5587.84 & 3.75 & tip $4 / 4$ \\
\hline sol1 & 20 & 1.8 & 5.14 & 5.39 & 10.7 & 0.131 & 5 & 0.000005 & 0.030461 & 6256.83 & 3.80 & tip $4 / 3$ \\
\hline sol2 & 20 & 1.5 & 5.32 & 5.63 & 10.58 & 0.197 & 5 & 0.000007 & 0.030341 & 4202.13 & 3.62 & tip $5 / 4$ \\
\hline sol1 & 20 & 1.2 & 6.2 & 6.4 & 10.61 & 0.211 & 5 & 0.000008 & 0.030447 & 3992.71 & 3.60 & tip 4/1 \\
\hline sol1 & 20 & 0.8 & 6.53 & 6.73 & 10.52 & 0.2276 & 5 & 0.000008 & 0.030445 & 3772.41 & 3.58 & tip $3 / 4$ \\
\hline sol1 & 20 & 0.55 & 7.27 & 7.53 & 10.54 & 0.0871 & 1 & 0.000015 & 0.030409 & 1993.16 & 3.30 & tip $3 / 2$ \\
\hline sol1 & 20 & 0.5 & 7.77 & 8.11 & 10.54 & 0.2859 & 1 & 0.000050 & 0.030235 & 605.23 & 2.78 & tip $3 / 3$ \\
\hline sol1 & 20 & 0.45 & 8.22 & 8.39 & 10.7 & 0.501 & 1 & 0.000087 & 0.030048 & 344.08 & 2.54 & tip $3 / 1$ \\
\hline sol1 & 20 & 0.35 & 8.68 & 8.49 & 10.36 & 0.736 & 1 & 0.000128 & 0.029847 & 233.79 & 2.37 & tip $2 / 1$ \\
\hline sol1 & 20 & 0.3 & 9.17 & 8.65 & 10.31 & 1.007 & 1 & 0.000174 & 0.029614 & 169.96 & 2.23 & tip $2 / 2$ \\
\hline sol1 & 20 & 0.3 & 9.64 & 8.82 & 10.34 & 1.3622 & 1 & 0.000236 & 0.029307 & 124.34 & 2.09 & tip 2/3 \\
\hline sol1 & 20 & 0.2 & 10.27 & 9.05 & 9.99 & 1.9135 & 1 & 0.000329 & 0.028838 & 87.53 & 1.94 & tip $2 / 4$ \\
\hline sol1 & 20 & 0.25 & 10.48 & 9.19 & 10.14 & 0.253 & 0.1 & 0.000437 & 0.028302 & 64.81 & 1.81 & tip $1 / 1$ \\
\hline sol1 & 20 & 0.1 & 11.06 & 9.69 & 10.14 & 0.501 & 0.1 & 0.000858 & 0.026193 & 30.52 & 1.48 & tip $1 / 2$ \\
\hline sol1 & 20 & 0 & 11.57 & 10.95 & 10.95 & 0.972 & 0.1 & 0.001657 & 0.022200 & 13.40 & 1.13 & tip $1 / 3$ \\
\hline sol1 & 20 & 0 & 12.05 & 12.02 & 12.02 & 0.9162 & 0.1 & 0.001562 & 0.022676 & 14.52 & 1.16 & tip 1/4 \\
\hline
\end{tabular}




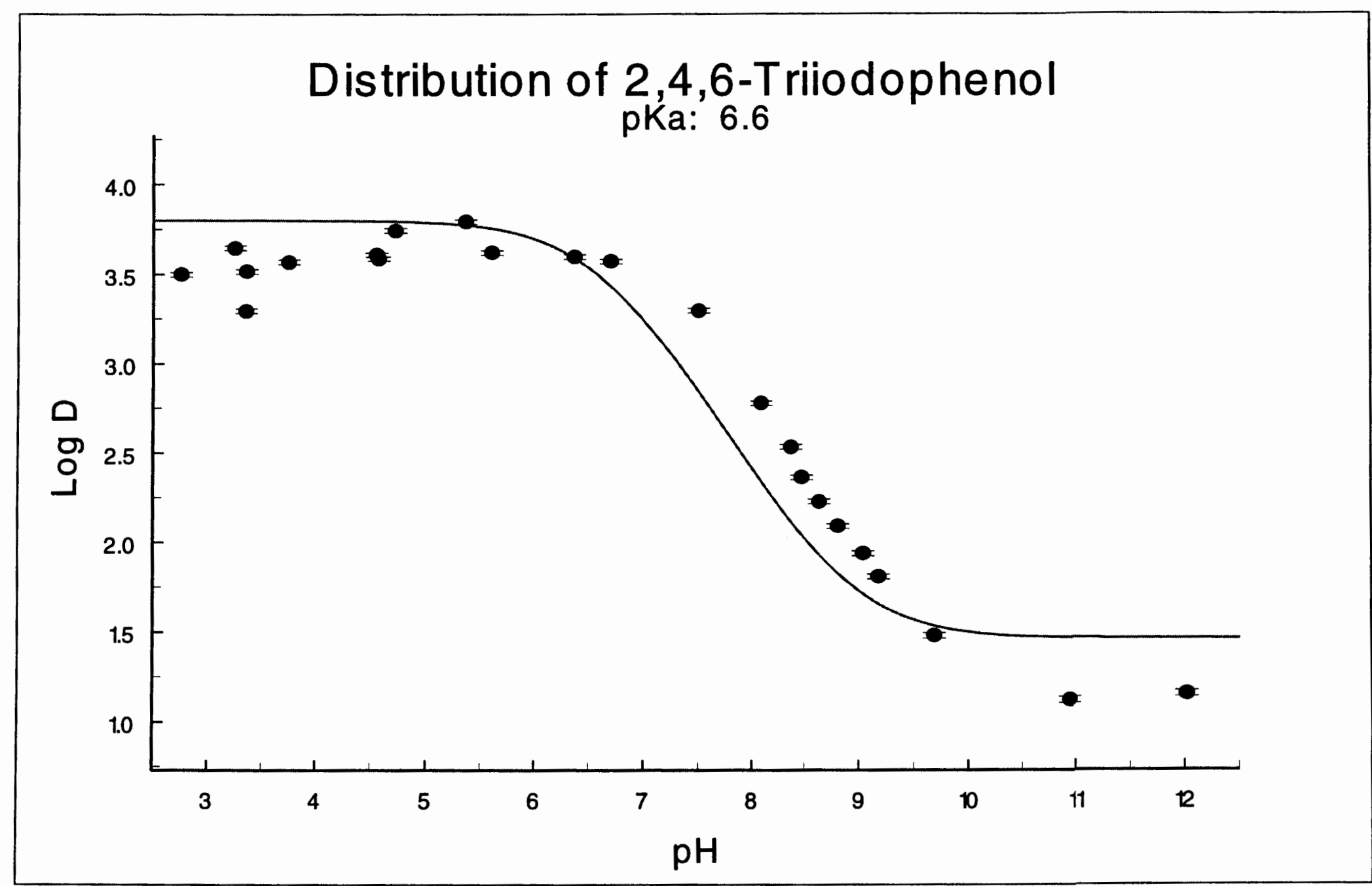

Figure 24: Distribution as a function of the pH for 2,4,6 triiodophenol. 


\section{Octanol-water distribution of 2,4,6 trihalophenols as a function of $\mathrm{pH}$}

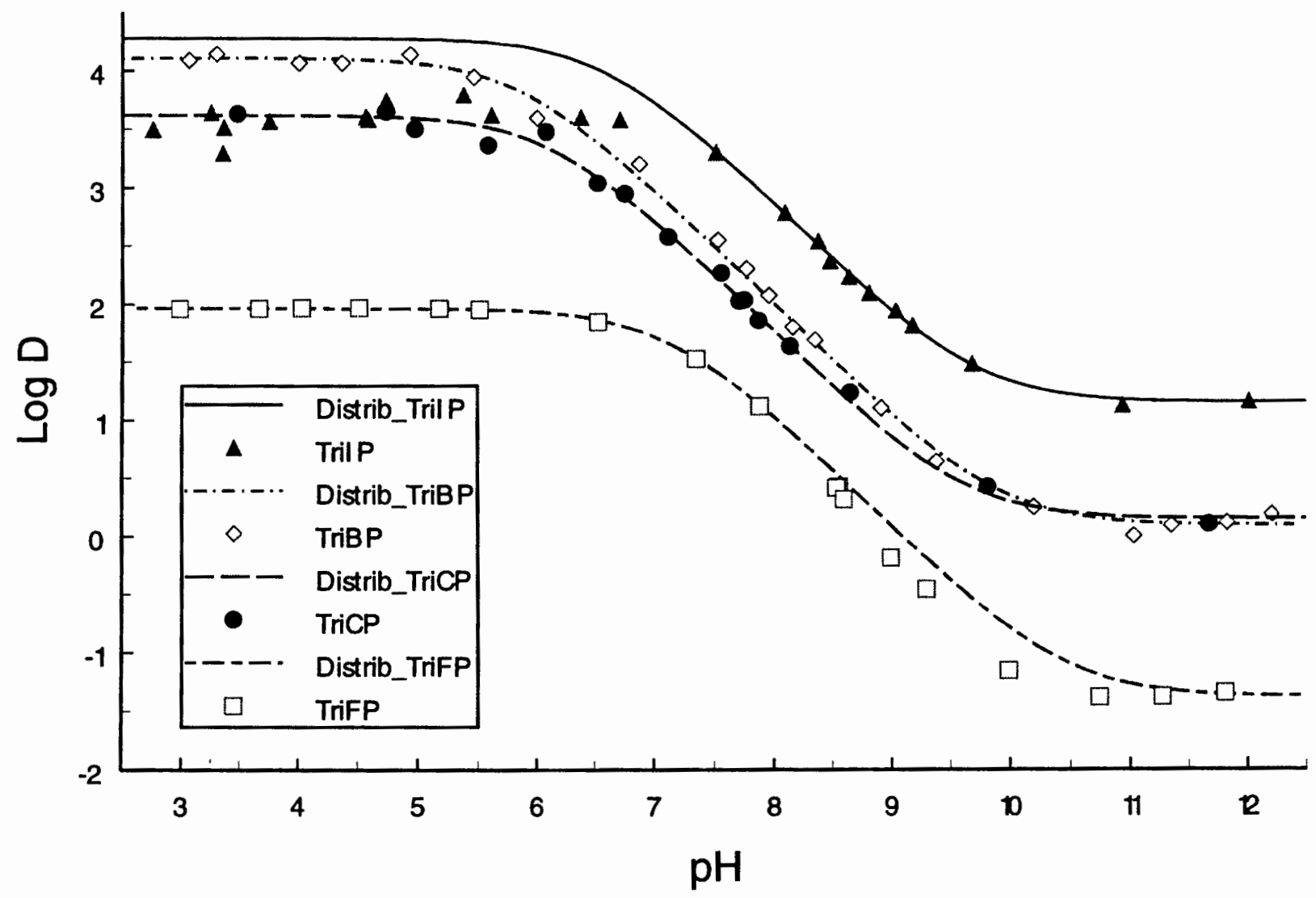

Figure 25: Distribution of 2,4,6 trihalophenols as a function of $\mathrm{pH}$. 


\section{Unexpected results observed in TriFP and TrilP experiments}

\section{TriFP}

In the high pH-range, the usual method for determination of the concentrations in the two phases failed. For unknown reason, the mass balance calculations yielded negative concentration in the octanol phase (Figure 26). This is probably due to the low concentrations in the octanol phase and the high concentrations in the water phase, and inaccuracy in the determination of the sample concentration in the water phase. It was found necessary to change the direction of TriFP partition from water into octanol. This change in the method yielded more reliable results.

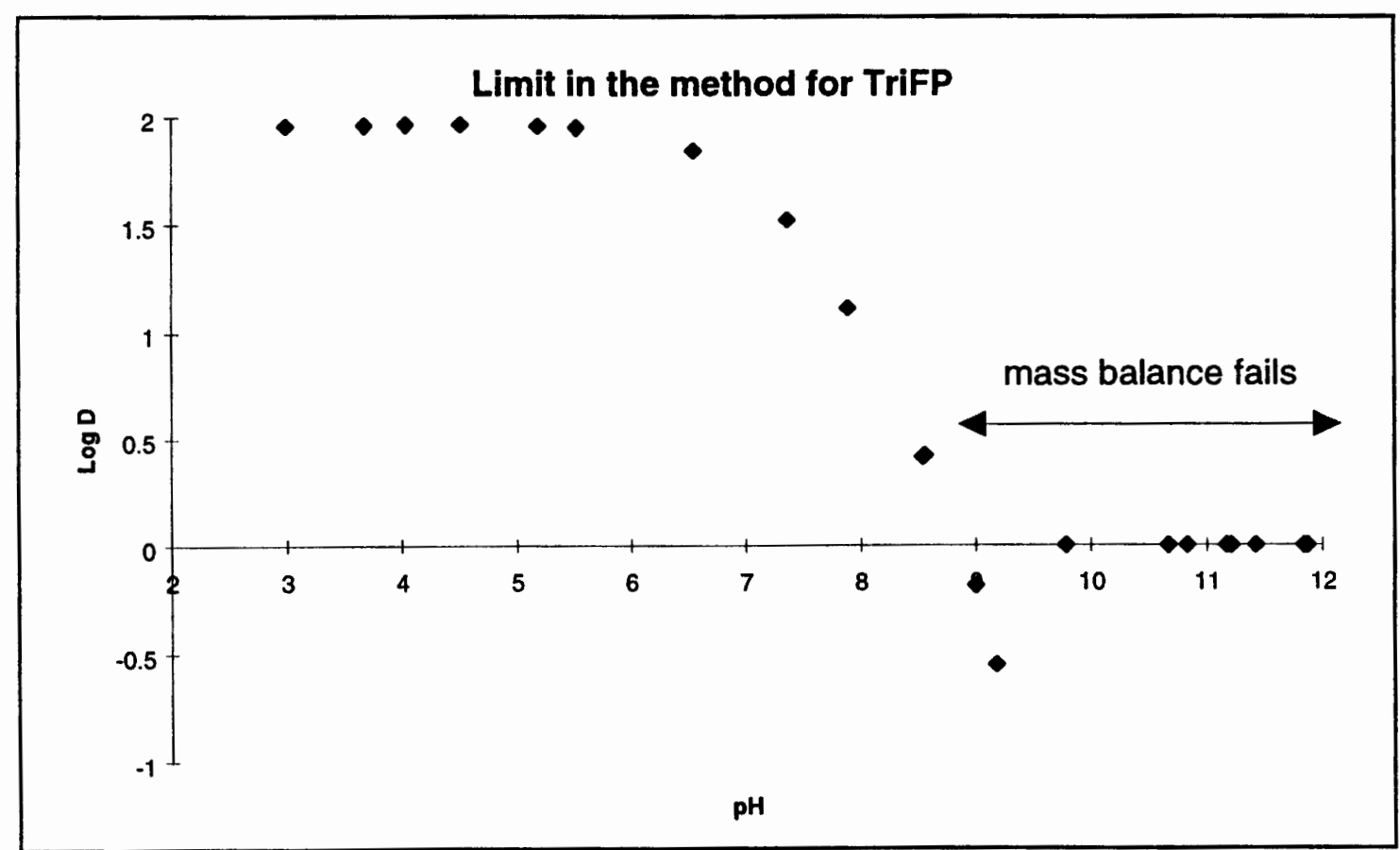

Figure 26: Failure of the mass balance calculation, for values in the high pH-range, no results could be obtained. 


\section{TriIP}

The $\mathrm{pH}$ dependence of the distribution coefficient of 2,4,6-triiodophenol is shown in Figure 24 where the solid curve illustrates the result of the least squares fit to the experimental data using the literature value of $\mathrm{pK}_{\mathrm{a}}=6.6$. In contrast to other compounds in this series the fit is rather poor. Since the distribution coefficient $D$ at high $\mathrm{pH}$ is determined by the value of the partition coefficient of the ionized species, $\mathrm{g}_{\mathrm{A}}$, another fitting strategy was to set the value of $\mathrm{D}=\mathrm{g}_{\mathrm{A}}$ at the high $\mathrm{pH}$ and to obtain the low $\mathrm{pH}$ value of the distribution coefficient from the fit of the model to the intermediate $\mathrm{pH}$ region where $\mathrm{D}$ is determined by the partition of the un-ionized species. Result is shown in Figure 27. The model can properly fit the transition $\mathrm{pH}$ region, but overestimates the partition of un-ionized TriIP at low pHs. Figure 27 also illustrates the prediction of the model if the distribution coefficient $D$ is set to the observed value of $\mathrm{g}_{\mathrm{HA}}$ of un-ionized species. In this case there is no fit to the intermediate $\mathrm{pH}$ region possible.

Several possibilities to understand this discrepancy were explored and additional experiments were performed. The error in the distribution coefficient can originate from errors in concentration of TriIP. From studies of the properties of the model it was found that the error in concentrations would have to be greater than $10 \%$ in order to substantially improve the fit. Such an error is highly improbable. The instrumental, spectrophotometric error, cannot explain the disagreement either. The range of absorbances was within 0.1 and 1.8 absorbance units, in a range where the accuracy of absorbance is given by three significant figures.

Another possible error is that in the extinction coefficient of the UV absorption band used to determine the concentration. The measurements of extinction coefficient were 
repeated but the differences in values of extinction coefficients were small and could not explain the discrepancy between the model and the data. It was also verified that "age" of the octanol-saturated buffer does not affect the spectrophotometric parameters relevant to the fit.

Another important parameter in the model that is critical to the $\mathrm{pH}$ dependence of the distribution coefficient is the $\mathrm{pK}_{\mathrm{a}}$ value of TriIP. In the above studies $\mathrm{pK}_{\mathrm{a}}=6.6$ reported in the literature TriIP in water was used. $\mathrm{pK}_{\mathrm{a}}$ measurements in pure water confirmed this literature value. One possibility that was experimentally explored was that the dissociation constant of TriIP in octanol-saturated buffer (which is the case in our studies) is different from that in water. Results of $\mathrm{pK}_{\mathrm{a}}$ measurements in octanolsaturated water also did not support this hypothesis.

We have also explored the possibility that the anomalous distribution of TriIP is related to some specific molecular property such as an effect of the dipole moment of TrilP on the octanol-water partition. In this study we calculated dipole moments of all trihalophenols using a molecular modeling software MMP (Chemview). The conclusion was that the dipole moment cannot be regarded as an origin of the anomalous octanol-water distribution because the differences in dipole moments between compounds in the series were small.

Another possible origin considered are micelles of octanol in water phase. (Word 1996) assumed presence of octanol micelles in water as the origin of failure to determine octanol-water partition coefficients greater than $10^{4.8}$. The micelles are formed during shaking the two phase system in the partition experiment. They cannot be separated by ultracentrifugation and constitute additional phase in the octanolsaturated water. This micellar phase can contain TriIP and thus lower the octanol- 
water partition coefficient of the un-ionized species, in agreement with data in Figure 27.

It was also expected that TriIP solvated in octanol micelle would exhibit a wavelength shift of the absorption band. Smejtek et al. (1987) showed that absorption spectrum of pentachlorophenol was sensitive to the polarity of local environment surrounding the pentachlorophenolate anion. The long-wavelength absorption band of pentachlorophenolate was red-shifted with the decreasing dielectric constant of the solvent. We have also observed shifts of the absorption band of ionized TriIP when partition experiment was done at low $\mathrm{pH}$. However, such a shift, about $10 \mathrm{~nm}$, is toward shorter wavelength, which is inconsistent with the micelle hypothesis.

We have further considered photodegradation of TriIP in low-pH octanol-water partition studies. According to this hypothesis, TrilP is chemically modified and the structurally modified molecules exhibits a lower octanol water partition coefficient and are the origin of a blue-shifted UV absorption band. To test this hypothesis the octanol-water partition studies were done light and in without light. No substantial differences were found.

Another spectral feature present in low-pH partition studies is the change of ratio of absorbance of main absorbance peak and absorbance valley in the long wavelength portion of the spectrum. The ratio changes when octanol-water partition is performed at low $\mathrm{pH}$, but it does not change at high and intermediate $\mathrm{pH}$. The UV absorption spectra are compiled in Figure 29. Figure 28 illustrate the relationship between the $\mathrm{pH}$ dependent distribution coefficient $\mathrm{D}$, the ratio of absorbances of the long wavelength peak and valley, and the blue shift of the long wavelength absorption peak. It appears that there is the following correlation: at $\mathrm{pH}<7$ the distribution coefficient reaches a plateau corresponding to the partition of neutral TriIP into octanol. Under these conditions the absorbance peak-to-valley ratio changes and a blue shift of the long 
wavelength absorption band is observed. None of these features were noted with other compounds whose $\mathrm{pH}$ dependence of the distribution coefficient could be fitted with the model. For these reasons we believe that TrilP undergoes molecular structure change at low $\mathrm{pH}$ and the experimentally determined octanol water distribution coefficient is incorrect. For these reasons the value predicted from the fit of the model to the data will be used in further analysis. The appropriate value of the octanol-water partition coefficient of the neutral TriIP is 4.42 .

We have used molecular modeling software to predict octanol-water partition coefficient from the molecular structure. The results are summarized in the Table 11.

Table 11: Predictions of molecular modeling software

\begin{tabular}{lll}
\hline $\begin{array}{l}\boldsymbol{g}_{H A} \text { predicted } \\
\text { for TriIP }\end{array}$ & $\begin{array}{l}\text { Molecular modeling } \\
\text { software }\end{array}$ & $\begin{array}{l}\boldsymbol{g}_{H A}, \text { from distribution } \\
\text { model }\end{array}$ \\
\hline 4.84 & MMP, Chemview & 4.42 \\
4.56 & CLogP, BioByte Corp. \\
3.88 & ACD, Advanced & \\
& Chemical Development \\
\hline
\end{tabular}

We find that the value predicted from ACD software package is closest to our measured value. (Word 1996) also found that octanol-water partition coefficient predicted from ACD software was closest to the measured values of the octanol-water partition coefficients of other halogenated phenols. The ACD program is empirical, based on contributions of substituents and molecular structural elements to the partition coefficient. According to the computed results using ACD (see Figure 30), 
the relatively low partition coefficient of TriIP, relative to other trihalophenols, is primarily determined by the iodine-octanol interactions.

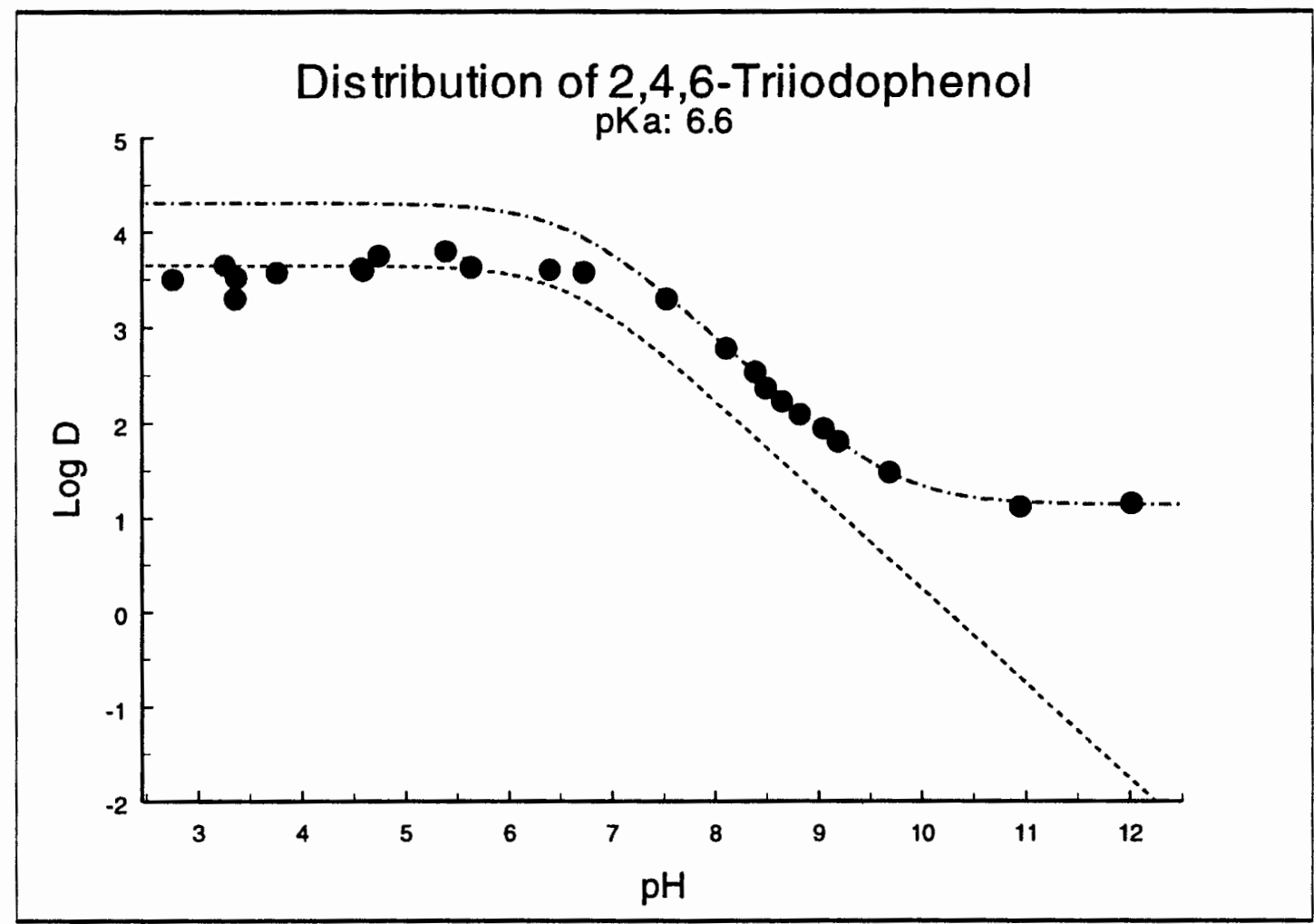

Figure 27: Attempts to fit the distribution model to the data. 


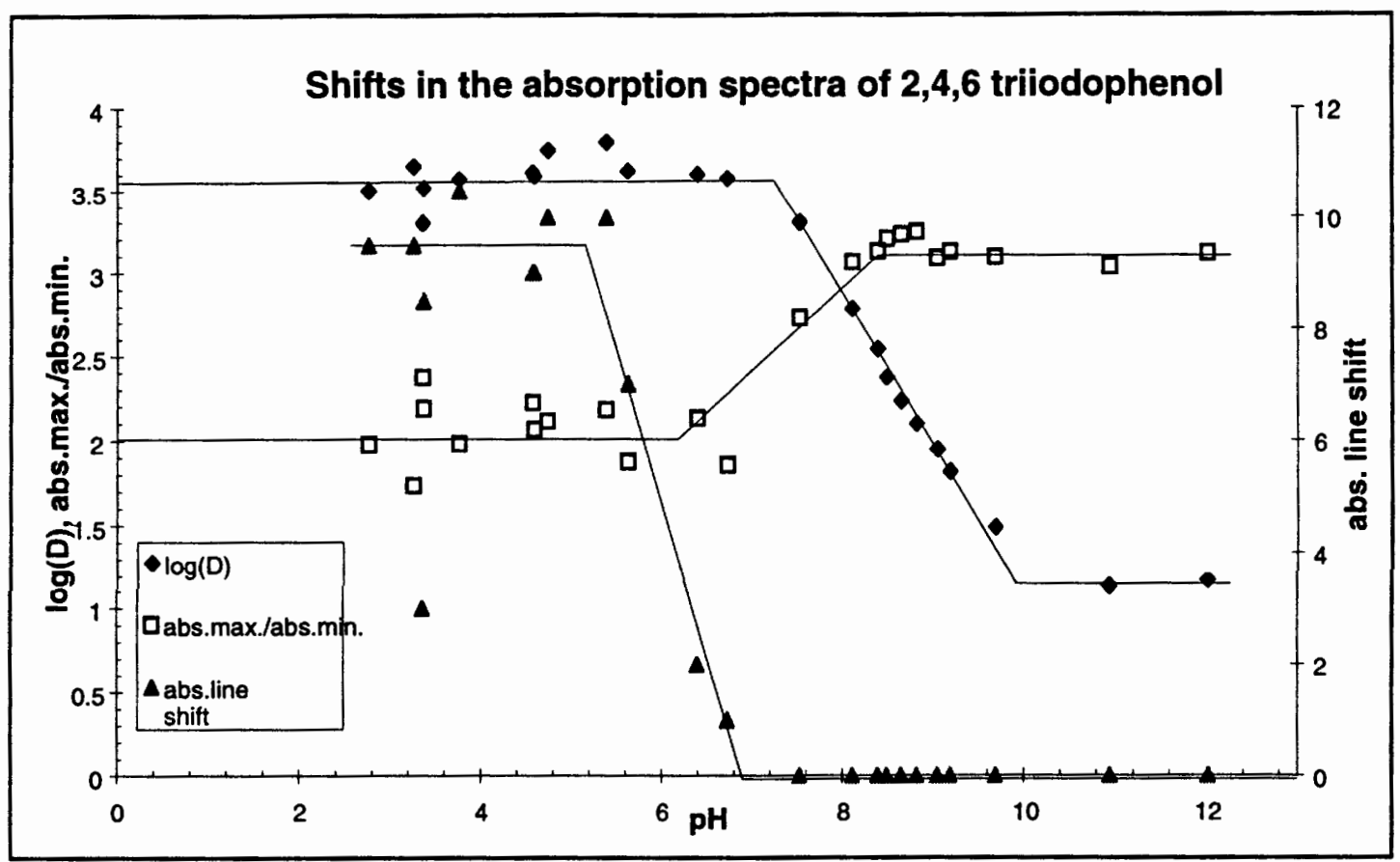

Figure 28: Shifts in the absorption spectra of 2,4,6 triiodophenol

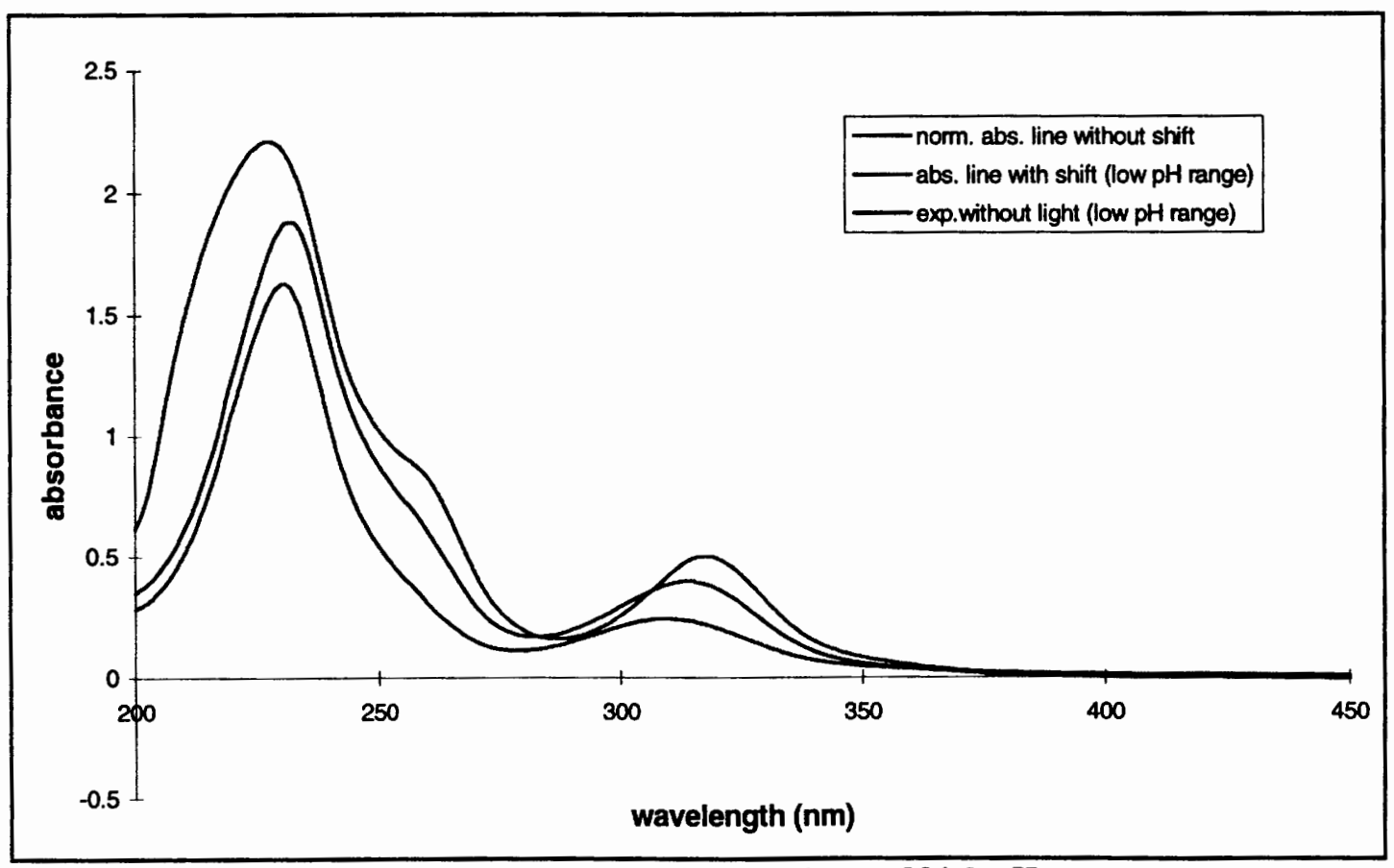

Figure 29: Change in the absorption spectrum between low and high $\mathrm{pH}$. 


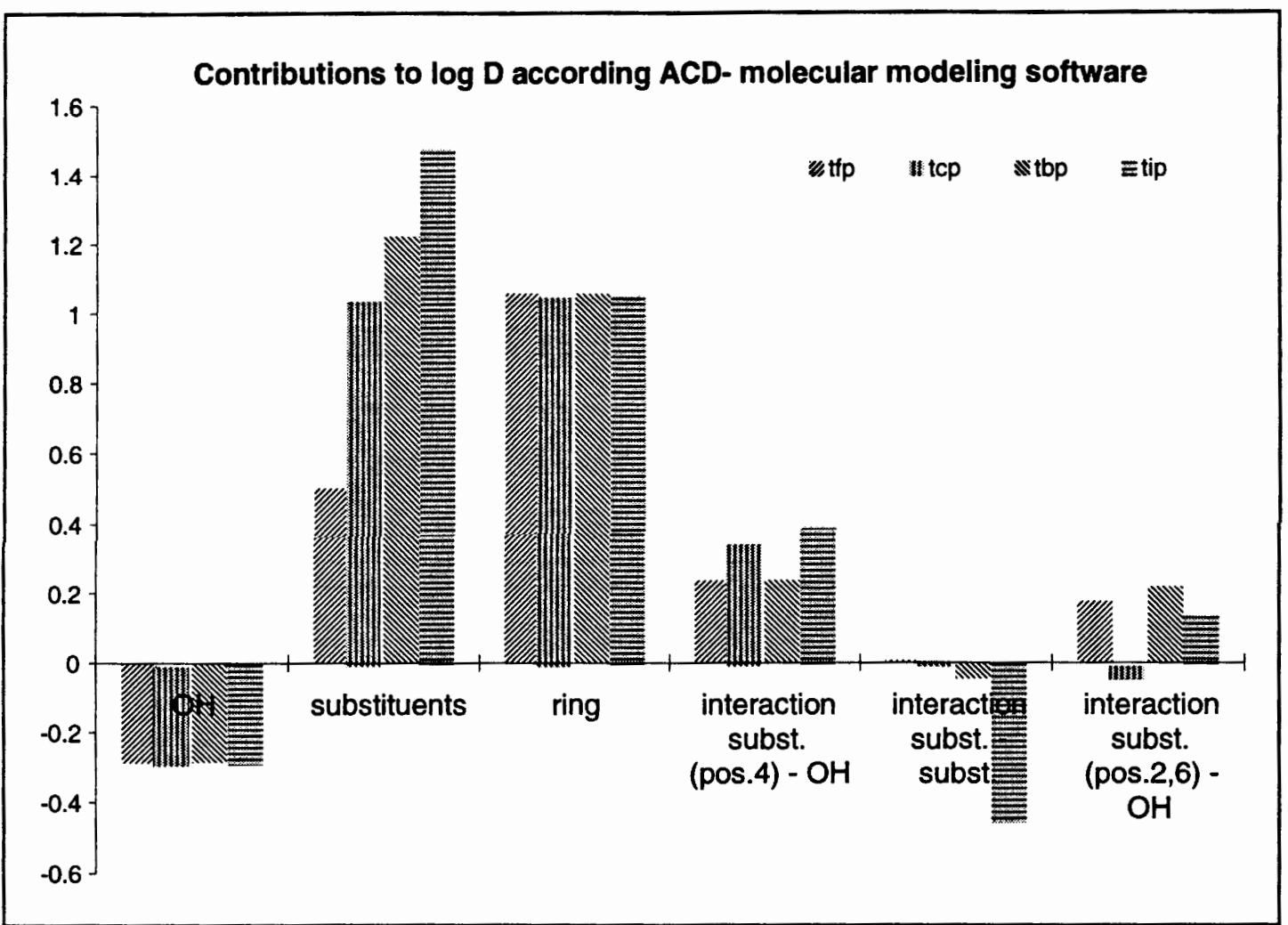

Figure 30: Structural contributions to the $K_{o w}$ according to the ACD molecule modeling software 


\section{Molecular Surface Area and Molar Volume Models}

In this chapter, we apply and discuss the two $\mathrm{K}_{\mathrm{ow}}$ prediction models presented in section 2.4. The data set was enlarged to include experimental results for structurally related compounds whose properties are given in Table 12. All of these halogenated phenols were previously studied in this laboratory under very similar conditions.

Table 12: Molecular properties of the 2,4,6 trihalophenols and other related halophenols

\begin{tabular}{|c|c|c|c|c|c|c|}
\hline Molecule & $\begin{array}{l}\text { Molar } \\
\text { Volume } \\
{\left[\mathrm{cm}^{3} / \mathrm{mol}\right]}\end{array}$ & $\begin{array}{l}\text { Surface } \\
\text { Area }^{9} \\
{\left[\mathrm{~nm}^{2}\right]}\end{array}$ & $\begin{array}{l}\text { Dipole } \\
\text { Moment } \\
\text { of neutr. } \\
\text { species } \\
\text { [debye] }\end{array}$ & $\log g_{H A}$ & $\log g_{A}$ & $p K_{a}$ \\
\hline 2,4,6 Trifluorophenol & 102.81 & 1.393 & 1.845 & 1.96 & -1.38 & 7.2 \\
\hline 2,4,6 Trichlorophenol & 132.56 & 1.798 & 1.756 & $3.65^{9}$ & $0.15^{10}$ & 6.15 \\
\hline 2,4,6 Tribromophenol & 139.4 & 1.993 & 1.794 & 4.11 & 0.08 & 5.9 \\
\hline \multirow[t]{2}{*}{ 2,4,6 Triiodophenol } & 153.67 & 2.092 & 1.903 & 3.65 & 1.16 & 6.4 \\
\hline & & & & 4.42 (cal.) & & \\
\hline Pentafluorophenol & 108.58 & 1.504 & 1.923 & $2.79^{10}$ & $-0.85^{11}$ & 5.7 \\
\hline Pentachlorophenol & 144.88 & 1.988 & 1.992 & $4.77^{11}$ & $1.16^{11}$ & 4.9 \\
\hline Pentabromophenol & 160.84 & 2.373 & 1.965 & $4.67^{11}$ & $1.77^{11}$ & 3.7 \\
\hline 2,3,4,5 Tetrachlorophenol & 134.79 & 1.835 & 3.48 & $4.52^{11}$ & $0.87^{12}$ & 6.35 \\
\hline 2,3,4,6 Tetrachlorophenol & 134.59 & 1.832 & 3.019 & $4.28^{11}$ & $0.48^{11}$ & 5.4 \\
\hline \multicolumn{7}{|c|}{${ }^{8}$ Calculated with MMP molecule modeling software } \\
\hline \multicolumn{7}{|l|}{${ }^{9}$ (Sieder 1995) } \\
\hline \multicolumn{7}{|l|}{${ }^{10}$ (Word 1996) } \\
\hline${ }^{11}$ (Schmidt 1995) & & & & & & \\
\hline
\end{tabular}


Molar volume and surface area could only be determined for the un-ionized molecules. Since all ionized molecules are smaller by one hydrogen-atom bounded to the oxygenatom, it seems reasonable to reduce the values for molar volumes and surface areas of the neutral atoms by a constant number. This contribution of the hydrogen is ignored which allows us to use the slope and the intercept of the graph of the un-ionized molecule for the interpretation of the octanol-water partition data and molecular properties.

\section{Surface Area Model}

The following linear relationship between molecular surface area and $\log \mathrm{K}_{\mathrm{ow}}$ was derived in chapter 2.4 .

$$
\begin{aligned}
\log K_{o w} & =-0.746\left(\alpha M S A+\Delta G_{o w, e l .}\right)-0.96 \\
& =-0.746 \alpha M S A-\left(0.746 \Delta G_{o w, e l .}+0.96\right)
\end{aligned}
$$

In Figure $31 \mathrm{Log} \mathrm{K}_{\mathrm{ow}}$ of the halophenols and halophenolates is plotted as a function of their molecular surface area. A simple linear relationship between the surface area and the decadic logarithm of the octanol-water partition coefficient can be observed, as predicted by Equation 25 . The values for neutral species and those for ionized molecules form separate lines.

The regression lines in Figure 31 are based on data for the 2,4,6 trihalophenols (full symbols). As mentioned earlier, gHA predicted from the distribution is used because of experimental artifacts at low $\mathrm{pH}$. The data for tetrahalophenols, pentahalophenols and their halophenolates are plotted as open symbols. 
Hydrophobicity parameter $\alpha$ and $\Delta \mathrm{G}_{\mathrm{ow}, \mathrm{el}}$, which were obtained from these regression lines, are shown in Table 13.

Table 13: Hydrophobicity parameter $\alpha$ and $\Delta G_{\text {ow,el }}$ for $\mathbf{2 , 4 , 6}$ trihalophenols

\begin{tabular}{l|ll}
\hline species & $\begin{array}{l}\alpha \\
\left(\mathrm{nm}^{-2}\right)\end{array}$ & $\begin{array}{l}\Delta G_{\text {ow,el }} \\
(\text { rel. } \text { units })\end{array}$ \\
\hline neutral species & -4.72 & 2.59 \\
ionized species & -4.28 & 6.53 \\
\hline
\end{tabular}

The negative values for the $\alpha$ 's implies a larger surface tension at the water-phenol and water-phenolate interface, respectively, relative to their interface with the octanol phase.

The slopes of the regression lines of the ionized and neutral species, and thus the $\alpha$ 's, are approximately equal. Therefore the partition coefficient of the ionized and the neutral species are related by a constant factor. This factor can be related to the difference in the electrostatic free energy of transfer of the neutral and ionized species from water into octanol. Since the main physical difference between the ionized and the neutral species of each halogenated phenol is the electric charge, the electrostatic part of the free energy of transfer is expected to remain constant. Thus, this result confirms the assumption that the free energy of transfer can be divided into a nonelectrostatic part, which linearly depends on the molecular surface area, and an electrostatic part, which determines the difference between the regression lines, and hence the change in the partition coefficient $\mathrm{K}_{\mathrm{ow}}$ from low to high $\mathrm{pH}$.

A possible further contributions to the electrostatic free energy of transfer is the dipole - medium interaction. Based on the symmetry, the tri- and pentahalophenol have about 
the same dipole moment. Hence, the effect of the dipole moment is hard to observe. Perhaps, the deviation of the $\log \mathrm{K}$ of neutral tetrachlorophenols from the regression line can be explained by the their higher dipole moment.

Striking are the positions of the tetrahalophenols and the pentahalophenols data on this plot (Figure 31). With the exception of pentabromophenol ${ }^{12}$, the distribution coefficients of these halophenols are above the regression line based on the trihalophenols.

\section{Molar Volume model}

As in the molecular surface model, the molar volume model predicts a linear relationship between molar volume $\mathrm{V}_{\mathrm{s}}$ and $\log \mathrm{K}_{\text {ow }}$.

$$
\log K_{o w}=\frac{W-O}{R T} V_{s}+I
$$

Figure 32 demonstrates this relationship. Again the regression line is based on the data for the 2,4,6 trihalophenols (solid symbols) using the calculated value $\mathrm{g}_{\mathrm{HA}}$ for the neutral species of TriIP. Table 14 list the difference in the free energy of cavity formation per unit of cavity volume between water and octanol (W-O) and the intercept I (for T=293K).

\footnotetext{
${ }^{12}$ The low value for the neutral pentabromophenol is, according Word (1996), due to the limit of the shake flask method.
} 
Table 14: Results of the molar volume model

\begin{tabular}{l|ll}
\hline species & $\begin{array}{l}(W-O) \\
\left(\mathrm{cal} / \mathrm{cm}^{3}\right)\end{array}$ & $I$ \\
\hline neutral & $8.67 * 10^{-5}$ & 3.13 \\
ionized & $8.24 * 10^{-5}$ & 6.34 \\
\hline
\end{tabular}

The positive values for the difference in the free energy of cavity formation yields a higher value for $\mathrm{W}$. The slopes of the two lines are again very close.

Unlike the molecular surface area model, the molar volume model has no explicit dependence on the electrostatic properties of the molecules.

The constant $I$ is described by the ability of a molecule to leave the cavity in the octanol phase and to move into a cavity in the aqueous phase. Since the main difference in the properties between the halophenol and its halophenolate is the electric charge, the electrostatic effect is contained in the constant I.

$\log \mathrm{K}_{\mathrm{ow}}$ of the tetra- and pentahalophenols are again higher than predicted by the regression for trihalophenols and triphenolates, respectively. As in the molecular surface area model, the value of the neutral pentabromophenol is inconsistent with the other pentahalophenols.

Based on the low number of data and the similar form of the equations, it is not possible to give a preference to one model over the other. 


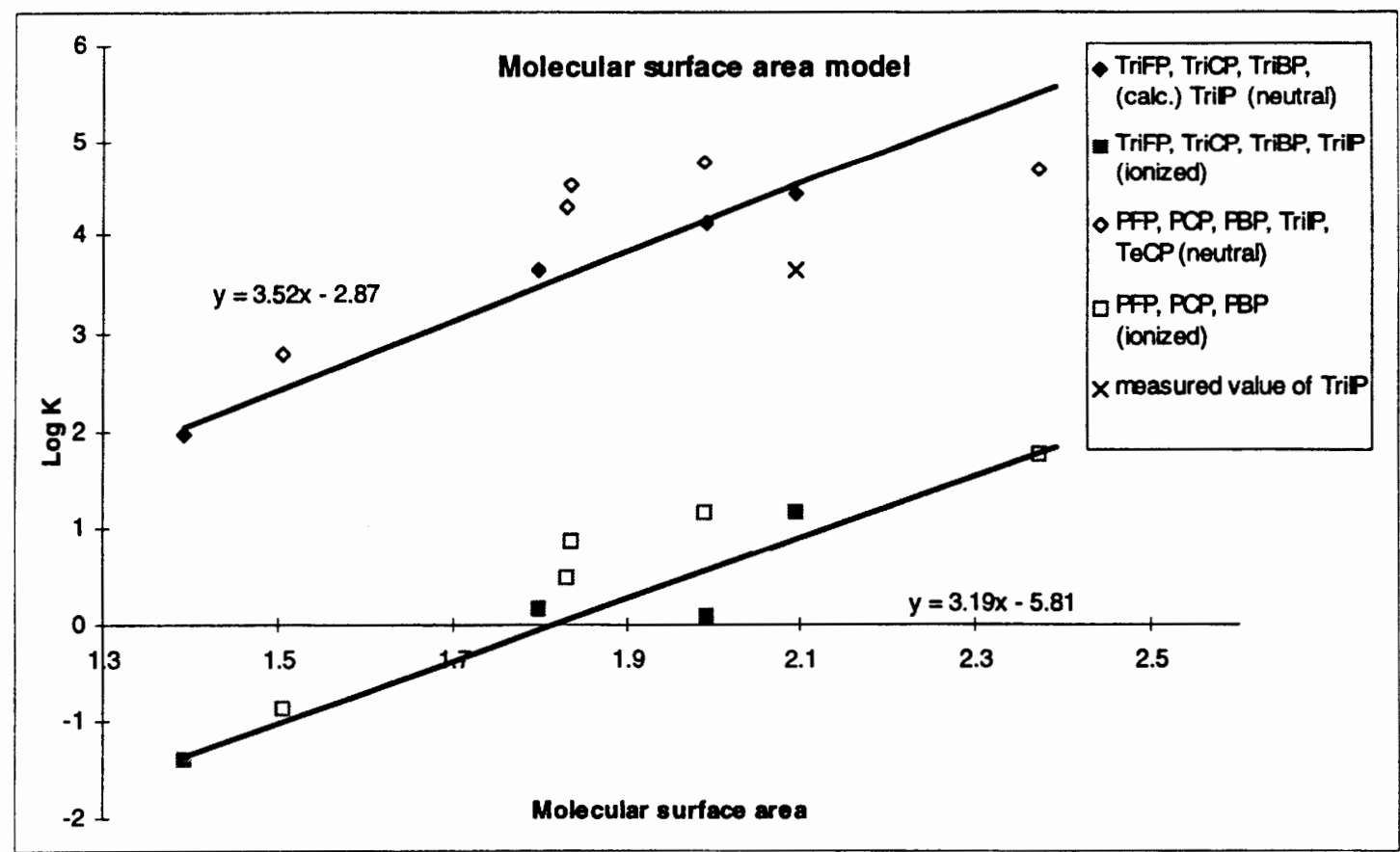

Figure 31: Molecular surface area model

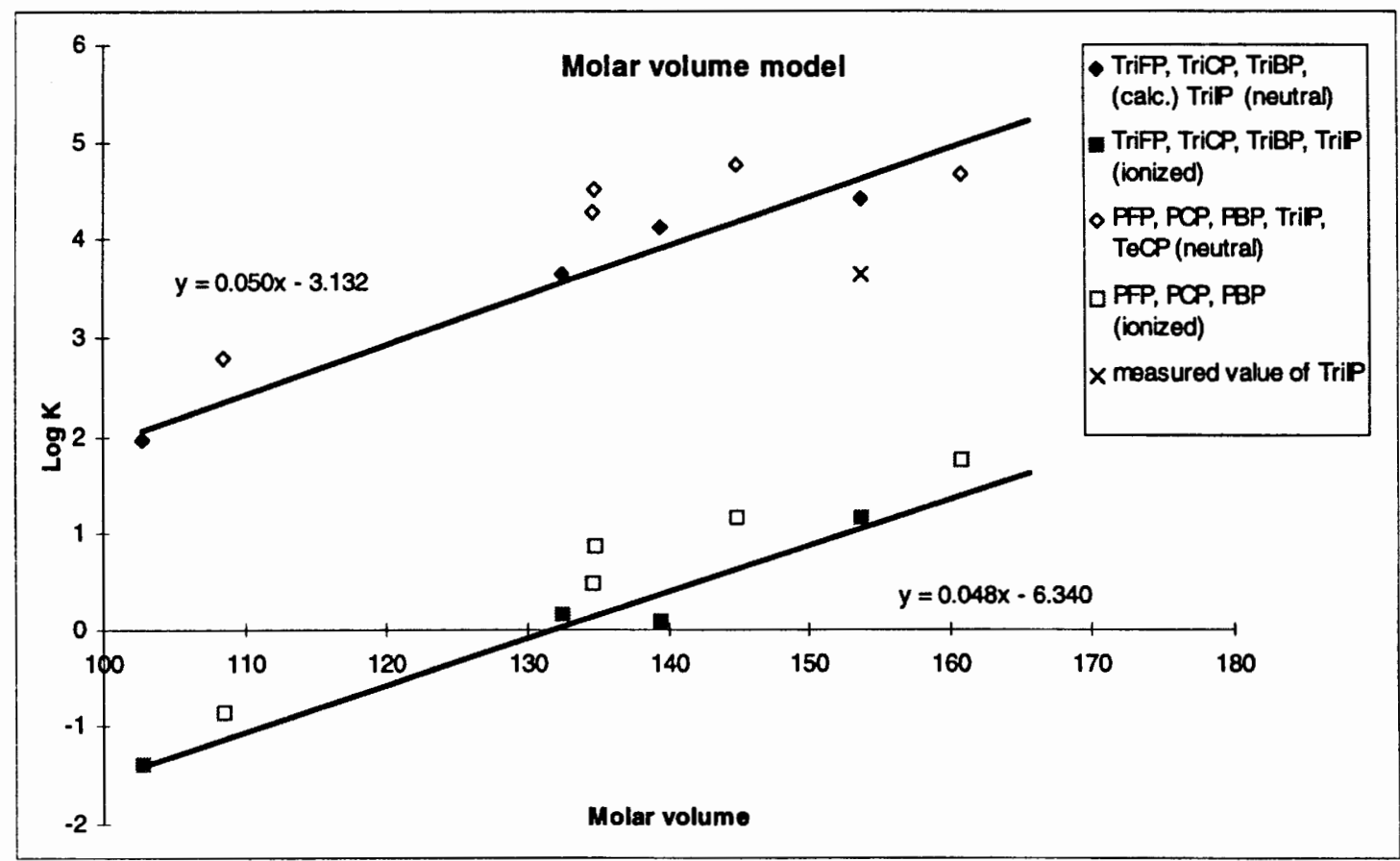

Figure 32: Molar volume model 


\section{Conclusions}

This work presents experimental results obtained from the studies of the $\mathrm{pH}$ dependence of octanol-water distribution of four trihalophenols: 2,4,6-trifluorophenol, 2,4,6-trichlorophenol, 2,4,6-tribromophenol and 2,4,6-triiodophenol.

1. It is shown that with the exception of 2,4,6-triiodophenol, the distribution of these compounds can be understood in terms of a model that accounts for the dissociation of the trihalophenol by the $\mathrm{pK}_{\mathrm{a}}$ value for the aqueous phase and the octanol-water partition coefficient of the neutral and ionized molecules.

2. The values of the partition coefficients of the neutral molecular species are as follows: $\mathrm{g}_{\mathrm{HA}}(2,4,6$-trifluorophenol $)=92 \pm 5.6, \mathrm{~g}_{\mathrm{HA}}(2,4,6$-tribromophenol $)=12893 \pm$ 569 and $\mathrm{g}_{\mathrm{HA}}(2,4,6$-triiodophenol) $=26302$ (cal.) (measured: $4427 \pm 225$ is not reliable).

3. The values of the partition coefficients of the ionized molecular species are as follows: $g_{A}(2,4,6$-trifluorophenol $)=0.042 \pm 0.006, g_{A}(2,4,6$-trifbromophenol $)=1.19$ \pm 0.1 and $g_{A}(2,4,6$-triiodophenol $)=14.3 \pm 2.3$.

4. In addition to octanol-water partition coefficients the values of the dissociation constant of the trihalophenols were determined. The dissociation constants obtained correspond to $\mathrm{pKa}(2,4,6$-trifluorophenol $)=7.12, \mathrm{pKa}(2,4,6-$ chlorophenol $)=6.15, \mathrm{pKa}(2,4,6$-tribromoophenol $)=5.9$ and $\mathrm{pKa}(2,4,6-$ triiodophenol) $=6.6$. It was shown for the case of 2,4,6-triiodophenol, that the effect of octanol present in the aqueous phase is insignificant.

5. The octanol-water partition coefficients of the un-ionized and ionized trihalophenols were related to the molecular properties and were analyzed in terms of two models: one relates the free energy of transfer from water into octanol to the 
molecular surface area, and one to molecular volume. Linear relationships between the logarithm of the partition coefficient and the molecular surface areas or molecular volume were demonstrated. Based on the data, it was not possible to discriminate between them and to argue as to which model is appropriate.

6. The results show the energetic disadvantage of transfer of the ionized trihalophenols from water into octanol which can be associated with the electric charge of the molecule. 


\section{References}

Albert, A. and E. Serjeant. (1984). The determination of ionization constants. Chapman and Hall Ltd.

Bowman, B. and Sans W.W. (1983). "Determination of octanol-water partitioning coefficients of 61 organophosphorus and carbonate insecticides and their relationship to respective water solubility values." Journal of environmental Science and Health 6, 667-683.

Chiou, C., Schmedding D.W. and M. Manes. (1982). "Partioning of organic compounds in octanol-water systems." Environ. Sci. Technol. 16, 4-10.

Escher, B. and R. P. Schwarzenbach. (1996). "Partitioning of substituted phenols in liposme-water, biomembrane-water, and octanol-water systems." Environ. Sci. Technol. 30, 260-270.

Geyer, H. J., I. Scheunert and F. Korte. (1987). "Correlation betweenthe bioconcentration potential of organic environmental chemicals in humans and their n-octanol/water partition coefficients." Chemosphere 16, 239-252.

Gobas, F. A., P. C. (1988). "A Novel Method for Measuring Membrane-Wter Partition Coefficients of Hydrophobic Oranic Chemicals: Comparison with 1-OctanolWater Partitioning." American Pharmaceutical Assosiation 77(3), March, 265.

Grimm, H., B. Schellmann, K. Schaller and Gossler K. (1981). "Pentachlorophenol concentrations in in tissues and body fluids of normal persons." Zentralbl. Bakteriol. Hyg. B 172, 77-90.

Hattemer-Frey, H. A. and C. C. Travis. (1989). "Pentachlorophenol: environmental partitioning and human exposure." , 482-489.

Jafvert, C. T., J. C. Westall, E. Grieder and R. P. Schwarzenbach. (1990). "Distribution of hydrophobic ionogenic organic compounds between octanol and water: organic acids." American Chemical Society 24(12).

Jansson, K. and V. Jansson. (1993). "The toxicity of chlorophenols in V79 Chinese hamster cells." Toxicology Letters 69, 289-294.

Krahl, M. and G. Clowes. (1938). "Physiological effects of nitro- and halosubstituted phenols in relation to extracellular and intracellular hydrogen ion concentration." Journal of cellular and comparative physiology 11(1), february, 1-20. 
Leo, A., C. Hansch and D. Elkins. (1971). "Partition coefficients and their uses." Chem. Rev. 71, 525-616.

Mussalo-Rauhamaa, H., H. Pyysalo and K. Antervo. (1989). "The presence of chlorophenols and their conjugates in finish human adipose and liver tissues." The Science of the Total Environment 83, 161-172.

Schmidt, P. O. (1995). "Origins of effective charge of multivalent ions at a membrane/water interface and distribution of 2,3,4,5 tetrachlorophenol in a membrane model system." .

Sieder, I. (1995). "Electrostatic interactions at water-membrane interfaces and distribution of $2,4,6$ trichlorophenol in a membrane model system." .

Smejtek P., A. W., Barstad and Kwan Hsu. (1987). "Dielectric properties of adsorption/ionization site of pentachlorophenol in lipid membranes." Biochimica et Biophysica Acta 902, 109-127.

Smejtek, P. and S. Wang. (1993). Archives of Environmental Contamination and Toxicology 25, 394-404.

Smejtek, P., A. Blochel and S. Wang. (1996). "Hydrophobicity and sorption of chlorophenolates to lipid membranes." Chemosphere.

Standard for test data development (octanol/water partition coefficient). (1980). Section 4, TSCA.

Stryer, L. (1975). Biochemistry. W.H. Freeman and Company.

Uhlig, H. (1937). "The solubility of gases and surface tension." J. Phys. Chem. 41, 1215-1224.

Westall, J. C., C. A. Johnson and W. Zhang. (1990). "Distribution of $\mathrm{LiCl}, \mathrm{NaCl}$, $\mathrm{KCL}, \mathrm{HCl}, \mathrm{MgCl} 2$, and $\mathrm{CaCl} 2$ between octanol and water." Environ. Sci. Technol. 24, 1803-1810.

Word, R. (1996). "Distribution of ionized and and neutral halogenated phenols in an octanol-water membrane model system." .

Zaslavsky, B. Y. (1995). Aqueous Two-Phase Partitioning. Marcel Dekker, Inc.

Zhang, X. and F. A. Gobas. (1995). "A thermodynamic analysis of the relationships between molecular size, hydrophobicity, aqueous solubility and octanol-water partitioning of organic chemicals." Chemosphere 31(6), 3501-3521. 